Portland State University

PDXScholar

$12-17-1986$

\title{
The Cognitive Learning Styles of International Students
}

Shelley L. Smith

Portland State University

Follow this and additional works at: https://pdxscholar.library.pdx.edu/open_access_etds

Part of the Bilingual, Multilingual, and Multicultural Education Commons, and the International and Intercultural Communication Commons

Let us know how access to this document benefits you.

\section{Recommended Citation}

Smith, Shelley L., "The Cognitive Learning Styles of International Students" (1986). Dissertations and Theses. Paper 3731.

https://doi.org/10.15760/etd.5615

This Thesis is brought to you for free and open access. It has been accepted for inclusion in Dissertations and Theses by an authorized administrator of PDXScholar. Please contact us if we can make this document more accessible: pdxscholar@pdx.edu. 
AN ABSTRACT OF THE THESIS OF Shelley L. Smith for the Master of Science in speech Communication presented December 17 , 1986.

Title: The Cognitive Learning styles of International Students.

APPROVED BY MEMBERS OF THE THESIS COMMITTEE:

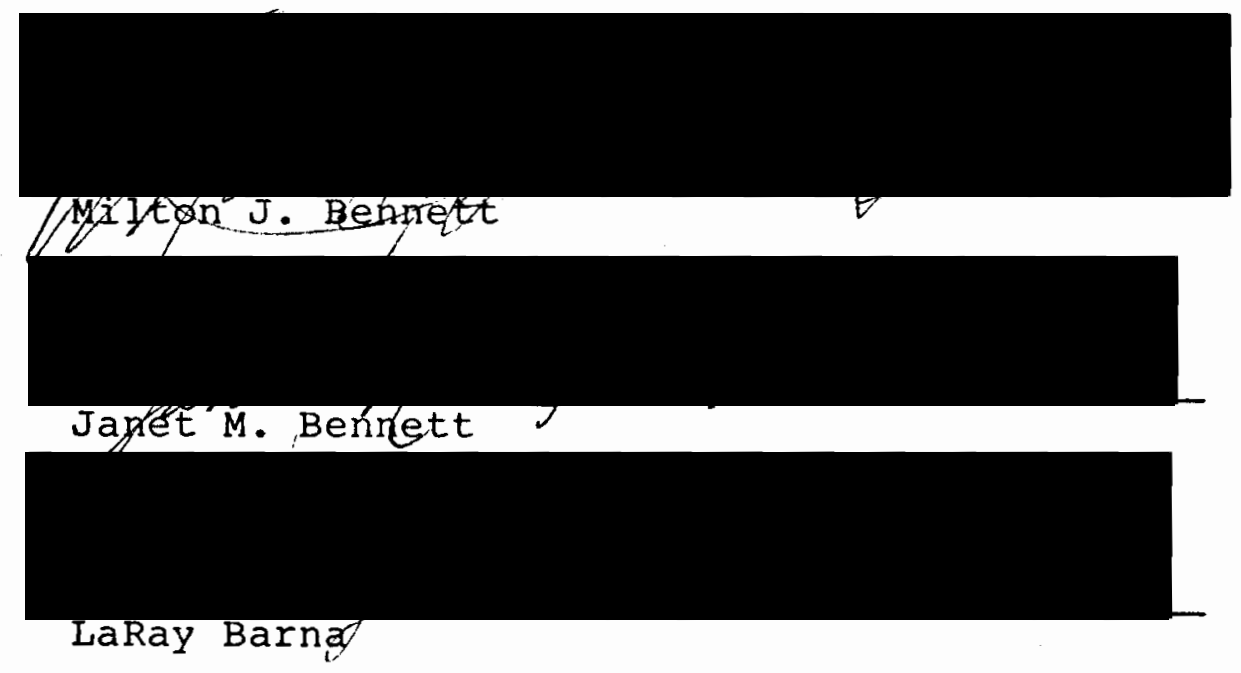

The purpose of this research was to examine the usefulness of David A. Kolb's Learning Styles Inventory (LSI) as a tool for categorization and analysis of systematic differences between American and International students. The research addressed five primary questions:

1. Are the learning styles of the International students tested different from those established by Kolb in previous studies of American students? 
2. Do the learning styles of the International students tested differ among the various groups?

3. Are there differences among the groups of International students tested that can be related to gender?

4. Do the learning styles of the International students tested show any variation according to age? And if present, does that pattern differ in any way from patterns identified for American subjects tested?

5. Are the learning styles of the International students tested similar or dissimilar from the norms established by Kolb for American students in various fields of academic study?

Testing involved the administration of a linguistically simplified version of the LSI to a cross-section of 105 nonEnglish speaking International students who had been in this country for no more than a year. The population included Indochinese refugees who, while not listed officially as "International students" by the universities, clearly met the criteria for cultural difference laid down in this research.

The results of the study showed significant differences 
between American and International students existing in all four of the learning style categories--concrete experience, reflective observation, abstract conceptualization and active experimentation--with the greatest frequency and degrees of difference occurring in the abstract and reflective modes.

Among the groups of international students tested, the most pronounced differences existed between the non-Arabic Middle Eastern and Arabic groups. The non-Arabic sample showed much lower reflective and much higher concrete scores than the Arabic sample. Among the Asian and Southeast Asian groups tested, no significant differences were found to exist.

While only three of the national groups showed differences in overall scores that could be related to gender, an analysis of variations according to age and gender showed significantly different developmental patterns between males and females in the sample population. Among the males, the relationship in the active/reflective dimension was curvilinear. This pattern is very similar to that of the Americans measured by Kolb. The female population, however, exhibited a pattern that showed a progressive narrowing of flexibility in all areas but one.

A full 808 of the International students tested had learning style preferences dissimilar from those established 
by Kolb as normative for their chosen field of study.

overall, this study supports the view that cognitive learning styles of International students differ significantly from those of American students and that these differences need to be taken into consideration if the education of these students is to be maximized. 


\title{
THE COGNITIVE LEARNING STYLES OF INTERNATIONAL STUDENTS
}

\author{
by
}

SHELLEY L. SMITH

A thesis submitted in partial fulfillment of the requirements for the degree of

\author{
MASTER OF SCIENCE \\ in \\ SPEECH COMMUNICATION
}

Portland State University

1987 
TO THE OFFICE OF GRADUATE STUDIES AND RESEARCH:

The members of the committee approve the thesis of Shelley L. Smith presented December 17, 1986

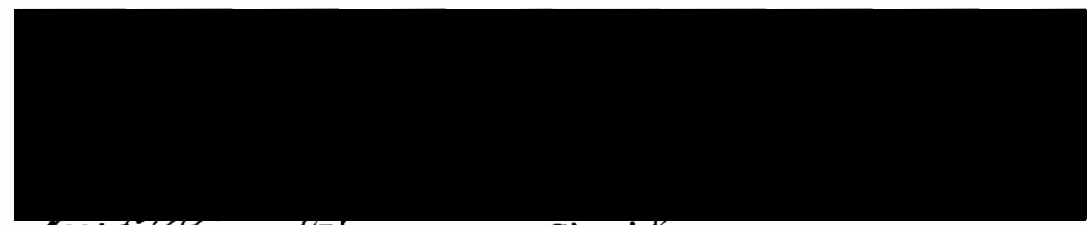

Milleon J./Bennett, Chaif
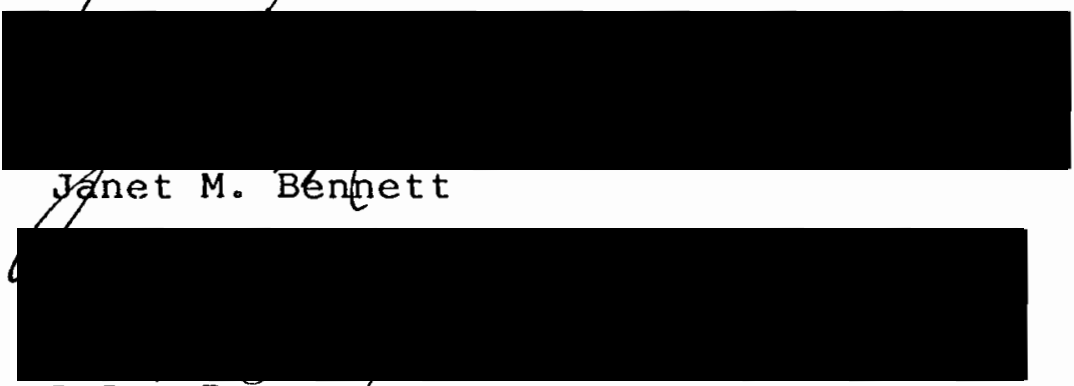

LaRay Barna

APPROVED :

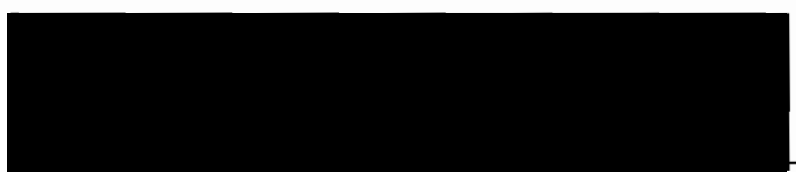

Mary E. Gnrdon, Acting Head, Department of Speech Communication Bernard Ross, Dean, Graduate Studies and Research 
In the process of abstracting [in contrast with measuringl people take in some things and unconsciously ignore others. This is what intelligence is: paying attention to the right things.

Edward T. Hall 


\section{ACKNOWLEDGEMENTS}

I have found the process of education to be so dynamic and convoluted that it is particularly difficult for me to single out the few who have been most instrumental in the completion of this thesis. It would be even worse to leave those who have given so much so freely no praise or recognition for their contributions of love and knowledge. Therefore, it is with great humility that I offer these brief words of appreciation.

I would first like to thank my mother who in spite of failing health has provided me with constant love and support and who has expressed at just the right times her pride in my accomplishments.

To Ted Grove who taught me the importance of intellectual exuberance, Steve Kosokoff who has stood as a model of social conscience and fairness, Larry steward who made me aware of the power of listening, John Condon who showed me that gentleness and humility are great facilitators of learning and La Ray Barna whose warmth and willingness to give have reminded me of the value of the more "feminine" aspects of my character I give my deepest appreciation.

To all of my friends--Rich, Lora, Bonny, Dan, Deanna, 
Umayma, Marta, Caroline, Marie Claire, Ted, Audrey and all the "Roberts"--I give my undying gratitude for their warmth and support in good times and bad and for their ability to "hang in there" when the pressures of school left me little time to show my love.

Special thanks to Amir (whose generosity saved me countless hours in rewriting) for the use of his computer. To my International students who served as the inspiration for this thesis, and whose insights have provided me with an ever-expanding and enriched view of the world, I give my hope that this research might bear some fruit in easing their way along the path of learning.

To Jim Baldwin who donated precious time out of an already full schedule to assist me with the statistical part of this research (a difficult and sometimes extremely creative task), I acknowledge a deep and probably unpayable indebtedness.

To Janet Bennett, I give my love and deepest respect. She has shown by her own example that the power of the mind can be gracefully integrated with tremendous sensuality and sensitivity to the constant delight and gratitude of those who work with her.

Finally, to my advisor Milton Bennett who has given knowledge, patience, a sympathetic ear, rigorous thought, precious time, unfailing confidence, a firm hand, a warm 
heart, opportunities to apply what I had learned and the framework that tied it all together; who has been the consumate teacher, a mentor and when necessary a friend, I give my love, appreciation, respect and deepest gratitude. 
TABLE OF CONTENTS

PAGE

ACKNOWLEDGEMENTS . . . . . . . . . . . . . iv iv

LIST OF TABLES . . . . . . . . . . . . . . . xi

LIST OF FIGURES • • • • • • • • • • • • • • • • xiv

CHAPTER

I INTRODUCTION . . . . . . . . . . 1

Research Goals . . . . . . . 11

Research Questions ....... 13

Overview of the Study . . . . . . . 14

Limitations and Scope

The Intercultural Communication

Perspective

Kolb's Perspective

Methodology

Analysis

Application

I I THEORETICAL OVERVIEW, PROFILE OF TEST MODEL

ASSUMPATIONS, AND DISCUSSION OF

LEARNING STYLES INVENTORY . . . . . . 22

Kolb's Theoretical Base....... . 26

Experiential Learning Theory:

A Synthesis . . . . . . . 36

Learning is Best Conceived as a

Process, not in Terms of

Outcomes

Learning is a Continuous Process

Grounded in Experience 
The Process Requires Resolution of Conflicts Between Dialectically Opposed Modes of Adaptation to the world Learning is an Holistic Process of Adaptation to the World

Learning Involves Transactions Between the Person and the Environment

Learning is the process of Creating Knowledge

Learning: A Definition

Structural Foundations of Experiential

Learning Theory . . . . . .

The Prehension Dimension--

Apprehension and Comprehension

The Transformation Dimension--

Intention and Extension

Synthesis . . . . . . . . .

Growth and Development in the

Experiential Learning Model . .

Internal Properties of the LSI . . .

Item Analysis

Reliability

Split-Half Reliability

Test-Retest Reliability

Generalized Adult Norms

Validity

Summary

Development of the MLSI . . . . . 69

Population . . . . . . . . . 73

Administration of the Test . . . . 75

Statistical Methodology ....... 76 
Description . . . . . . . . . . .

Research Questions . . . . . . .

Are the Learning styles of the International students Tested Different from Those Established by Kolb in Previous Studies for American Students?

Do the Learning styles of the International students Tested Differ Among the Various Groups?

Are There Differences Among the International students Tested That Can be Related to Gender?

Do the Learning styles of the International students Tested Show any Pattern of Variation According to Age? If present, Does that Pattern Differ in Any way from Patterns Identified by Kolb for American Subjects Tested?

Are the Learning styles of the International students Tested Similar or Dissimilar from the Norms Established by Kolb as Normative for Various Fields of Study at American Universities?

American and International

Student Differences for the

Six Variables

Differences Among National Groups

Gender Differences in Learning Style

Age as a Variable in Determining Learning Style 
Similarity and Dissimilarity of

Learning style in Chosen

Field of Study

Summary . . . . . . . . . .

VI LIMITATIONS, IMPLICATIONS FOR FURTHER

RESEARCH, AND APPLICATIONS OF THE STUDY

Limitations of the Study . . . . . 117

Implications for Future Study . . . . 119

Application . . . . . . . . . 120

Recognition of Differences

Respect for those Differences

Application of those Differences

Increased Teaching Flexibility

Increased student Flexibility

Awareness of the Process

BIBLIOGRAPHY . . . . . . . . . . . . . 124

APPENDIX . . . . . . . . . . . . . . 131 


\section{LIST OF TABIES}

TABLE

PAGE

I Relationship Between Left Brain

Specialization and Comprehension

Mode and Right Brain Specialization

and Apprehension Mode . . . . . . .

II Correlations Between LSI Items and Total

Scale Scores . . . . . . . . . .

II Spearman-Brown Split-Half Reliability

Coeffients for the Learning style

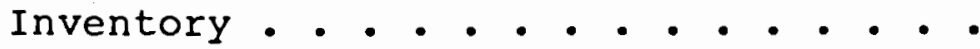

IV Learning style Inventory Test-Retest

Reliability Studies . . . . . . . 60

$v$ Learning style Inventory scores for Various

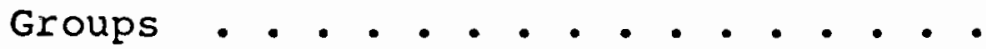

VI Correlation of LSI with Wunderlic Aptitude

Test Scores . . . . . . . . . . .

VII Correlations Between Learning style Inventory

Scores and Personality Tests . . . .

VIII Correlations Between Students' Learning style

and Learning Style of Teacher who

Exerted Most Influence ........

IX Descriptive Statistics by Nationality . . . 
x Descriptive statistics by Major . . . . .

XI Descriptive statistics by sex . . . . . .

XII Sample Age by Nationality and Sex . . . .

XIII Comparison of Sample and Extrapolated LSI

Norms for Adults . . . . . . . .

XIV Comparison to Extrapolated ISI Norms by Nationality . . . . . . . . . . 86

XV Analysis of Variance Within Groups . . . .

XVI Kruskal Wallis one-Way Analysis of Variance

for Gender . • . . . . . . . . . .

XVII Correlation Between Age and Scores . . . .

XVIII Comparison of University of Massachusetts

Engineering Undergrads and Obtained

Engineering Major Sample . . . . . .

XIX Comparison of Professional Engineers to

Engineering Major Sample . . . . . .

XX Comparison of Computer Programmer

Occupational Sample and Computer Major Sample . . . . . . . . . . . .

XXI Preferred Educational and Vocational Fields by Learning Style......... . 100 
XXII Dissimilarity of Learning style in Chosen

Field of Study Between International

Students and American Norms . . . . . 101

XXIII Percentage Breakdown of National Groups by

Learning style . . . . . . . . 102 


\section{LIST OF FIGURES}

FIGURE

PAGE

1. Dewey's Model of Experiential Learning . • . 28

2. The Lewinian Experiential Learning Model . . 31

3. Piaget's Model of Learning and Cognitive Development . . . . . . . . . .

4. Structural Dimensions underlying the Process

of Experiential Learning and the

Resulting Basic Knowledge Forms . . .

5. The Experiential Learning Theory of Growth

and Development . . . . . . . . 51

6. Abstract/Concrete and Active/Reflective

Learning orientations by Age Group • • 94 
CHAPTER I

\section{INTRODUCTION}

The presence of International* students on our campuses has, in essence, provided us with a microcosm of Dean Barnlund's (1975) "Global village." Nationally and culturally different groups are brought physically closer together in the university environment, becoming our neighbors, yet they often ". . speak a different tongue, seek different values, move at a different pace, and interact according to a different script" (p. 3). Such differences can create a "psychic distance" far more difficult to bridge than any national or geographic boundaries that exist among people.

Educators might easily ask themselves the same questions about the effects that this "erosion of cultural boundaries" will have on themselves and their students that Barnlund has raised about interaction on a global level. will it bring "the realization of a dream or a nightmare?"

* The word "International" will be capitalized throughout the thesis because it serves as a synthesis of the nationalities reflected by the students in this study, i.e. Cambodian, Chinese, Japanese, Philippine, etc. 
will it be

- a mere collection or a true community? Will
its residents be neighbors capable of respecting
and utilizing their differences, or clusters of
strangers living in ghettos and united only in
their antipathies for others? (p. 4)

These students are a potentially rich resource in the development of intercultural and educational understanding. Yet we cannot necessarily assume that taking International students out of their home cultures and putting them in American universities will automatically result in our being able to understand or communicate with each other; nor can we necessarily expect that they will be able to learn or that we will be able to teach them. The processes of learning and education require a good deal more than simply placing a student in an environment where knowledge is made available; it requires that the student have the means and the ability to "make sense" out of the information provided. As George Kelly (1963) has stated,

It is not what happens around him that makes a man experienced; it is the successive construing of and reconstruing of what happens, as it happens, that enriches the experience of his life. (p. 73)

It is this constant "construing" or making sense of our experiences which can be seen to constitute our learning process. If this assumption is accepted, it would follow that one of the purposes of education would be to insure that the "constructs" necessary for processing the available 
information be provided, yet it is an aspect we frequently disregard, unconsciously assuming that the same cognitive structures exist for all.

It is the premise of this research that these constructs and the resulting patterns of cognition which dominate our logical and analytical processes, and therefore our approaches to problem solving and learning in general, are culturally bound. As a result, our educational institutions and the students they produce must be seen as both products and purveyors of their unique cultural perspectives.

When we begin to accept that students come to the university as "cultural beings," then we must accept other assumptions that go along with that awareness. Not only may these students dress, behave and speak differently, they may hold different beliefs and values and live in very different realities; what exists, what is important and what is considered to be intrinsically right and wrong, good or bad, are all included in that package (Hoopes, 1981; Stewart, 1972; Condon \& Yousef, 1981; Barnlund, 1975). Further, and perhaps most disconcerting, is the idea that they may well possess different patterns of thinking or cognition. As Barnlund (1975) states, "The mental process, forms of reasoning, and approaches to problem solution prevalent in a community are another major component of culture" (p. 27). 
The complex dynamics which underlie the relationship between culture and cognition are central to this discussion. David S. Hoopes (1981) points out that our "realities" are constructed from "vast quantities of stimuli" which we selectively screen and categorize. This process is affected by " . . environment, personality and immediate needs; but the basic framework is provided by culture.. [It is] culture which is the basis for categorization" (p. 14).

Stewart (1972) adds that "acquiring the patterns of thinking, values, and assumptions which represent culture" involves

categorization or abstraction [and] is seen to underly both perception and thinking . . . [further] the process of thinking itself can be seen to differ according to the effects of culture. (pp. 15-16)

Tyler (1969) in his discussion of the basic principles of cognitive anthropology asserts that

Each people has a unique system for organizing material phenomena--things, behaviors, and emotions - . Cultures are not material phenomena; they are cognitive organizations of material phenomena. (p. 177)

And Witkin (1976) states that "cognitive styles" are 
- . the characteristic, self consistent modes of functioning found pervasively throughout an individual's perceptual and intellectual activities - . [and] to the extent that cognitive styles are the end products of particular socialization processes, they may be used in the comparative study of those processes. (p. 234)

In other words, to study cognition or patterns of thinking is to study culture and all of its assumptions, beliefs and values.

It has further been discussed that these cultural patterns of thinking are an integral part of a person's communication patterns, nonverbal and verbal, and that those verbal patterns include both oral and written communication (Kaplan, 1966; Barnlund, 1975; Condon \& Yousef, 1981). The complex interaction of culture, perception, language, thought and communication was touched on by Benjamin Whorf (1956), who theorized that

- . the forms of a person's thoughts are controlled by inexorable patterns.. . patterns that are the unperceived, intricate systemizations of his own language. . and every language is a vast pattern-system, differing from others, in which are culturally ordained the forms by which the personality not only communicates, but also analyzes nature, notices or neglects types of relationships and phenomena, channels his reasoning, and builds the house of his consciousness. (p. 332)

More specifically, Sereno and Mortensen (1970) have defined human communication as a "composite process" which involves the complex interrelationship of the basic 
determinants of human behavior: perception, learning, drives, emotions, attitudes, beliefs, values, encoding, decoding, meaning, messages and social contexts (p. 4). A person's style, then, "cannot be considered apart from the world he knows and perceives, nor can it be considered apart from his cognitive stylen (Sereno \& Bodaken, 1975, p. 10). It is the basic assumption of the speakers and readers of English that coherence of language, thought and communication must follow a "sequencing that is dominantly linear in its development" (Kaplan, 1966, p. 4). Kolb (1981) has also observed that the western system of higher education has

- . often emphasized the linear trend of human growth and development at the expense of acknowledging and managing the diverse developmental pathways that exist (p. 233).

To think, to teach, to communicate otherwise is to appear illogical. This "logic, which is the basis of rhetoric, is evolved out of culture; it is not universal" (Kaplan, 1966, p. 2), yet it is the assumption of universality which has dominated the exploration of cultural patterns of cognition.

To be "logical" is to be "rational," "reasonable," or "able to be reasoned with" (Condon \& Yousef, 1981, p. 92). These definitions indicate a concomitant assumption of sanity, i.e., if we are not "rational, we must be 
"irrational." Mead (1936) noted that "rationality" is judged by a certain consistency of behavior between ourselves and others; we consider communication behavior to be rational only if it is the same behavior which we would use in a given situation (p. 149). In essence, it is this natural assumption of similarity which is the basis of much of our judgment of and response to the communication of others.

MCLuhan (1964) in his book Understanding Media took the position that "rationality" is only possible in societies that use a phonetic alphabet. He hypothesized that it is the possession of a phonetic script which allows for linear thought and the resultant forms of abstraction and "logic." Such thinking, he admitted, had a cost; Western man had sacrificed his sense of belonging, of being part of a greater whole, but he had gained his individuality and his "freedom" (Ch. 9). It was a trade McLuhan clearly felt was worth the sacrifice. He had recognized that differences existed, but the feeling that one was obviously better than the other persisted.

Gladwin (1964) noted that he had searched in vain for theory and research which attempted to define cognitive learning style in a way that did not quantify it in terms of "intelligence," and intelligence whose standards had been "operationally defined as that which is measured by 
[Western] intelligence tests" (p. 27). He observed that

- . numerous non-European peoples, many of whom do bright things, had been given intelligence tests by both psychologists and anthropologists . . and had consistently come out with low IQ's. . . We are in effect accepting an assumption that there is only one really good way to use the human brain and that is our way. (p. 29)

Kaplan (1966) pointed out marked differences in the "logical" or rhetorical patterns of native English writers and foreign-student writers of English by quoting extensively from theme papers. He presented the differences in the diagrams shown below:
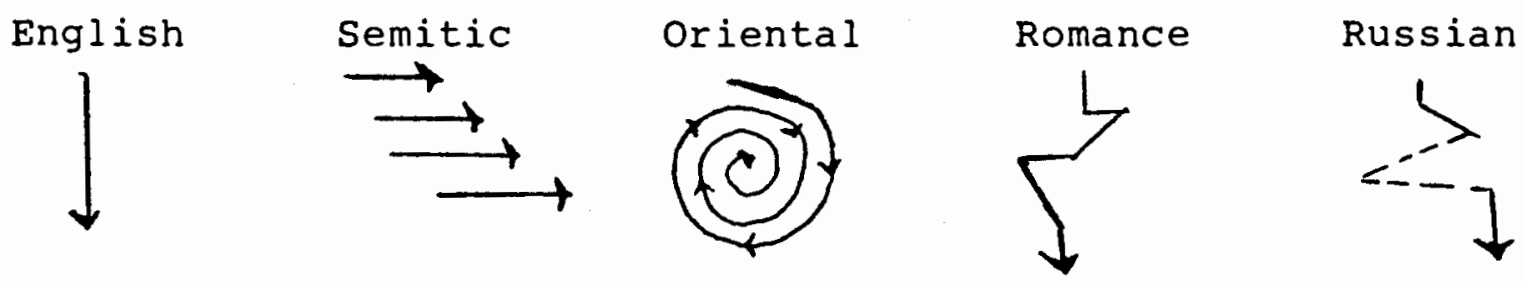

Is it any wonder that he found university instructors complaining that the work of International students was often "out of focus," lacking "coherence," "cohesion" and "organization" (pp. 3-4), or that he concluded that these comments were

- . essentially accurate. . because the student was employing a rhetoric and sequencing of thought which violate the expectations of the native [American] reader. (pp. 3-4) 
This process is further complicated by the fact that the student will frequently have mastered the vocabulary and the "academic jargon" required for performance at the university long before he has a grasp of the actual patterns of logic and thinking that will guide their use, and is, therefore, "unable to make the same discriminating judgements as his instructor" (Stewart, 1976, p. 11). The result is deceptive. The form is there, but the meaning not clear, and the instructor often "decides that the foreign student is incapable of thinking analytically ... [while] the foreign student feels that the educational institution is making blind impositions upon him" (p. 11).

Our educational institutions are more than just places where information is passed from teacher to student. They are "part of the socialization process" and carry the "objectified knowledge" reflective of a culture's values (Berger \& Luckman, 1967, p. 71); they are bastions of cultural knowledge that tell us not only what we need to know, but, more importantly, how we are to know it. Eo be successful in such a system, a student must have the ability to cognitively function according to the expectations of the culture. If we assume that a student is the product of a particular cultural perspective, it is reasonable to imagine that a cultural change in educational systems may require a major alteration in the student's world view. 
In his discussion of problems experienced by Iranian students at American universities, Zonis (1978) echoes Stewart's perception of confusion and frustration on the part of these students as a result of the demands placed on them by the American academic system. Products of educational institutions in which the student/teacher relationship is seen as one of helping " . . to provide students with information which they need to be educated and to pass their examinations (the two being synonymous)" ( $p$. 84), these students frequently feel betrayed. They are expected to be academically successful when, from their perspective, the teacher has not carried out her part of the contract. In many cases, the necessary information is considered to have been withheld "on purpose." The result is a range of behaviors that varies from "apathy or withdrawal from school" to "suicide." Perhaps the most common complaint leveled against these students, however, is that of "cheating." zonis' statements relating to this behavior provide interesting insight into the perceptions of both the students and the instructors involved:

It is difficult to assess the validity of this charge, especially given what I perceive to be a rather general discomfort on the part of U.S. professors with Iranian students. However, to the extent that Iranian students do cheat, such behavior can be understood as an attack on the central values of the system which is causing them difficulties. (p. 84 ) 
As Hall (1976) has stated: "In real life, the code, the context, and the meaning can only be seen as different aspects of a single event" (p. 90). When one of those aspects is out of synch, the communication becomes miscommunication and the people involved in the transaction pass each other in their intent, frequently confused and frustrated by their failure to make sense out of a simple situation.

\section{RESEARCH GOALS}

Communication has been defined as a dynamic, interactive and ever-changing process through which meaning is mutually created between two or more people (Tubbs \& Moss, 1983, p. 5). The identical definition could be given for the process of education. If communication and understanding break down, meaning is lost; and it is learning, the major goal of education, which is ultimately the victim of the misunderstanding.

The idea that the processes of learning and education are part of a broader experiential framework is not a new idea. In 1938 Dewey noted that

- . the fundamental unity of the newer educational philosophy is found in the idea that there is an intimate and necessary relation between the process of actual experience and education. (pp. 19-20) 
And Kolb (1981) defined experiential learning as the "process of human adaption to the environment" (p. 31) and as

- - a molar concept describing the central process of human adaption to the environment an active, self-directed process that can be applied not only in the group but in everyday life. (Kolb, 1984, pp. 31ff)

By taking this experiential perspective, the students or learners are no longer separated from their social and cultural background. Instead, they are seen as intrinsically tied to those experiences and continually influenced by them. If educators accept this as a basic premise, then they must be prepared to adapt their methods of teaching to include a broader spectrum of learning styles and approaches in order to make classrooms truly accessible to the increasing variety of students with whom they are required to deal.

If the goals of education are to be realized and maximum learning is to take place, it will be helpful to find ways to label and define the differences that exist in patterns of thinking and learning. It is the purpose of this research to advance toward that goal by selecting one tool, the Learning Styles Inventory based on Kolb's experiential learning theory, and see whether it would provide useful categories for analysis of systematic 
differences between American and International students.

\section{RESEARCH QUESTIONS}

In looking at the results of the research, the following questions will be addressed:

1. Are the learning styles of International students tested different from those established by Kolb in previous studies for American students?

2. Do the learning styles of the International students tested differ among the various groups?

3. Are there differences among the groups of International students tested that can be related to gender?

4. Do the learning styles of the International students tested show any pattern of variation according to age?. If present, does that pattern differ in any way from patterns identified for American subjects tested?

5. Are the learning styles of the International students tested similar or dissimilar from the norms established by Kolb for American students in various fields of academic study? 
OVERVIEW OF THE STUDY

\section{Limitations and Scope}

Triandis (1984) noted that "Every research method can be seen as an approximation of the truth" (p. 85), a constant balancing of the accuracy of the data applied to specifics and the danger of generalization when it is applied to all members of a given group (p. 86). The delicacy of this balance is exaggerated when the research is cross-cultural; and the researchers must be even more aware, not only of the incredible complexity of studying something as fluid and dynamic as culture, but also of the effect of their own cultural biases on the observation and interpretation of the data. Barnlund (1975) has cautioned

- - no matter how objective the conclusions, they must be read from some cultural perspective. Although the effects of cultural bias can be resisted, they can never be totally eliminated. (p. ix)

In the realm of cognitive research these pitfalls have caused misuse and misinterpretation of data that has supported racist arguments and unjust causes since the advent of psychological testing (Lessor, 1976, p. 158). In an effort to limit European immigration to the United States, for instance, some of America's most esteemed psychologists examined large numbers of immigrants and concluded that 838 of Jews, 808 of Hungarians, 798 of 
Italians and 878 of Russians were "feebleminded" (Rappaport citing Kamin, 1977, p. 32).

Even the best intentioned research frequently resulted in the "pigeon-holing" of students as cognitive style became synonymous with the idea of "intelligence" or "aptitude," and "Black children were placed in remedial classes while Chinese-American children were placed in accelerated physics" (Cole, 1976, p. 164).

It was the awareness of this tendency for abuse which caused a near moratorium on testing of cultural difference in cognitive style in the late 60's and early $70^{\prime} \mathrm{s}$ (Cole, 1976; Lessor, 1976). Yet as Lessor (1976) has stated: ". . disregard for an experimental orientation in higher education combined with deliberate ignorance about cultural difference will serve us poorly" (p. 160).

Educators can no longer ignore the cultural differences that exist in cognitive learning style if they are to maximize the learning opportunities of international students and broaden the flexibility of their teaching skills and approaches. To minimize the dangers inherent in this kind of research, it is important that the research be rooted soundly in a theoretical base which reflects respect for rather than denigration of difference.

\section{The Intercultural Communication Perspective}

The intercultural communication perspective will serve 
as a guideline for the theoretical approach, choice of instrumentation, analysis of data and application of results. It is not an arbitrary choice. It is a perspective which is uniquely suited to dealing with the exigencies of change, conflict and information overload that are associated with the intercultural experience. It stresses the view of human beings as actors rather than reactors with the ability to both create and change their conceptual spheres, and it provides a framework for interpretation and action in dealing with the uncertain world of human interaction.

The intercultural communication perspective has been defined as difference-based, face-to-face interactive, processual and humanistic (Bennett, 1979). Since these components form the interdependent framework through which this study will be viewed, an in-depth explanation of these terms is necessary.

Difference-based. This involves the assumption that peoples from different cultures will have marked differences in their behaviors, institutions and underlying value systems, and that it is through the understanding of these differences that communication can be realized on a maximum level. It embraces the view that these cultural differences should not only be respected, but enjoyed, since they can offer us new and exciting insight into the rich diversity of 
man's creative and human potential.

Face-to-Face Interactive. This connotes direct interaction among individuals from different cultural backgrounds who bring with them their unique, culturallybased perceptions of reality, behaviors and values. This process involves continuous feedback and the mutual creation of meaning. Since meaning is not in the message, but in the message-users, and the participants in an intercultural interaction are using two different cultural (and possibly linguisticl codes, the potential for misunderstandings is virtually endless. Consequently, the need for feedback is essential if communication is to occur.

Processual. This element sees culture as dynamic and ever changing, both creating and emerging from the continual interaction and interdependence of society's individuals and institutions.

Humanistic. It is based on the belief that human cultures and institutions--linguistic, social, religious and economic--are created by people to meet their need for mutual support and predictability. These institutions are seen as mutable and nonuniversal in nature, existing only in relationship to their human components. It legitimizes subjective experience.

\section{Kolb's Perspective}

The idea that differences in learning styles (1) exist, 
and (2) should be an important consideration in the educational setting have been addressed by a number of researchers and theorists (Dewey, 1938; Bruner, 1966; Cole, 1971, 1976; Witkin, 1976; Lessor, 1976; Hall, 1976; Gay, 1978; Kolb, 1981, 1984). For the purpose of this study, a brief survey of what has been done in the area of cognitive research and theory will first be discussed.

This overview will provide the basis for an in-depth discussion of the work of David A. Kolb in this area: the theoretical roots of his work, the actual assumptions on which it is based, and the explanations and definitions that are part of Kolb's Learning Styles Inventory (LSI) itself. Kolb's LSI has been chosen as the method for testing for three reasons: (1) it is difference-based, (2) it is built on a cultural metaphor, and (3) it is processual in its approach. It is these features which uniquely qualify it to be used in conjunction with the intercultural perspective.

\section{Methodology}

Testing for this study involved the administration of a linguistically simplified version of the LSI that had been developed for American junior high school students to a cross-section of International students. Students chosen for this study were from non-English speaking countries and had been in the United States for no more than a year. The 
population includes Indo-Chinese refugees who are not officially listed as International students by the university but who clearly meet the criteria for cultural difference laid down in this thesis. The majority were from intermediate and advanced level English as a Second Language (ESL) classes at various colleges and universities. A few were already mainstreamed into the general university system.

The subjects were chosen in this way for two reasons: (1) they would most likely have developed adequate skilis in English to manage the vocabulary used in the inventory, and yet, (2) they hopefully would still be new enough to the American university environment to be reflective of any cognitive learning style that might predominate in their home culture.

When a sample group of twenty-five student was tested, it became apparent that further modification of the inventory would be needed if it were to be easily comprehensible to these students. Modification of sentence structure, vocabulary and scoring method were developed to simplify International student understanding of the inventory. This modified Learning Styles Inventory (MLSI) was then administered to 130 students at six different institutions. These one-hour sessions involved explanation of the instrument itself, one-to-one assistance with method 
and vocabulary and the administration of a data sheet with demographic information on age, sex, nationality and major.

\section{Analysis}

The data will first be reviewed to see whether there are any systematic variations among cultures in cognitive learning style. Further breakdown will be made within each culture to check for the presence of any differences between males and females within the sample.

Results will then be compared to existing data gathered by Kolb on the "optimum" learning style determined for various academic disciplines within the university system. How well have these International students been prepared to perform within the standards set by Americans in their chosen fields of study? Are there some cultures for whom adjustment to the American system of higher education will be more challenging than others? Are there internal factors such as gender which might affect the learning process?

\section{Application}

The results of this study will be examined for possible implications and insights into the special learning needs of International students. Suggestions for implementing those insights will involve both teachers and students: 
1. How can educators in a multicultural classroom maximize the effectiveness of the learning environment and their methods of teaching to reach students with a variety of learning style preferences?

2. How can the students be trained to increase the scope and flexibility of their own learning style needs and preferences? 
CHAPTER II

THEORETICAL OVERVIEW, PROFILE OF TEST MODEL ASSUMPTIONS, AND DISCUSSION OF LEARNING STYLES INVENTORY

When choosing an instrument for this study, several major concerns needed to be addressed. Primary among these was an assessment of the theoretical perspective on which the study was based. The task of ferreting out just exactly what the assumptions of a researcher might be is not as simple as it first may appear. In their discussion of the theoretical bases for research that has been done on culture and cognition, Cole and Scribner (1974) have observed that

In actual practice different psychologists use the term [cognition] to denote human questions on information [quite differently] depending on their point of view in psychology and the specific nature of their research. (p. 2)

As a guideline for a study that emphasizes intercultural application of theory, it is important that the theoretical framework used be consistent with the intercultural communication perspective noted in Chapter I. It should be processual in nature and based on the assumption that differences in cognitive processes are not measurable on a linear scale that moves from "good" to "bad," "intelligent" to "stupid." 
Cole \& Scribner (1974) in their discussion of cognitive testing across cultures are unequivocal in their disdain for such methods of research:

It has too often been assumed that questions about the difference in some capacity (intelligence is the capacity most frequently investigated) are the same as questions about the differences in cognitive process. But this equation is not valid... (p. 33)

Each culture will define the content issues of which bits and pieces of information will be the definers of "intelligence" differently. If it is a form of universal measurement or categorization of cognition that we are looking for, it is the "processes" of cognition, the methods by which people examine, organize and make sense of the available information, that are likely to prove the most useful in meeting this end.

The final concern is that the whole individual be taken into consideration in the measurement that is used. Intellect and emotion, action and perception should be considered, and the learner should be viewed as both product and creator of his cognitive and cultural worlds. This view is nicely summarized by Cole \& Bruner (1971) and finds its inspiration in these words from educator-philosopher Francis Bacon: "Neither hand nor mind alone, left to themselves, amounts to much; instruments and aids are the means to perfection" (p. 245). 
In this brief statement, Bacon has defined the essential components of learning, the need for balancing those components and the value of education as the means to that end. Cole \& Bruner assert that all this must be considered if educators are

\footnotetext{
- - concerned with comparative research of social and ethnic group differences. . . [They] must take seriously the study of the way different groups organize the relationship between their hands and minds; without assuming the superiority of one system over another, they must assume that man is a cultural animal. (pp. 245-6)
}

It is the ways that people grasp information and transfer or make meaningful that knowledge that may define the essence of an individual's cognitive relationship with her culture and environment. As a result, it should be a major concern in any instrument used in assessing cultural differences in learning style.

There have been a number of interesting and credible pieces of research in the area of culture and cognition. However, it was David A. Kolb's experiential learning theory which ultimately proved most compatible with the intercultural perspective and the needs of this study.

Kolb based his work on a cultural metaphor which sought to explain the diversity of perspective among academic disciplines, each with 
- its own language, norms, and values, its own ideas about the nature of truth and how it is to be sought. . education in an academic field is a continuing process of selection and socialization. (Kolb, 1981, p. 233)

He defined the challenge of assessing the demands of these various perspectives as

- . the same difficulties that characterize all cross-cultural research--the problem of access and the problem of . - a perspective for interpreting data that is unbiased. To analyze one system of inquiry according to the ground rules of another is to invite misunderstanding and conflict and further restrict access to the data. (p. 234)

His solution was to view the problem from the perspective of "learning and learner" in an approach "that seeks to integrate cognitive and socioemotional factors into an 'experiential learning theory'" (p. 235).

Taking an experiential approach when assessing learning and cognition involves the adoption of a perspective that views individuals as part of rather than separate from their culture and experience. A constant dialectical tension is assumed to exist between the concrete dimensions of the senses and behavior and the abstract dimensions of thought and intellect. It is an approach that defines people as being "in process," possessing fluid rather than static characteristics. Internal and external worlds act and interact in a constant exchange of mental and perceptual experience that cannot be separated except as a momentary 
"stop-action" frame in our imagination. We may attempt to analyze the parts, but even our analysis can be seen as the product of our own unique experience, experience that is subjective personally and culturally, experience that has structured our world view and the patterns of our thinking. It is attention to these individual perspectives and the needs that are contingent on them that is the crux of an experiential approach to learning and teaching.

This chapter will present a brief overview of the theoretical base of Kolb's experiential learning theory, a profile of the assumptions of the test model itself and a brief discussion of the internal properties of the Learning Styles Inventory.

\section{KOLB'S THEORETICAL BASE}

In developing experiential learning theory, Kolb based his research on the integration of work by a number of theorists and researchers who preceded him. of these, the three most influential were John Dewey, Kurt Lewin and Jean Piaget.

In the twentieth century, it is John Dewey's pragmatic approach to educational philosophy that is seen as the root of the experiential approach to education. In his Experience and Education (1938), Dewey drew a comparison between the aims of the old and the new educational 
perspective, calling for a balance of approaches:

- . To imposition from above is opposed

expression and cultivation of individuality; to external discipline is opposed free activity; to learning from texts and teachers, learning by experience; to acquisition of isolated skills and techniques by drill is opposed acquisition of them as means of attaining ends which make direct vital appeal . . .

I take it that the fundamental unity of the newer philosophy is found in the idea that there is an intimate and necessary relationship between the processes of actual experience and education. (pp. 19-20)

It was Dewey's hypothesis that it was the intervention of learning which transformed the impulses, desires and feelings of daily life into a purposeful action. This process involved: (1) observation of actions and situations; (2) knowledge of similar events obtained either from one's own experience or that of another, and (3) judgment, which synthesizes what is observed and what is known into a plan of action.

A purpose differs from an original impulse and desire through its translation into a plan and method of action based on foresight of the consequences of action. . . The crucial educational problem is that of procuring the postponement of immediate action on desire until observation and judgment have intervened. (Dewey, 1938, p. 69)

Figure 1 gives a graphic representation of Dewey's model of experiential learning. Its dialectical nature is 
28
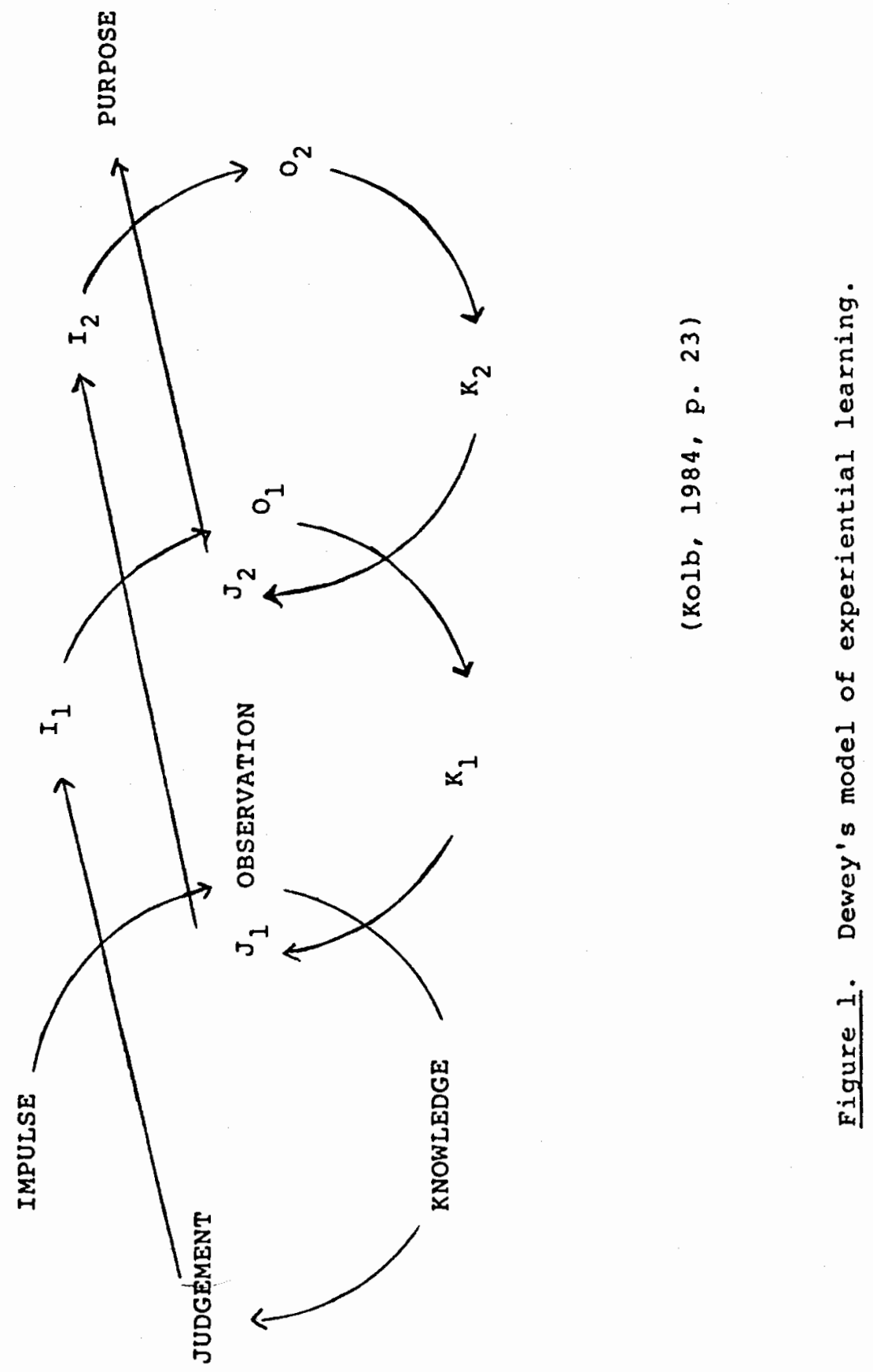
apparent in the relationship between the parts, with the impulse of experience giving "ideas their moving force, and ideas giving direction to impulse" (Kolb, 1984, p. 22).

Dewey's was an eloquent statement of an approach to learning that was demonstrated in 1946 by Kurt Lewin and his colleagues Lippett, Bradford, and Benne in their research on group dynamics. According to Lippett's (1949) account, the analysis of the day's events which had originally been restricted to the staff had begun to include the participants. It was discovered that their responses about their immediate, subjective experience added a new and exciting vitality and creativity to the discussions.

The evening session from then on became the significant learning experience of the day, with the focus on actual behavioral events and with active dialogue about differences of interpretation and observation on the events by those who had participated in them. (p. 94)

This experience was to provide the roots for the laboratory training movement and the beginning of the debate that was to characterize its history, the value of the "here and now" experiential approach versus the "there and then" analytical approach (Kolb, 1984, p. 10). Lewin's statement that "There is nothing so practical as a good theory" leads one wonder whether his death in 1949 contributed to this "either/or" conflict and the blurring of the original vision that 
- - learning is best facilitated in an environment where there is dialectical tension and conflict between immediate experience and analytic detachment. (p. 9)

The laboratory training method provided an opportunity to participate in a four-stage learning cycle where the learner is first steeped in a "here-and-now" concrete experience, allowed to reflect on that experience, assimilate the resulting ideas into an existing theoretical base, and then actively test them in a secure environment where a common meaning is shared. Lewin believed that it was the constant application of feedback toward a desired action which allowed for the institution of goal-directed change.

The Lewinian experiential learning model shown in Figure 2 depicts this continuous four-stage cycle of interaction. Immediate concrete experience gives rise to observation and reflection which is then assimilated into theory that becomes the basis for action and further experience (Kolb, 1984, p. 2).

Dewey came from the philosophical base of pragmatism, Lewin from the phenomenological school of Gestalt psychology. The third major contributor to the body of experiential learning theory was French constructionist psychologist Jean Piaget. Figure 3 gives a graphic representation of Piaget's model of learning and cognitive 


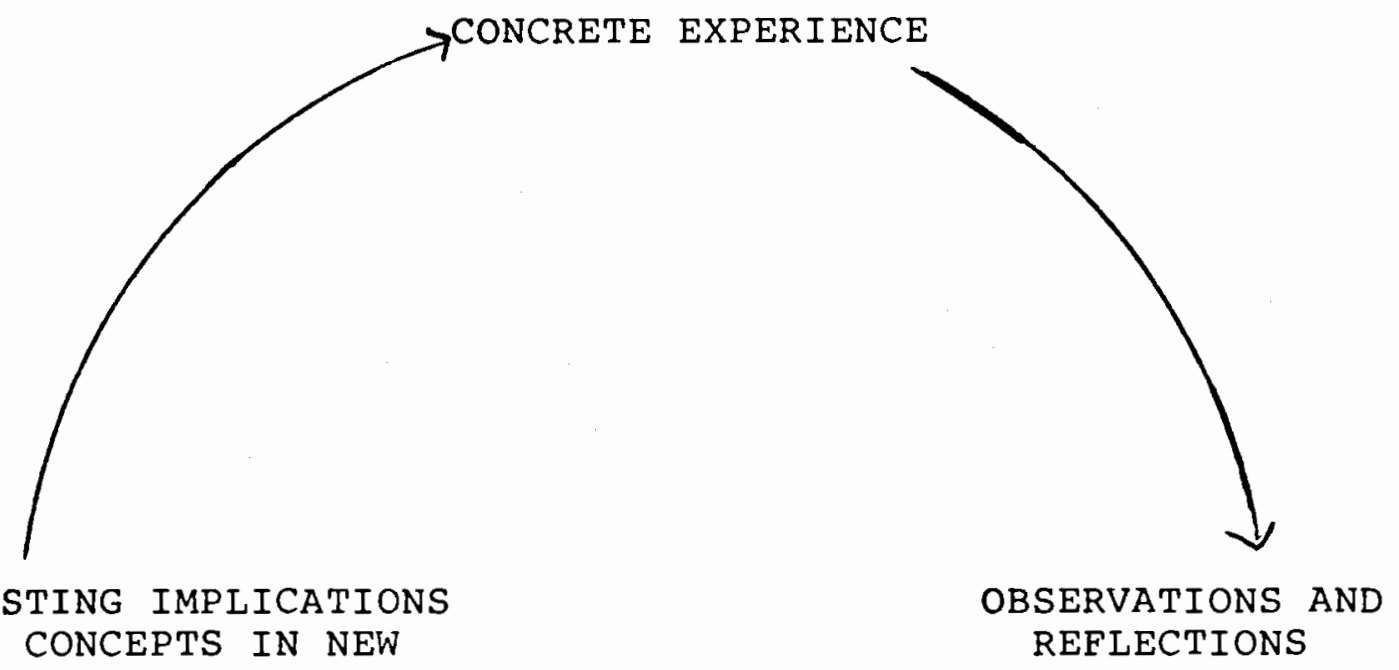

\section{SITUATIONS}
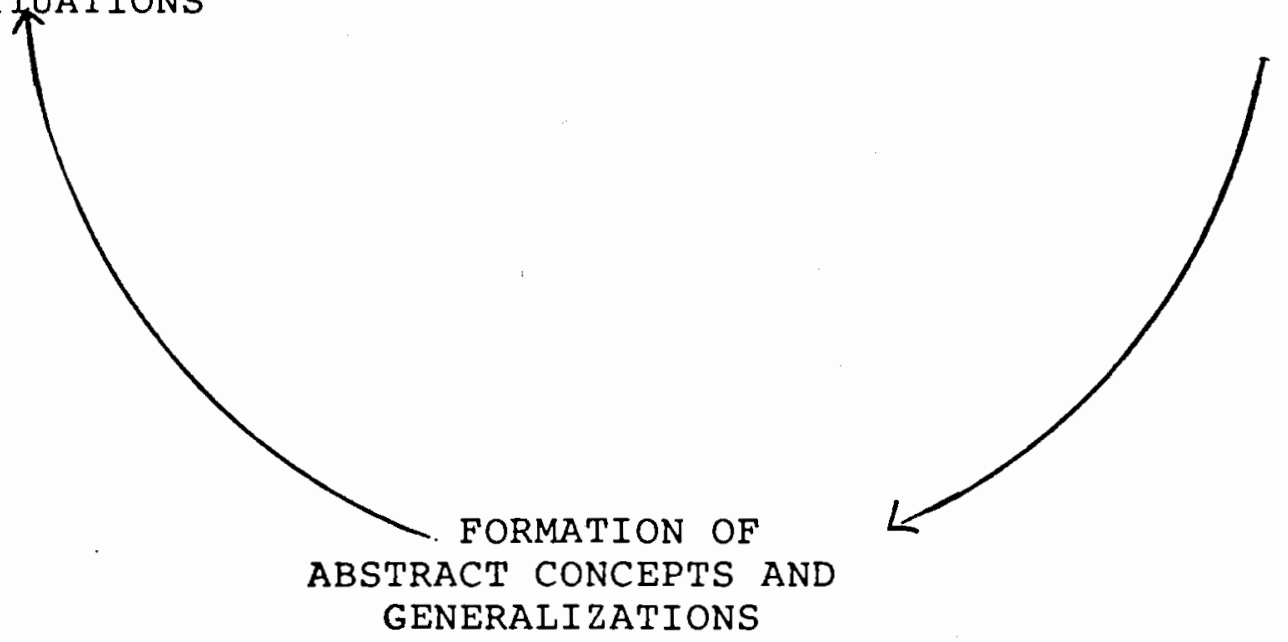

GENERALIZATIONS

$$
\text { (Kolb, 1984, p. 21) }
$$

Figure 2. The Lewinian experiential learning model. 


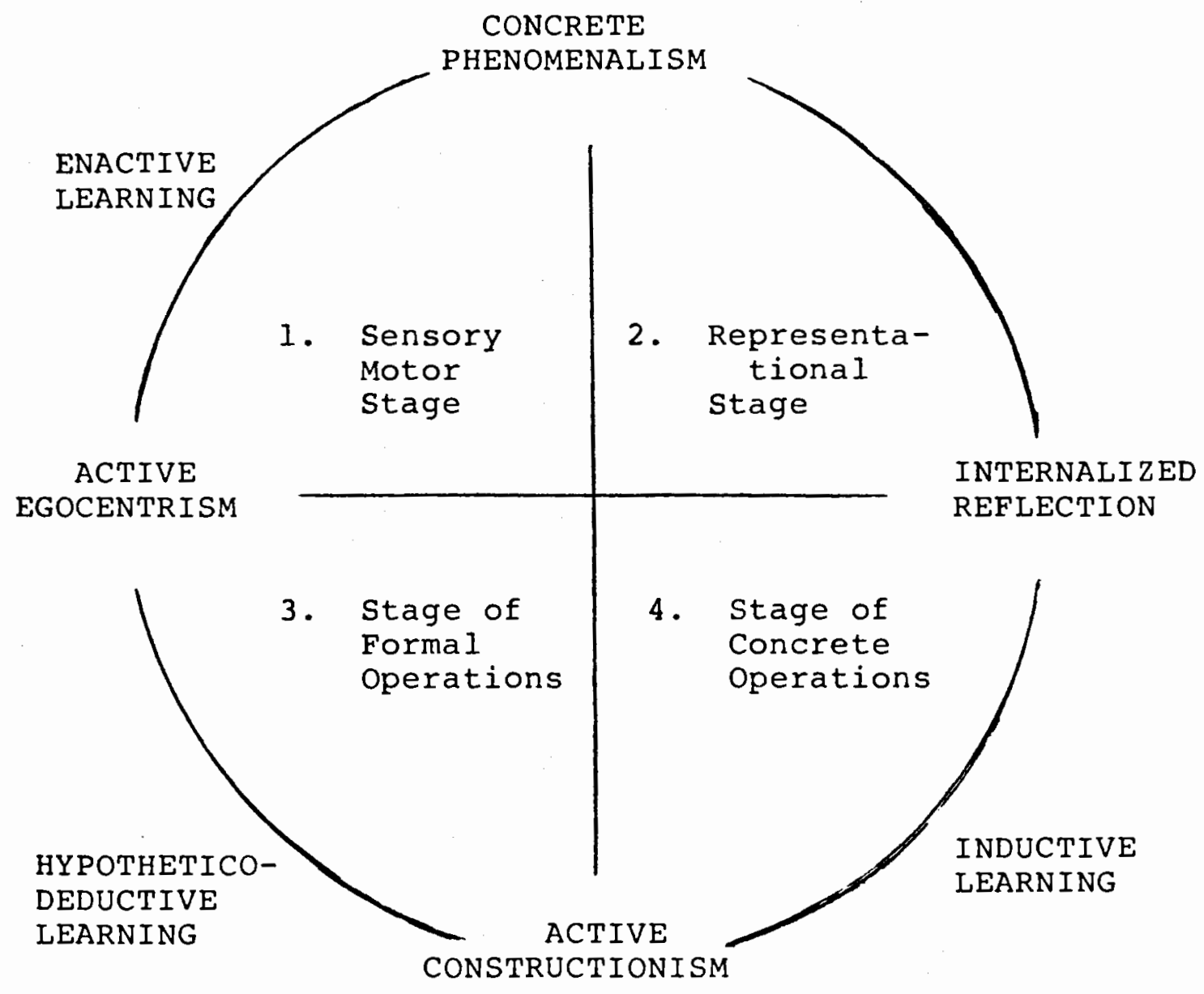

(Kolb, 1984, p. 25)

Figure 3. Piaget's model of learning and cognitive development. 
development (Kolb, 1984, p. 25).

In careful descriptive studies of children from infancy to adolescence, Piaget presented a unique epistemological approach to the field of cognitive development. At the base of his work were two essential assumptions.

The first is that "knowing" is ultimately accomplished only through the "active participation of the knower in understanding the world." Intelligence was viewed not as an innate characteristic, but as one that developed through continuous interaction and involvement with the environment (Kurfiss, 1980, p. 2).

Although it changes in character, the role of action remains primary to the developmental process. In the early stages it is intrinsically tied to the concrete experiences in which it occurs. As learners become increasingly capable of generalizing their experiences from one situation to another, the use of symbols becomes more internalized and the ability to create or recreate experience free from the external environment is developed.

The second assumption is that learning and development occur only when learners must confront the discrepancies that exist between what they already believe to be true and the new information that has been presented. Once confronted with this "disequilibrium," learners seek to reestablish balance in one of two ways: assimilation (the 
Incorporation of information into the learner's existing vorld view) or accommodation (adjusting or changing one's understanding of the world to include the possibility of the change presented) (Kurfiss, 1980, p. 8).

It is this moment of "surprise" that is the cognitive link in the learning chain. The description is highly reminiscent of Jerome Bruner's (1979) discussion on "The Conditions of creativity." It is, he avers, the moment of "effective surprise" that is the harbinger of creativity, the "hallmark of the creative enterprise" (p. 58). For although he sees this as a mental process, it is intrinsically linked to activities that are expressed in ways that cover the entire range of Piaget's developmental stages from the concrete to the abstract.

It may express itself in one's dealing with children, in making love, in carrying on a business, in formulating a physical theory, in painting a picture. (p. 58)

From the perspective of experiential learning theory this is not a surprising connection since "learning" and "creativity" can be viewed as one and the same process. It is not really possible for the teacher to "make the student learn;" it is only possible to "establish conditions for the discovery of the discrepancy and provide support for the learner's efforts to resolve it" (Kurfiss, 1980, p. 9).

Piaget (1970) identified four basic stages of cognitive 
growth and development. In the sensory-motor stage, children are active and concrete in their approach to learning about the world. Relying mainly on sensation for information, they are consistently touching, tasting and inspecting the objects that make up their experience. The major task of this stage is to move from non-intentional to goal-directed activity.

In the representational stage children maintain their concrete organization but become increasingly reflective as the ability to internalize events through vivid, actionoriented images develops.

In the stage of concrete operations, increasing ability to internalize experience through symbolization further separates the learner from the need to depend on immediate experience for information. Abstraction increases, and powers of induction allow for the continuing refinement of theoretical manipulation.

The stage of formal operations is the final phase of development. Working from a base of abilities mastered in the previous stages, learners are now ready to enter a much more active phase. The ability to reason deductively has provided the incentive for testing both their own theories and ones provided by those in authority. The seeds are sewn for discovery and adolescent rebellion.

To Piaget, these stages seem to represent, not so much 
specific behaviors as a general orientation toward organizing information and approaching problem solving.

While diverse in their inception, all three theorists have developed perspectives on learning which share a number of common elements. In the next section, Kolb's integration of these perspectives into his experiential learning theory will be explored.

\section{EXPERIENTIAL LEARNING THEORY: A SYNTHESIS}

Experiential learning theory as conceived by Kolb has essentially been derived from a synthesis of the models and perspectives of Dewey, Lewin and Piaget discussed above. While diverse in their origins land possessing disagreements that there is not time to discuss here), they contain several significant similarities. Kolb (1984) has identified six major assumptions about the nature of the learning process that are common to all. Before moving on to the actual structural dimensions of Kolb's model those aspects will be briefly discussed.

Learning is Best Conceived as a process, not in Terms of outcomes

This is the first and perhaps the most important of the basic premises. From this perspective, ideas are not seen as "fixed and immutable elements of thought but are formed and reformed through experience" (p. 26). Information is 
not "out there" to be known; instead learning and knowledge are constructed and reconstructed through the active participation of the learner in a process of creation. This postulate is of fundamental importance in explaining the acceptability of experiential learning theory as a tool for assessing cultural difference. It is consistent with the assumption of the intercultural, perspective which sees human beings a creators of their own realities and rules out the practical existence of definable absolutes as they relate to the products of human culture.

Learning is a Continuous Process Grounded in Experience

This assumes that learners do not approach an experience with a "clean slate," but carry with them all previous knowing and experience. In this sense, all learning becomes "relearning" (p. 28) as the new or unexpected becomes integrated into the previous mind set. Human beings are thus seen as consciousness in process, the same yet always changing. And it is this change/shock which is the root of all growth, or as Hegel so nicely put it, "Any experience that does not violate expectation is not worthy of the name experience" (Kolb quoting Hegel, 1984, p. 281 .

This view provides a base for assessing learning as related to a person's experience, an experience for which culture can be seen as one of the major orchestrators. 
The Process of Learning Reguires the Resolution of Conflicts Between Dialectically opposed Modes of Adaptation to the World

This suggests the idea that all learning is a result of the constant tension arising between the four modes of experiential learning:

1. Through concrete experience (CE) the learner must be able to participate "fully, openly, and without bias in new experiences" (p. 30).

2. Through reflective observation (RO) the learner must be able to sit back and reflect on the possibilities suggested from many different perspectives.

3. Through abstract conceptualization $(A C)$ the learner must be able "to create concepts that integrate his observations into logically sound theories" (p. 30 ).

4. Through active experimentation ( $A E)$ the learner must be able "to use these theories to make decisions and solve problems" (p. 30$)$.

It is the dialectical tension existing between these elements as one balances and shifts between the abstract and the concrete, the active and the reflective, that determines the depth of the learning that will occur. For maximum effectiveness, all must be employed. Yet it is clear that learners will express preferences for certain modes, with 
none being seen as "better" than another. It is the nonevaluative nature of this processual view which may allow insight into the nature of the preferences that a culture might impose on its members.

Learning is an Holistic Process of Adaptation to the World

This takes the view that learning is a life-long

process and the most important process by which human beings adapt to their environment. As a result, it is not confined to the functions of "cognition or perception," but rather is an integrated process which involves "the functioning of the total organism--thinking, feeling, perceiving, and behaving" (p. 30$)$.

When viewed in this manner, learning in the classroom cannot practically be separated from learning in the world. It becomes a process which extends through time and space, which is fluid and ever changing, and which is intrinsically tied to the environment and therefore the culture.

Learning Involves Transactions Between the Person and the Environment

This statement relies on applying a dual meaning to the term "experience"--one subjective, internal and highly personal, the other external and objective, referring to the person's relationship with the environment. It is the nature of these transactions that "objective conditions and subjective experience" interrelate and interpenetrate in a 
dynamic process that leaves both "essentially changed" ( $p$. 36). The individual is seen simultaneously as both an individual and a cultural, social being for whom learning involves a constant intermingling of the various aspects of the person and her world.

Learning is the Process of Creating Knowledge

This is based on the understanding that learning is the result of the transactional relationship that occurs when what people "know" according to their own subjective experience and what the world "knows" in terms of the "previous collected human experience" (p. 36) collide. It involves repeated moments of "surprise" during which learners reconstruct their world views, creating new ways of being based on those reconstructions.

It is this aspect of experiential learning theory which both explains the difficulties faced by International students as they confront the collision of realities presented by the university and defines the potential for profound adjustment and adaptation. We no longer need to view learning styles as measurements of "aptitude." Instead, we can see them as guidelines for growth.

\section{Learning: A Definition}

In summary, an operational definition of learning is offered by kolb (1984) that is succinct and gets nicely to 
the heart of the matter: "Learning is the process whereby knowledge is created through the transformation of experience" (p. 38).

STRUCTURAL FOUNDATIONS OF EXPERIENTIAL LEARNING THEORY

The previous discussion has introduced the four adaptive modes that Kolb has identified as the essential components of the learning process: concrete experience (CE), reflective observation (RO), abstract conceptualization $(A C)$ and active experimentation ( $A E$ ). This section will deal with the structural aspects of the theory. It provides a "blueprint" or functional model of how these modes operate and maintain and elaborate their operation and examines the nature of their holistic interdependence.

Learning is seen to consist of two dimensions, each "representing two dialectically opposed adaptive orientations" or poles, all equally important and dynamically interrelated "as they proceed along a third, developmental dimension." In other words, knowledge is gained through a constant process whereby we grasp or participate in experience and transform that experience in a way that allows it to become meaningful to us (Kolb, 1984, pp. $40-1)$. 
The Prehension Dimension--Apprehension and Comprehension

The process through which we grasp our experience is referred to as prehension. Surrounded by a constant ebb and flow of perceptual stimulation, our participation in the events going on about us can occur in two ways: through sensually immersing ourselves in the tangible aspects of immediate, concrete experience, referred to as apprehension, or by relying on the more abstract forms of conceptualizing through the use of symbolic interpretation referred to as comprehension.

It is the first way of knowing, apprehension, which adds color, vividness and intensity to our experience, but it is comprehension which transcends time and space and allows that experience to remain with us and to be used as a guide for future action. It is the constant tension between these two polarities--the richness of our sensory experience being circumscribed and categorized, and to some degree diminished (and distorted) by our intellectual capacities-which determines our epistemological relationship to the world around us.

Support for these hypotheses comes from two diverse areas, research on brain physiology and research on psychological behavior. Studies done by Sperry, Gazzaniga and Bogen (1969) first documented marked hemispheric specialization in the brain in patients who had undergone 
surgical division of the corpus callosum (a complex bundle of neurofibers connecting the right and left hemispheres of the brain) for treatment of epilepsy.

While the nature of these patients' conditions was obviously remarkable, further studies of "normal" subjects (Edwards, 1979; Galin, 1974; Benton, 1980) has shown interesting evidence of bimodal tendencies in the brain's processing of information. Table I gives a brief elaboration of the findings and shows a strong correlation between right brain specialization and the apprehension mode described by Kolb, and left brain specialization and the comprehension mode.

Psychologist Robert Zajonc (1980) provides further interesting parallels to Kolb's theories in his article "Feeling and Thinking: Preferences Need No Inferences." In a review of research, he concluded that not only are thinking and feeling two entirely different processes; but contrary to widely accepted assumptions, it is the affective or intuitive response which frequently occurs prior to any cognitive analysis of a new situation. It is the assumption of the "coequal" importance of these two modes that offers the most outstanding support of an experiential approach to learning (Kolb, 1984, p. 50). 
TABLE I

\begin{abstract}
RELATIONSHIP BETWEEN LEFT BRAIN SPECIALIZATION AND COMPREHENSION MODE \& RIGHT BRAIN SPECIALIZATION AND APPREHENSION MODE
\end{abstract}

Verbal: using words to name, describe.

Analytic: figuring things out step-by-step and part-bypart.

Abstract: taking out a small bit of information and using it to represent the whole.

Temporal: keeping track of time, sequencing; doing first things first, second things second, etc.

Rational: drawing conclusions based on reason and facts.

Digital: using individual units in a linear fashion, i.e., as in using numbers to count.

Logical: drawing conclusions based on logic; one thing based on another in a cause-effect relationship.

Linear: thinking in terms of linked ideas, one thought directly following another.
R-MODE

Nonverbal: awareness of things, but minimal connection with words.

Synthetic: putting things together to form wholes.

Analogic: seeking likeness between things; understanding metaphoric relationships.

Nontemporal: without a sense of time.

Nonrational: not requiring a basis of reason or facts; willingness to suspend. judgment.

Spatial: seeing things in relation to other things; how they fit together to form a whole.

Intuitive: having leaps of insight, based on incomplete patterns; hunches, feelings, visual images.

Bolistic: seeing whole things all at once; perceiving overall patterns and structures. 
The Transformation Dimension--Intention and Extension

Once experience has been grasped either through

apprehension or comprehension, it is "transformed" through intention (the process of internalization and reflection) or extension (the process of acting on or acting out that which has been experienced).

It is intention which provides a basis for the exercise of our imagination. We internalize and reflect on our experience, engaging in a kind of "internal play" which allows us to explore the possibilities and connections presented by a new piece of information about our world. "What," we ask ourselves, "might this have to do with what we already know? Does it change our world or just enhance or support our expectations? What possibilities does it possess?" Freed from external censure or physical limitation, we are allowed to be as creative as we like with our imaginings.

Through extension, we reach outside ourselves and act on the information we have been given. It is purposeful behavior, bent on achieving some end that will ultimately enhance whatever it is that we already know about the world. There is creative potential here as well, but it is a physical creativity which finds its rewards in the external transformation of the environment rather than the internal transformation of ideas and the self. 
Physiological parallels for this dimension are less clear-cut but leave room for some interesting conjecture. Some connection may exist in the functioning of the limbic system, with extension triggered by sympathetic stimulation lcausing increased proficiency in motor tasks and a narrowing of the perceptual field) and intention controlled by parasympathetic stimulation (causing increased proficiency in perceptual restructuring skills and a decrease in motor abilities) (Broverman et al., 1968; Diekman, 1971).

Luria's (1979) findings that the areas governing the processing of sensory, perceptual, motor, and cognitive and analytical skills are all located in relatively close proximity to each other in the neocortex of the brain adds further fuel to the fires of possibility in this area. The holistic interrelatedness of these functions in the process of learning may have some sound physiological basis.

Further psychological parallels can be seen in Jung's (1977) concepts of extroversion (extension) and introversion (intension), Rorschach's (1951) extratensive and intratensive elements of experience balance, and Kagen's impulsivity/reflection dimension (Kagen \& Kagen, 1970). In all three cases, researchers have identified and discussed corresponding processes which interrelate and profoundly affect how an individual learns and interacts with her 
world.

\section{SYNTHESIS}

Learning has been described as an holistic process whereby knowledge is gained through grasping experience and transforming it into some form meaningful to the learner. The final addition to the structural basis of experiential learning theory and the LSI is the identification of the "four different elementary forms of knowledge" (Kolb, 1984, pp. 41-2) that result from the possible combinations of the learning modes. The resulting relationship of all these elements is pictured in Figure 4.

Experience grasped through apprehension and transformed via intention is referred to as divergent knowledge. Divergent learners tend to be synthetic and imaginative, able to view a situation from many perspectives and see relationships between many different elements, thus forming "meaningful gestalts" (Kolb, 1976, p. 5). Learning by observing and listening to others, they act only when they feel that they are adequately tuned into the situation. They create with their emotions and tend to dislike and avoid conflict.

Experience grasped through comprehension and transformed through intention is assimilative knowledge. Assimilative learners are theory and model builders who 


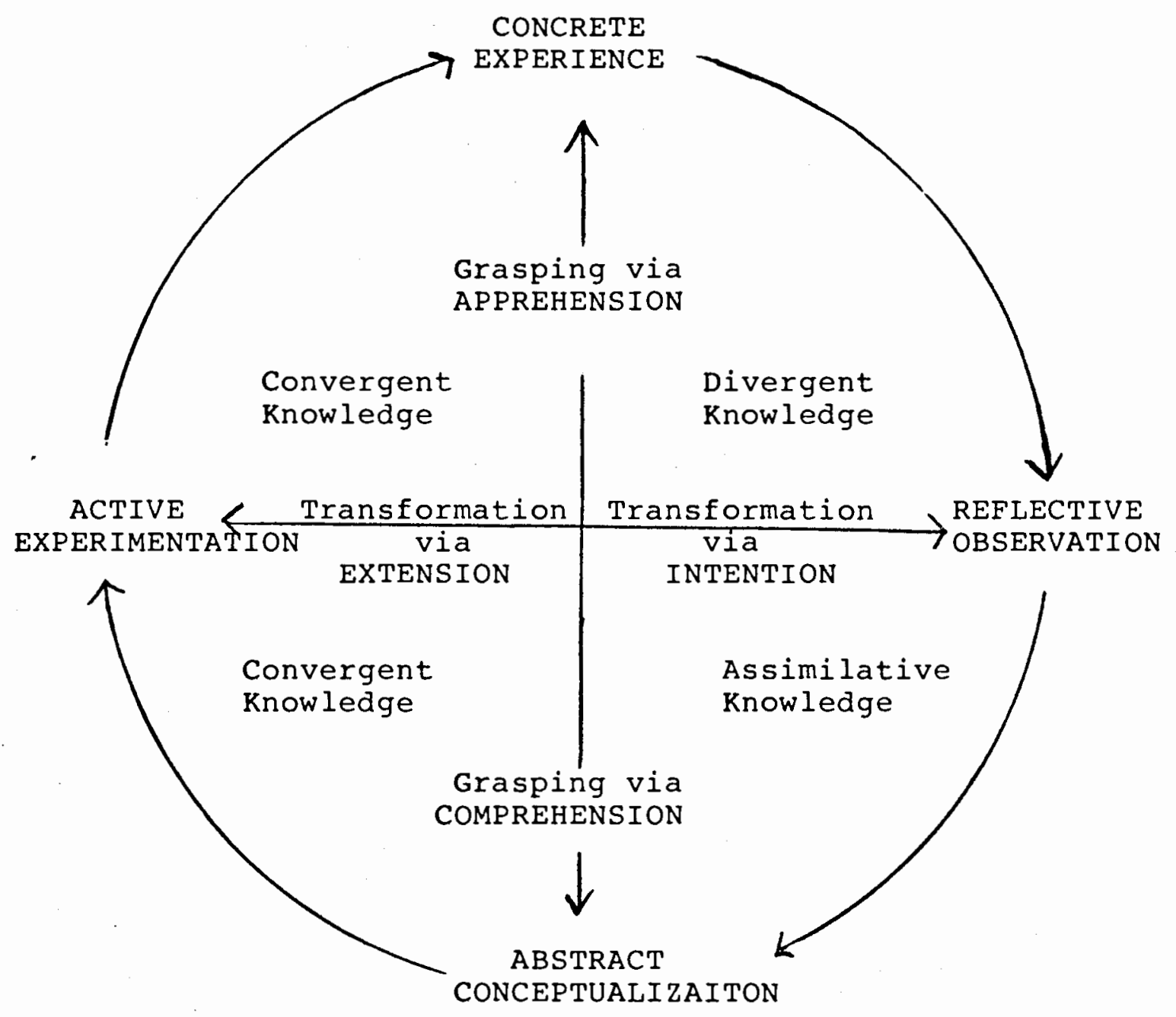

Figure 4. Structural dimensions underlying the process of experiential learning and the resulting basic knowledge forms. 
prefer to work and learn alone, taking their time to carefully analyze ideas and situations. They tend to be rational, logical and mentally organized, avoiding most emotional involvements and "assimilating disparate observations into an integrated explanation" (p. 6).

Experience grasped through comprehension and transformed through extension is referred to as convergent knowledge. Convergent learners are highly practical, responsible, logical and tend to be unemotional. They enjoy speculation, seek to control a situation and approach problems actively and independently. "Their greatest strength lies in the practical application of ideas" (p. 5). Experience grasped through apprehension and transformed via extension is accommodative knowledge. Accommodative learners are intuitive, impulsive and highly adaptive. They enjoy risk taking and dislike routines, often seeking out new ideas and experiences, relying on others rather than on their own analytic skills for information, and tend to "solve problems in an intuitive, trial and error manner" (p. $6)$.

GROWTH AND DEVELOPMENT IN THE EXPERIENTIAL LEARNING MODEL

The experiential learning model provides a framework for viewing individual differences in the processes of adaptation to various aspects of the environment; it seeks 
to describe how a person approaches decision-making, problem-solving, creativity and management of change. In addition to all of this, it also suggests a framework for looking at normative directions for human growth and development.

Figure 5 shows a model of that developmental process. Stage one, acquisition, "extends from birth to early adolescence and marks the acquisition of basic learning abilities and cognitive structures" (Kolb, 1976, p. 7). In this phase, we essentially learn how to learn. The second stage, specialization, extends through formal education and career development. In this stage, increased specialization in a particular learning style is usually evident as the learner increasingly adapts to the pressures put on him by educational and organizational forces. The third stage, integration, sees the re-emergence of the nondominant learning modes and their resultant reintegration into the learning process. The process should not be seen as linear in its development, but instead as one that is fluid and most likely involves frequent movement from one stage to another.

Development throughout this process is characterized by 


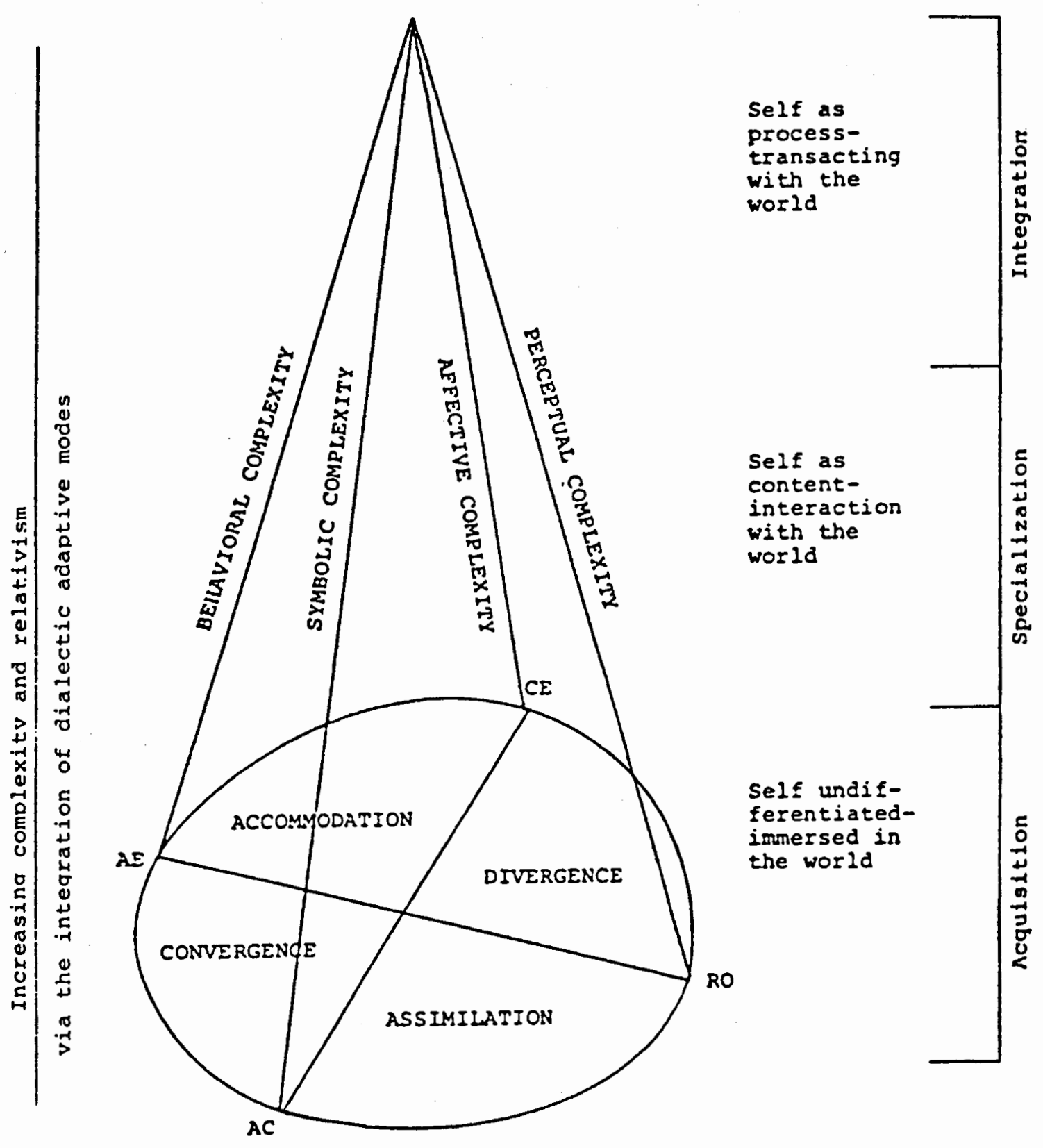

(Kolb, 1976, p. 17)

Figure 5. The experiential learning theory of growth and development. 
- . increasing complexity and relativism in dealing with the world and one's experiences, and by higher level integrations of the dialectic conflicts between the four adaptive modes: Concrete Experience, Reflective Observation, Abstract Conceptualization, and Active Experimentation. (p. 7)

Each of the adaptive modes carries with it an associated characteristic of personal growth. With the development of the concrete mode, affective complexity increases; reflective observation carries with it perceptual complexity which is evident; and active experimentation brings with it behavioral complexity. In the early stages of development these characteristics can develop quite independently, but as the learner matures, it is the integration of these adaptive modes that produces maximum learning ability and creativity.

So far the theoretical roots and the basic structure of experiential learning theory have been discussed and explored for its appropriateness in assessing cultural differences. The final portion of this chapter will explore the validity and reliability of the Learning styles Inventory which Kolb has developed in an attempt to measure the four adaptive modes and four kinds of knowledge previously identified. Does the instrument adequately measure what the theory so effectively defines? 


\section{INTERNAL PROPERTIES OF THE LSI}

To develop a working instrument that is both reliable and valid is difficult when testing any psychological or human behavior. When the theoretical base reflects a processual view in which the individual is seen as a dynamic process constantly reacting and adapting to both internal changes and environmental stimuli, the task becomes even more challenging. Just how does one measure something that is always in motion? In creating the LSI, Kolb took great pains to address these concerns. A short discussion of the process involved in developing and validating this instrument is reflective of the arduous task confronting those who labor to put theory into practice.

The basic purpose of the instrument is deceptively simple. It first seeks to measure a learner's individual preferences in the four basic learning modes described in Chapter II: $C E, R O, A C$, and $A E$. By combining the resulting scores, the most comfortable method by which the learner first grasps experience (AC-CE) and then transforms that experience $(A E-R O)$, is determined. The resulting equation places the learner in one of the four quadrants representing the divergent, assimilative, convergent and accommodative forms of knowledge. 
Item Analysis

The wording used in the ISI was originally selected from a longer 1 ist of words created by a panel of four behavioral scientists who had been familiarized with experiential learning theory. In selecting the four word sets, an effort was made to have all choices represent "equally desirable qualities for one to possess." In the original version of the test there were twelve key words for each of the four learning modes, "the sum of which equaled the total score of that mode." Preliminary testing revealed that three of the sets produced "virtually random answers," and they were eliminated. This left nine sets of four phrases which, when refined through item analysis, resulted in the use of only the six items that correlated best with the scoring on each mode (Kolb, 1976, p. 10).

The interrelationship of the words contained in the four learning style scales and the total scale scores are shown in Table II. No word correlates less than .45 with its scale total. High convergent and discriminant validity is further indicated by the negative correlations which exist between the scales that comprise the opposing poles of the scale $(e . g,, A E / R O$ and $C E / A C)$ and the lack of correlation between modes that are orthogonal, (e.g., AC words do not correlate significantly with either $A E$ or RO scales) (Kolb, 1976, p. 11). 
TABLE II

CORRELATIONS BETWEEN LSI ITEMS AND TOTAL SCALE SCORES

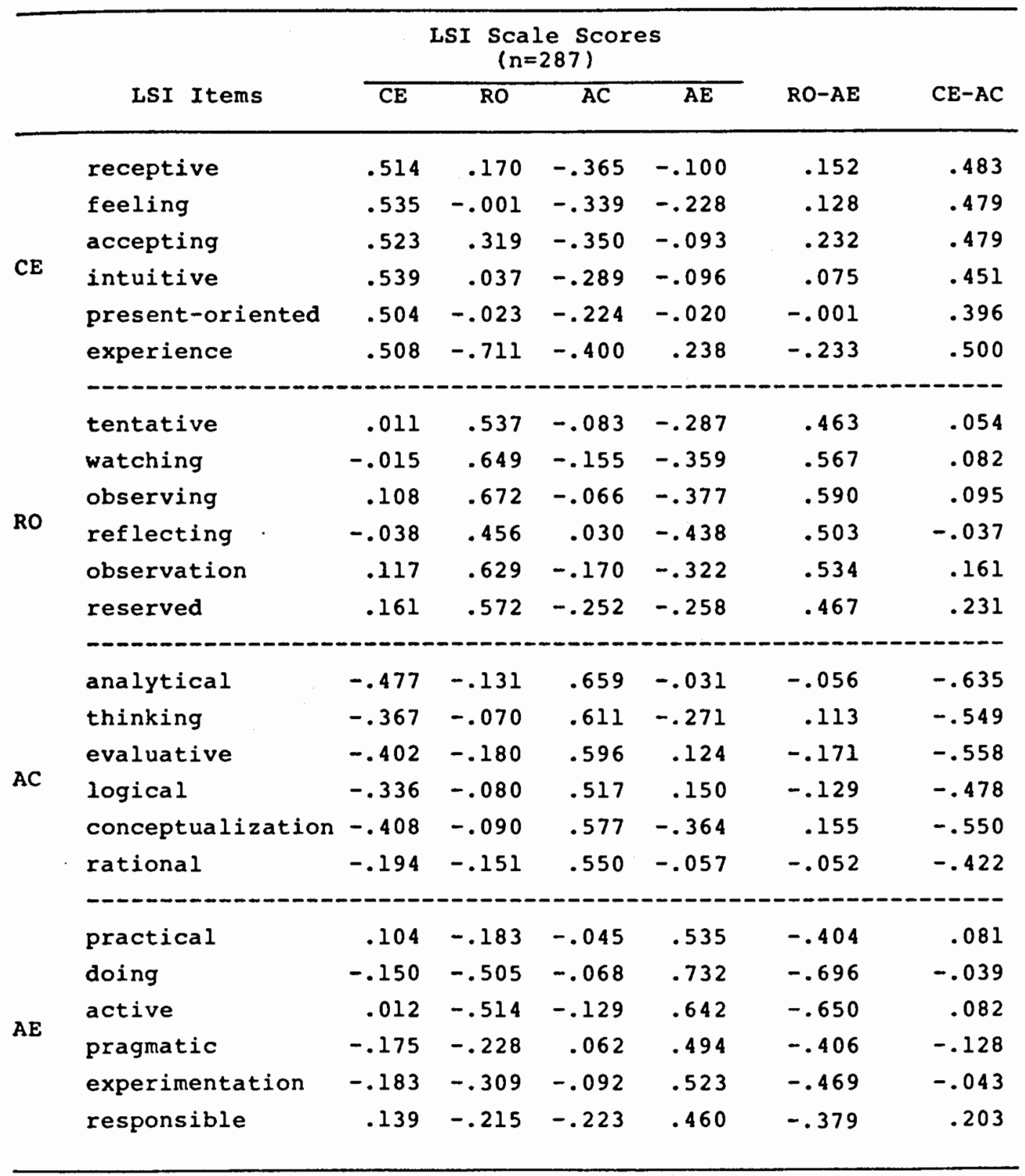


Reliability

split-half and test-retest reliability are considered the most appropriate techniques available for the assessment of error when attempting to measure "independent psychological traits" that are assumed to be "fixed and unchanging" over time. Experiential learning theory, however, assumes that there is a "dialectical interdependence" of all four learning style modes which creates "some special problems in assessing measurement error in the LSI." Any action, including responding to the test itself, is theoretically determined "in varying degrees by all four learning styles." And since few, if any, individuals in a given sample could be expected to be "pure types" in terms of preferred learning style, responses would further vary according to "the person's interpretation of the situation" in which he is asked to respond (Kolb, 1976, p. 12). This element makes accurate measurement more difficult because

An individual's learning style is conceived to be comprised of a modal orientation that varies to some degree from situation to situation. Thus an abstract person might become more concrete in viewing a painting, but still not experience it as concretely as a concrete person. (Kolb, 1976, p. 13)

In addition to this contextual component, there is the problem of the subjective nature of the test itself. The 
question becomes whether results reflect the reliability of the test or the test taker. Isabel Meyers (1962) defined this problem affectively:

The potent but as yet unmeasurable variable of "type development"--i.e., the extent to which the person actually has developed the processes and attitudes he prefers--enters every equation as an unknown. ( p. 19)

Presented with this "dilemma in assessing measurement error," additional "qualitative interpretations" in the form of exhaustive personal interviews were undertaken, and increased attention was paid to determining construct validity.

Split-Half Reliability

Table III shows split-half reliabilities obtained by applying the Spearman-Brown prophecy formula to determine correlation between halves for five different groups ( $\mathrm{n}=$ 687). The results show coefficients of about . 80 for the two combination scores $A C-C E$ and $A E-R O$ and are on "a par with most psychological self-report instruments" (Kolb, 1976, p. 14). The coefficients for the four basic scales are less conclusive, with the possible exception of $\mathrm{AC}$. Kolb hypothesized that the results might reflect measurement error due to the shortness of the scales (only six total scored items per mode). Personal interviews conducted by Plovnick (1974) shed further light on the results. He 


\section{TABLE III}

SPEARMAN-BROWN SPLIT-HALF RELIABILITY COEFFICIENTS FOR THE LEARNING STYLE INVENTORY

\begin{tabular}{|c|c|c|c|c|c|c|c|}
\hline Sample & $\mathrm{n}$ & $C E$ & Ro & $A C$ & $A E$ & $A C-C E$ & $A E-R O$ \\
\hline $\begin{array}{l}\text { MIT Sloan } \\
\text { Fellows }\end{array}$ & 47 & .69 & .37 & .65 & .64 & .78 & .78 \\
\hline $\begin{array}{l}\text { MIT Sloan } \\
\text { Fellows }\end{array}$ & 50 & .43 & .59 & .81 & .61 & .80 & .81 \\
\hline $\begin{array}{l}\text { Active } \\
\text { Managers }\end{array}$ & 90 & .61 & .58 & .71 & .62 & .78 & .85 \\
\hline $\begin{array}{l}\text { Harvard } \\
\text { MBA's }\end{array}$ & 442 & .50 & .63 & .74 & .67 & .75 & .84 \\
\hline $\begin{array}{l}\text { Lesley } \\
\text { Undergrads }\end{array}$ & 58 & .48 & .63 & .74 & .65 & .82 & .86 \\
\hline Total & 687 & .55 & .62 & .75 & .66 & .74 & .82 \\
\hline
\end{tabular}

(Kolb, 1976, p. 15) 
concluded that people with a predominantly AC orientation were more likely to do well because they focused on "accurately defining the words used and then systematically applying them to a generalized self-image" (Kolb, 1976, p. 15). Those with a more concrete orientation were much more likely to reflect on specific situations in which they may have found themselves in order to determine their response. As previously discussed, the dynamic nature of the interaction between preferred learning styie and the context in which the learner finds herself would theoretically account for this approach confounding the data to some degree.

The combined $A C-C E$ and $A E-R O$ scores were found to be "highly reliable indices suitable for most research applications" (Kolb, 1976, p. 16). The basic scales, particularly the $C E$ measurement, need to be used more cautiously and supplemented with additional information.

Test-Retest Reliability

Test-retest studies were conducted with four samples over periods of time ranging from three to seven months. The impact of situational factors was also assessed by varying the "degree of discontinuity" (i.e., changes in the situation or role in which the student found herself functioning). As shown in Table IV, results demonstrated that "test-retest correlations decreased as discontinuity 


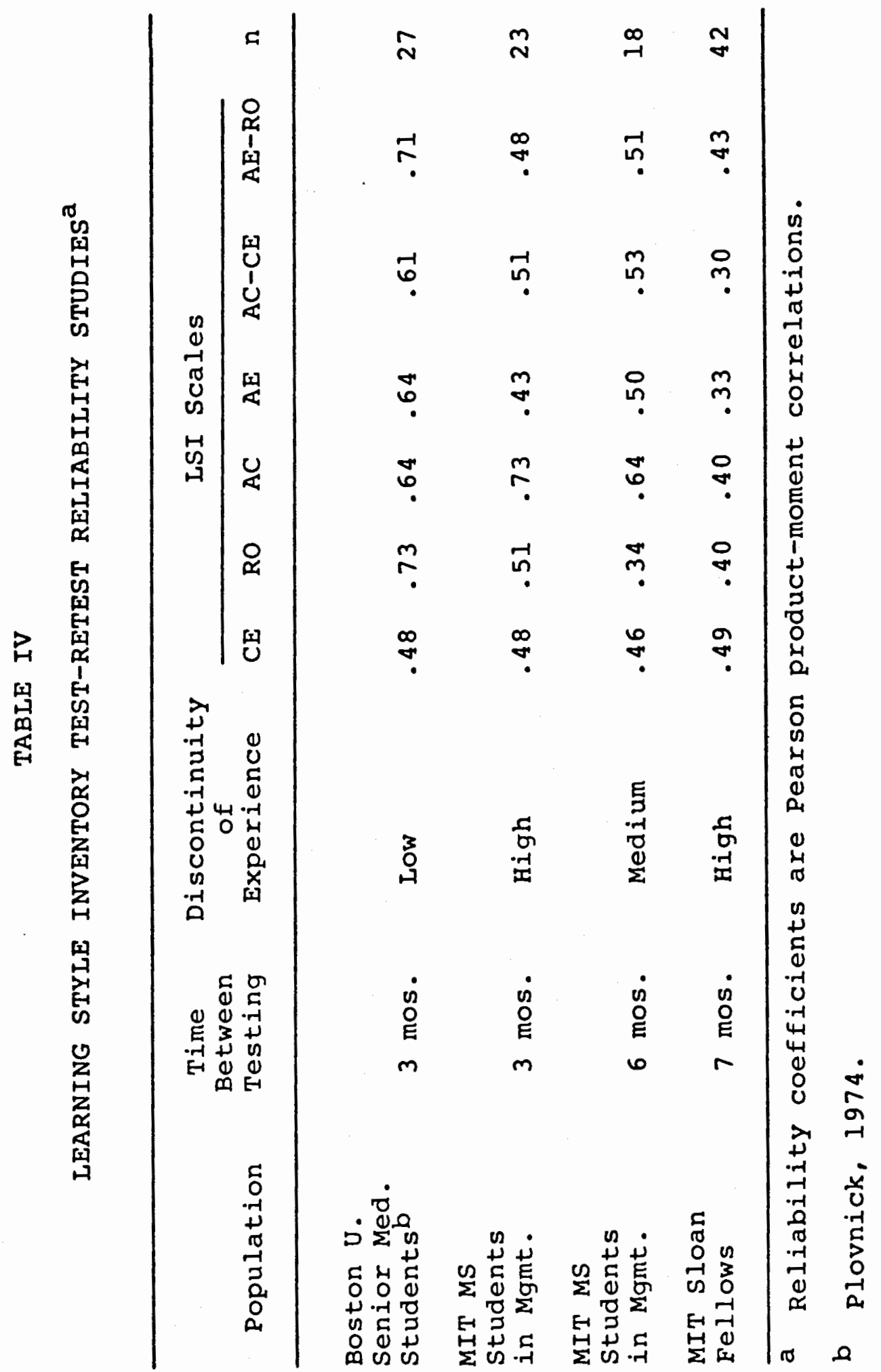


and the length of time between testing increased" (Kolb, 1976, p. 17)

Generalized Adult Norms

Table $V$ shows means and standard deviations for 17 other groups of college undergraduate and graduate student samples. The patterns of scores taken collectively across all of the different groups "suggest that LSI scores show sufficient variability across different populations to be used in assessing the learning styles that characterize occupations and groups" of highly variable backgrounds (Kolb, 1976, p. 23).

Validity

Correlations were done relating LSI scores to a number of other performance tests, personality tests and preferences for learning situations and teachers in order to establish the internal validity of the instrument. Tests were chosen that might provide areas of parallel measurement or theoretically predictable relationships based on the assumptions of experiential learning theory. This section will briefly discuss the most significant of these findings. Wunderlic Aptitude test scores for industrial managers showed the highest correlations with the LSI, as seen in Table VI.

Table VII shows correlations between the LSI and the 
TABLE V

LEARNING STYLE INVENTORY SCORES FOR VARIOUS GROUPS ${ }^{a}$

\begin{tabular}{|c|c|c|c|c|c|c|c|}
\hline Sample & $\mathbf{n}$ & $\mathrm{CE}$ & Ro & AC & $\mathrm{AE}$ & $A C-C E$ & $A E-R O$ \\
\hline \multicolumn{8}{|c|}{ College Undergraduate Samples } \\
\hline Kent State UG's & 135 & 14.9 & 13.8 & 17.2 & 16.0 & 2.7 & 2.6 \\
\hline MIT Seniors & 342 & $\begin{array}{l}14.79 \\
(2.85)\end{array}$ & $\begin{array}{l}13.64 \\
(3.91)\end{array}$ & $\begin{array}{l}17.24 \\
(3.86)\end{array}$ & $\begin{array}{l}15.03 \\
(3.63)\end{array}$ & $\begin{array}{l}2.65 \\
(5.65)\end{array}$ & $\begin{array}{l}1.39 \\
(6.62)\end{array}$ \\
\hline $\begin{array}{l}\text { U of Mass. } \\
\text { Engineering UG's }\end{array}$ & 284 & $\begin{array}{l}14.54 \\
(2.68)\end{array}$ & $\begin{array}{l}14.69 \\
(3.28)\end{array}$ & $\begin{array}{l}16.97 \\
(3.39)\end{array}$ & $\begin{array}{l}15.65 \\
.(2.73)\end{array}$ & $\begin{array}{l}2.42 \\
(5.10)\end{array}$ & $\begin{array}{c}0.97 \\
(5.18)\end{array}$ \\
\hline Lesley UG's & 66 & $\begin{array}{l}16.20 \\
(2.59)\end{array}$ & $\begin{array}{l}14.38 \\
(3.23)\end{array}$ & $\begin{array}{l}15.98 \\
(3.08)\end{array}$ & $\begin{array}{l}15.03 \\
(3.21)\end{array}$ & $\begin{array}{l}-0.65 \\
(5.82)\end{array}$ & $\begin{array}{c}0.21 \\
(4.72)\end{array}$ \\
\hline $\begin{array}{l}\text { Alverno Liberal } \\
\text { Arts-Women }\end{array}$ & 213 & $\begin{array}{l}15.73 \\
(3.21)\end{array}$ & $\begin{array}{l}14.68 \\
(3.04)\end{array}$ & $\begin{array}{l}15.62 \\
(3.31)\end{array}$ & $\begin{array}{l}15.65 \\
(2.85)\end{array}$ & $\begin{array}{l}-0.10 \\
(5.63)\end{array}$ & $\begin{array}{c}0.96 \\
(5.03)\end{array}$ \\
\hline \multicolumn{8}{|c|}{ Graduate student Samples } \\
\hline $\begin{array}{l}\text { Boston U Med. } \\
\text { Students lst Yr. }\end{array}$ & 69 & $\begin{array}{l}14.29 \\
(2.93)\end{array}$ & $\begin{array}{l}12.92 \\
(3.36)\end{array}$ & $\begin{array}{l}19.08 \\
(3.21)\end{array}$ & $\begin{array}{l}15.15 \\
(3.21)\end{array}$ & $\begin{array}{c}4.80 \\
(5.51)\end{array}$ & $\begin{array}{l}3.71 \\
(4.81)\end{array}$ \\
\hline $\begin{array}{l}\text { Boston U Med. } \\
\text { students } 4 \text { th } Y r \text {. }\end{array}$ & 63 & $\begin{array}{l}14.80 \\
(2.65)\end{array}$ & $\begin{array}{l}12.40 \\
(3.91)\end{array}$ & $\begin{array}{l}17.33 \\
(3.10)\end{array}$ & $\begin{array}{l}16.72 \\
(3.38)\end{array}$ & $\begin{array}{c}2.75 \\
(4.98)\end{array}$ & $\begin{array}{c}4.62 \\
(6.29)\end{array}$ \\
\hline U of Hisc. MBA's & 74 & 14.22 & 12.20 & 18.35 & 16.12 & 4.13 & $\begin{array}{c}3.92 \\
-.\end{array}$ \\
\hline $\begin{array}{l}\text { Hawaii Law } \\
\text { Students }\end{array}$ & 46 & $\begin{array}{l}15.71 \\
(4.46)\end{array}$ & $\begin{array}{l}14.33 \\
(4.57)\end{array}$ & $\begin{array}{l}16.74 \\
(4.12)\end{array}$ & $\begin{array}{l}14.65 \\
(3.71)\end{array}$ & $\begin{array}{c}0.95 \\
(6.52)\end{array}$ & $\begin{array}{c}0.41 \\
(6.41)\end{array}$ \\
\hline $\begin{array}{l}\text { Landscape } \\
\text { Architecture }\end{array}$ & 39 & $\begin{array}{l}14.82 \\
(3.36)\end{array}$ & $\begin{array}{l}12.79 \\
(3.73)\end{array}$ & $\begin{array}{l}17.13 \\
(3.82)\end{array}$ & $\begin{array}{l}16.23 \\
(3.07)\end{array}$ & $\begin{array}{c}2.31 \\
(6.25)\end{array}$ & $\begin{array}{c}3.41 \\
(5.80)\end{array}$ \\
\hline \multicolumn{8}{|c|}{ Occupational Samples } \\
\hline $\begin{array}{l}\text { Elementary } \\
\text { Teachers }\end{array}$ & 37 & $\begin{array}{l}16.86 \\
(2.95)\end{array}$ & $\begin{array}{l}12.92 \\
(3.03)\end{array}$ & $\begin{array}{l}14.62 \\
(3.23)\end{array}$ & $\begin{array}{l}16.62 \\
(2.83)\end{array}$ & $\begin{array}{l}-2.24 \\
(5.40)\end{array}$ & $\begin{array}{c}3.70 \\
(5.23)\end{array}$ \\
\hline $\begin{array}{l}\text { High School } \\
\text { Teachers }\end{array}$ & 76 & $\begin{array}{l}14.42 \\
(3.90)\end{array}$ & $\begin{array}{l}12.67 \\
(2.99)\end{array}$ & $\begin{array}{l}17.20 \\
(4.02)\end{array}$ & $\begin{array}{l}16.06 \\
(3.12)\end{array}$ & $\begin{array}{l}2.64 \\
(7.14)\end{array}$ & $\begin{array}{c}3.41 \\
(5.09)\end{array}$ \\
\hline $\begin{array}{l}\text { Military OD } \\
\text { Specialists }\end{array}$ & 257 & $\begin{array}{l}15.14 \\
(3.04)\end{array}$ & $\begin{array}{l}14.14 \\
(3.65)\end{array}$ & $\begin{array}{l}15.97 \\
(3.60)\end{array}$ & $\begin{array}{l}16.00 \\
(3.06)\end{array}$ & $\begin{array}{c}0.87 \\
(5.87)\end{array}$ & $\begin{array}{l}1.86 \\
(5.72)\end{array}$ \\
\hline $\begin{array}{l}\text { Alcoholism } \\
\text { Counselors }\end{array}$ & 47 & $\begin{array}{l}16.57 \\
(3.23)\end{array}$ & $\begin{array}{l}13.75 \\
(4.15)\end{array}$ & $\begin{array}{l}16.09 \\
(4.07)\end{array}$ & $\begin{array}{l}15.19 \\
(3.33)\end{array}$ & $\begin{array}{l}-0.48 \\
(7.20)\end{array}$ & $\begin{array}{c}1.44 \\
(6.24)\end{array}$ \\
\hline $\begin{array}{l}\text { Computer } \\
\text { Programmers }\end{array}$ & 103 & $\begin{array}{l}15.01 \\
(3.40)\end{array}$ & $\begin{array}{l}13.03 \\
(3.94)\end{array}$ & $\begin{array}{l}17.87 \\
(3.34)\end{array}$ & $\begin{array}{l}16.28 \\
(3.25)\end{array}$ & $\begin{array}{c}2.86 \\
(6.03)\end{array}$ & $\begin{array}{c}3.25 \\
(6.47)\end{array}$ \\
\hline $\begin{array}{l}\text { Industrial } \\
\text { Salesmen }\end{array}$ & 641 & $\begin{array}{l}15.02 \\
(2.78)\end{array}$ & $\begin{array}{l}13.82 \\
(3.13)\end{array}$ & $\begin{array}{l}16.35 \\
(3.29)\end{array}$ & $\begin{array}{l}16.52 \\
(2.90)\end{array}$ & $\begin{array}{l}1.33 \\
(5.03)\end{array}$ & $\begin{array}{l}2.71 \\
(5.14)\end{array}$ \\
\hline $\begin{array}{l}\text { Human Service } \\
\text { Workers }\end{array}$ & 90 & $\begin{array}{l}16.73 \\
(2.83)\end{array}$ & $\begin{array}{l}13.44 \\
(3.91)\end{array}$ & $\begin{array}{l}14.38 \\
(3.72)\end{array}$ & $\begin{array}{l}16.83 \\
(3.20)\end{array}$ & $\begin{array}{l}-2.37 \\
(5.26)\end{array}$ & $\begin{array}{l}3.38 \\
(6.03)\end{array}$ \\
\hline $\begin{array}{l}\text { Education } \\
\text { Administrator }\end{array}$ & 46 & $\begin{array}{l}14.47 \\
(3.36)\end{array}$ & $\begin{array}{l}12.47 \\
(4.09)\end{array}$ & $\begin{array}{l}17.28 \\
(4.27)\end{array}$ & $\begin{array}{l}17.52 \\
(9.99)\end{array}$ & $\begin{array}{l}2.80 \\
(6.59)\end{array}$ & $\begin{array}{c}5.04 \\
(12.66)\end{array}$ \\
\hline
\end{tabular}

a Means are given first with atandard deviations in parentheses. 


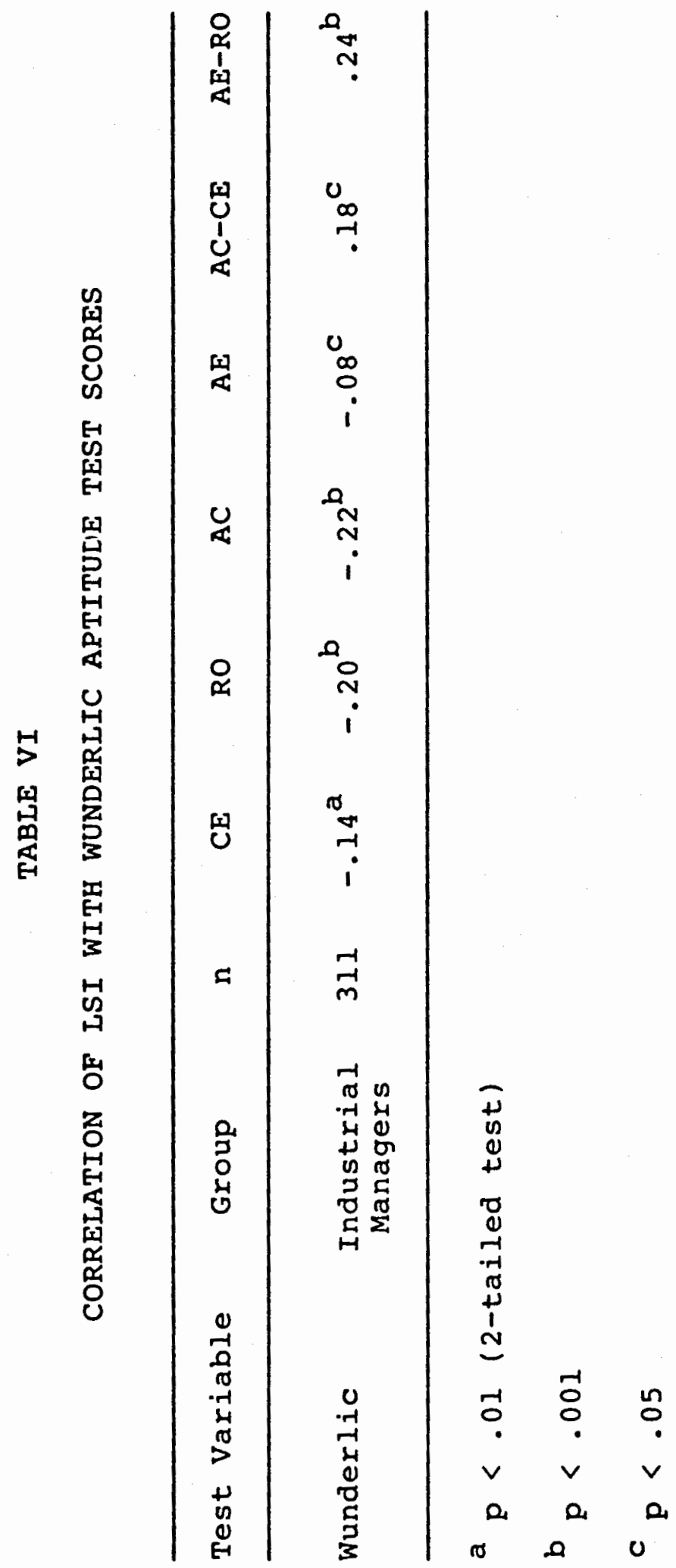


TABLE VII

CORRELATIONS BETWEEN LEARNING STYLE INVENTORY SCORES AND PERSONALITY TESTS

\begin{tabular}{|c|c|c|c|c|c|c|c|c|}
\hline Test Variable & Group & $\mathbf{n}$ & $\mathrm{CE}$ & RO & $A C$ & $\mathrm{AE}$ & $A C-C E$ & $A E-R O$ \\
\hline \multicolumn{9}{|l|}{$\begin{array}{l}\text { Myers-Briggs } \\
\text { Type Indicator }\end{array}$} \\
\hline \multirow[t]{2}{*}{$\begin{array}{l}\text { Extraversion/ } \\
\text { Introversion }\end{array}$} & $\begin{array}{l}\text { Kent State } \\
\text { Undergrads }\end{array}$ & 135 & .06 & .06 & .03 & $-.18^{a}$ & -.01 & -.13 \\
\hline & $\begin{array}{l}U \text { of wisc. } \\
\text { MBA's }\end{array}$ & 74 & .08 & $.34^{b}$ & .03 & $-.27^{a}$ & -- & - \\
\hline \multirow{2}{*}{$\begin{array}{l}\text { Sensation/ } \\
\text { Intuition }\end{array}$} & Undergrads & 135 & $-.25^{b}$ & -.07 & $.23^{\mathrm{b}}$ & $-.20^{\mathrm{a}}$ & $.29^{\mathrm{b}}$ & .09 \\
\hline & MBA's & 74 & -.02 & -.15 & .19 & -.12 & -- & - \\
\hline \multirow{2}{*}{$\begin{array}{l}\text { Thinking/ } \\
\text { Feeling }\end{array}$} & Undergrads & 135 & $.34^{b}$ & -.02 & $-.25^{b}$ & .05 & $-.35^{b}$ & .04 \\
\hline & MBA's & 74 & .08 & -.17 & .00 & -.01 & -- & -- \\
\hline \multirow{2}{*}{$\begin{array}{l}\text { Judging/ } \\
\text { Perceiving }\end{array}$} & Undergrads & 135 & -.06 & .11 & -.11 & -.13 & -.02 & -.16 \\
\hline & MBA's & 74 & .01 & -.12 & .06 & -.05 & -- & -- \\
\hline \multicolumn{9}{|l|}{$\begin{array}{l}\text { Myers-Briggs } \\
\text { Type Indicator }\end{array}$} \\
\hline Extraversion & $\begin{array}{l}\text { Education } \\
\text { Administr. }\end{array}$ & 46 & -.13 & -.27 & .28 & -- & .25 & -.16 \\
\hline Introversion & $"$ & 46 & .18 & $.36^{\mathrm{a}}$ & $-.35^{a}$ & -- & -.20 & $-.33^{a}$ \\
\hline Sensation & $"$ & 46 & -- & .12 & -.26 & -.11 & -.19 & -.13 \\
\hline Intuition & $"$ & 46 & - & -- & .20 & -- & .14 & -- \\
\hline Thinking & $"$ & 46 & $-.31^{a}$ & -- & .22 & -.16 & $.30^{\mathrm{a}}$ & -.16 \\
\hline Feeling & $n$ & 46 & $.39^{b}$ & -- & $-.34^{a}$ & .12 & $-.42^{b}$ & .11 \\
\hline Judging & $n$ & 46 & -.22 & -- & -- & -- & .14 & -- \\
\hline Perceiving & $"$ & 46 & .19 & -- & -- & -- & - & -- \\
\hline \multicolumn{9}{|l|}{ Motivation } \\
\hline$\underline{\mathrm{n}}$ Achievement & Businessmen & 53 & - & -- & - & -- & -.03 & -.10 \\
\hline$\underline{n}$ Power & $"$ & 53 & -- & -- & -- & -- & -.03 & .10 \\
\hline n Affiliation & $"$ & 53 & - & -- & - & -- & $-.33^{a}$ & .19 \\
\hline
\end{tabular}

(continued) 
Table VII (continued)

\begin{tabular}{|c|c|c|c|c|c|c|c|c|}
\hline $\begin{array}{l}\text { FIRO B } \\
\text { INCLUSION } \\
\text { expressed }\end{array}$ & $\begin{array}{l}\text { Kent State } \\
\text { Undergrads }\end{array}$ & 135 & $.19^{a}$ & -.09 & $-.23^{b}$ & .14 & $-.24^{b}$ & .11 \\
\hline wanted & $"$ & 135 & .09 & -.01 & -.15 & -.01 & -.11 & -.02 \\
\hline $\begin{array}{l}\text { CONTROL } \\
\text { expressed }\end{array}$ & " & 135 & -.13 & -.12 & $.23^{b}$ & -.06 & $.21^{a}$ & .07 \\
\hline wanted & " & 135 & $.19^{\mathrm{a}}$ & .04 & -.11 & -.06 & $-.17^{a}$ & -.02 \\
\hline $\begin{array}{l}\text { AFFECTION } \\
\text { expressed }\end{array}$ & $"$ & 135 & .13 & -.08 & -.11 & .07 & -.14 & .08 \\
\hline wanted & $"$ & 135 & .06 & -.07 & -.10 & .09 & -.09 & .08 \\
\hline $\begin{array}{l}\text { INCLUSION }^{3} \\
\text { expressed }\end{array}$ & $\begin{array}{l}\text { Education } \\
\text { Administr. }\end{array}$ & 46 & -- & $-.32^{a}$ & - & .26 & -- & $.31^{a}$ \\
\hline wanted & $"$ & 46 & - & $-.31^{a}$ & .26 & .28 & .18 & $.32^{a}$ \\
\hline $\begin{array}{l}\text { CONTROL } \\
\text { expressed }\end{array}$ & $"$ & 46 & -.11 & -.10 & .22 & .13 & .14 & .21 \\
\hline wanted & $"$ & 46 & .24 & .13 & $-.38^{b}$ & .11 & $-.37^{a}$ & - \\
\hline $\begin{array}{l}\text { AFFECTION } \\
\text { expressed }\end{array}$ & $"$ & 46 & -- & -.19 & -- & - & - & - \\
\hline wanted & $"$ & 46 & .17 & -.29 & .16 & .18 & .23 & -- \\
\hline
\end{tabular}

(Kolb, 1976, p. 30)

a $p<.05$

b $p<.01 \quad 2$-tailed test

1. High scores on MBTI variables indicate that the mode listed second is dominant (e.g.. a high score on thinking/feeling indicates the dominance of feeling orientation).

2. Scores on these MBTI variables are limited to the single modes and are not comparable to paired modes. Missing correlations are due to missing data.

3. Missing correlations are due to missing data. 
Meyers-Brigg Type Indicator (MBTI), the Thematic Apperception Test (TAT), measures of $\mathrm{n}$ Achievement, $\mathrm{n}$ Power, and $n$ Affiliation and FIRO-B.

The MBTI is designed to measure the Jungian psychological types of Extroversion/Introversion, sensation intuition, Thinking/Feeling and Judging/Perceiving. While not identical in what they are measuring, enough parallel exists between the LSI and the MBTI to assume some theoretical consistencies in the results of the two tests: people scoring high in CE should use sensation as a mode of perceiving and feeling as a mode of judging: abstract conceptualizers could be expected to use intuition as a perceiving mode and thinking as a judging mode, active experimenters should be extroverts who use the sensation perceiving mode, and those with an Ro orientation should be introverts who use the intuitive perceiving mode. The data shown in Table VII give evidence of these relationships with the strongest correlations between the concrete/abstract and feeling/thinking modes and between the active/reflective and extrovert/introvert modes (Kolb, 1976, p. 29).

Within the TAT measures the correlation between a high $\mathrm{n}$ affiliation and concreteness is consistent with the assumption that concrete experiencers can be expected to be "people- and feeling-oriented" (p. 29).

The FIRO-B scores, which measure personality 
dispositions toward interpersonal relationships, show a consistent relationship between $A C$ and the expression of control and $\mathrm{CE}$ and the desire for control (Kolb, 1976, p. 31). These findings are consistent with the assumption that individuals with a strong $C E$ orientation will be more contextually dependent.

The correlations in Table VIII show a strong similarity between the learning styles of 88 students and the instructors they felt had "influenced them most" (p. 32). The assumption that an individual will have an affinity for learning situations which are consistent with their own preferred cognitive styles is congruent with these results.

\section{Summary}

Combined reliability and validity testing have strongly indicated that: (1) the LSI is an instrument that can be used with reasonable confidence to measure both the four basic learning styles (CE, $R O, A C$ and $A E)$ and the combined $A C-C E$ and $A E-R O$ modes, and (2) these scales do, in fact, measure to a reasonable degree the psychological processes that they theoretically were designed to describe. 
TABLE VIII

CORRELATIONS BETWEEN STUDENTS' LEARNING STYLE AND

LEARNING STYLE OF TEACHER WHO EXERTED MOST

INFLUENCE

Harvard MBA's

$(n=88)$

\section{STUDENT LEARNING STYLE}

CE RO AC AE AC-CE AE-RO

\begin{tabular}{|c|c|c|c|c|c|c|}
\hline$C E$ & $.21^{\mathrm{a}}$ & .09 & $-.27^{b}$ & .03 & $-.29^{b}$ & -.07 \\
\hline RO & .10 & $.24^{a}$ & $-.28^{a}$ & $-.32^{c}$ & $-.21^{a}$ & $-.32^{c}$ \\
\hline$A C$ & $-.21^{\mathrm{a}}$ & $-.21^{\mathrm{a}}$ & $.44^{C}$ & .05 & $.38^{c}$ & .15 \\
\hline $\mathrm{AE}$ & .00 & .01 & .09 & $.36^{c}$ & .00 & $.21^{a}$ \\
\hline$A C-C E$ & $-.32^{c}$ & -.17 & $.42^{C}$ & .02 & $.43^{c}$ & .11 \\
\hline E-RO & 0.08 & -.16 & .09 & $.39^{C}$ & .14 & $.32^{c}$ \\
\hline
\end{tabular}
a $\mathrm{P}<.05$
${ }^{b} p<.01$ (2-tailed test)
c $\mathrm{p}<.001$ 


\section{CHAPTER III}

\section{METHODOLOGY}

Testing for the present study involved the administration of a linguistically modified version of David A. Kolb's Learning Styles Inventory (MLSI) to a crosssection of International students. Students used in this study were from non-English speaking countries who had been in the United States for no more than one year. The population included Indochinese refugees, who, while not officially listed by the university as "International students," clearly meet the criteria for cultural differences laid down in this thesis. The majority were from intermediate and advanced level English as a Second Language (ESL) classes at various community colleges and universities. A few had already been mainstreamed into the general university system.

\section{DEVELOPMENT OF THE MLSI}

Originally chosen as the testing instrument in this study was a simplified version of the LSI developed in 1980 by Kolb and McCarthy for use with junior high school students (see Appendix). The test involves rank ordering nine sets of four items that are in some way descriptive of 
the way a student might best like to learn or approach a new situation or task. Each set contains answers that correspond to the four learning style categories outlined by Kolb in his research: Concrete experience (CE), Reflective Observation (RO), Abstract Conceptualizaiton ( $A C)$ and Active Experimentation $(A E)$. On a separate answer sheet, the student was to place a (4) beside a response that described her best, a (3) beside the one that was second most descriptive, etc.

On initial examination, the choice of language appeared to be simple and straightforward. It was anticipated that the students might require assistance with some of the vocabulary, but this was not seen as a serious problem.

In addition to the inventory, students were asked to fill out a one-page fact sheet (see Appendix) listing their age, nationality, sex, native language, length of time spent in the United States, other countries where they may have lived for a year or more and their major field of study. They were also asked to comment on the difficulty of the test and what was most problematic about it, i.e., difficulty of language, the idea of thinking about how they learn, etc.

A sample group of twenty-five International students was then tested to determine the effectiveness of the instrument with this type of population. The results were 
disastrous. Both observation and self-report confirmed that every aspect of the testing procedure would require modification if it were to be successful.

First, the wording of the test contained sentence fragments which required the student to mentally "fill in" the missing nouns and verbs, an almost unconscious task for a native speaker of English which proved confusing or even traumatic to those who learned English as a second language. Second, the test frequently involved an assumption of "doing something," an idea that expresses a very "American" action orientation that was, in some cases, quite the farthest thing from the mind of the international student taking the test. Third, the idea of "rank-ordering" the choices on a separate answer sheet required a comfort with linear thought which simply proved mind-boggling to a number of the students.

In response to these problems, the following changes were made in the test in an effort to create the MLSI, an instrument the researcher hoped would: (1) maintain the established reliability and validity of the LSI, (2) be easily converted to the established scoring method, and (3) still address the cultural concerns listed above (see Appendix). First, the sentence fragments were converted into full sentences with the assumptions all fully elucidated In this manner, set one: 
CE

RO

AC

$\mathrm{AE}$

1. get involved take my time before acting etc.

became:

1. I LEARN BEST WHEN:

A. I get actively involved in doing something.

B. I take time to think before I act on an idea.

C. I am learning about something which I like.

D. I am learning about things that I think will be useful to me in my life.

Second, ranking was transferred directly below each set of responses, and the student was asked to insert the letter of the phrase that:

Describes me best

Describes me third best
Describes me second best Describes me least

since it was beyond the scope of this research to completely recheck the validity and reliability of this modified inventory, two actions were taken: (1) an attempt was made to adhere as closely as possible to what was understood as the original intention of each phrase as it was converted into sentences. For this reason, the original translation by the researcher was checked and corrected by three people with experience in teaching English as a second language and a background in intercultural communication, and (2) subjective feedback was obtained from both teachers and students when the results were calculated about whether or not the student's reported learning style seemed 
genuinely descriptive of them or not. The results were overwhelmingly positive in that regard. A third unsolicited (and unimperical) confirmation came with the researcher's later exposure to the most recent version of the LSI developed by Kolb, which is in full sentences and bears a striking resemblance to the MSLI independently developed for this study (see Appendix).

\section{POPULATION}

Previous studies on culture and cognition appear to have fallen into two categories: psychologists and social psychologists studying the cognitive differences of immigrants and ethnic sub-groups, and cognitive anthropologists studying the cognitive and perceptual differences of pre-modern tribal cultures. International students were not included in these studies, perhaps because no apparent assumption existed that any significantly interesting or testable differences might exist between this and other essentially "literate and educated" peoples.

In the last ten years, the studies of cognitive learning styles and their effect on all levels of education have burgeoned, but, again, International students have been ignored as a potentially interesting and discrete group to be tested. It is an interest in these students, the effect that their cultural difference might be having on their 
success or failure in American universities, and the unique challenge that they seem to pose to the educators who must try to teach them that lies behind the choice choice of them as the target population for this study.

For the purpose of this study, "International students" are defined as those who possess "significant cultural difference." Specifically, this refers to students who come from national cultures outside of the United States, have as a first language something other than English, and as a result are assumed to possess behaviors, values, beliefs and attitudes that are to some degree different from those of most mainstream Americans.

Upon arrival in the U.S., most International students spend from six to nine months studying English before being mainstreamed into the regular university system. It was decided that the students to be tested should have been in the United States for less than a year for two reasons: they would most likely have developed adequate skills in English to manage the vocabulary used in the inventory, and yet, (2) they would still be new enough to the American university environment to reflect any cognitive learning style that might be common to their home culture. As a result, the majority of the students used in the study were taken from intermediate and advanced level ESL classes. A few had already begun to attend general university classes. 


\section{ADMINISTRATION OF THE TEST}

The MLSI was administered to 130 subjects at six different institutions with each session taking between one and one-and-one-half hours. When the purpose of the test was explained, students were assured that there were no "right answers" to the questions, only answers that gave information about how students from other cultures might prefer to learn. It was hoped that this information would help in teaching them more effectively. A detailed explanation and demonstration of how to take the inventory that included a brief overview of significant vocabulary followed.

Special attention needed to be paid to defining words such as "analysis," "logical," and hunches." One-on-one assistance with method and vocabulary was given when necessary. Most often the students were comfortable asking for assistance once it had been made clear that the researcher expected to give it, but it was also necessary to keep a close eye out and offer help when it was needed but not solicited. The last step was filling out the data sheet which provided demographic information and feedback on the test.

Once the tests were scored, the results were returned to the classes with a brief explanation of each learning style, i.e., preferred learning environments, methods of 
obtaining information, favorite questions, etc. (see Appendix). Both teachers and students were asked to read the results and give feedback as to whether they were or were not reasonably descriptive of the student. Only five tests were discarded for this reason. Another ten were discounted because of errors made in filling out the inventory.

\section{STATISTICAL METHODOLOGY}

The raw scores of the test results were collated and entered into a database computer program (MCNichols, 1984, pp. 246-258) on a Sanyo MBC-555 personal computer. Descriptive statistics were first compiled using MCNichols' BSTAT statistical program in BASIC (pp. 242-310) in order to get a general feel for the data obtained.

The sample was scored on an ordinal scale. Since this kind of measurement prohibits the assumption that the distance between adjacent responses is a constant value, mathematical operations are limited to rank order comparisons, and only nonparametric statistics are appropriate for internal examination of the data (MCNichols, 1984, pp. 19-21). In an effort to establish a degree of internal validity, histograms were done in order to determine whether the results presented themselves in a way that approximated a normal distribution. 
Because of the availability of a limited amount of raw data on the Americans previously studied, I statistics needed to be reconstructed for this research. Means, standard deviations and sample size for the American norms were extrapolated from percentile tables (Kolb, 1976, p. 47) for comparison with the national sample groups. A program was written for this task using Hatch and Fahardy (1982, pp. 110-1131, and a one-tailed $T$ test was performed. It is emphasized that these values are approximate and therefore cannot be of conclusive value in supporting the research questions. They are, however, of interest as approximations that broadly paint the nature of the differences between the various groups and their American counterparts.

While it seemed unnecessary to compare each cultural group with every other group tested, a Kruskel Wallis OneWay Analysis of Variance was performed on three sets of national groups frequently "lumped together": (1) Asians-Japanese, Chinese and Korean; (2) "Southeast Asians"-Vietnamese, Cambodian and other Southeast Asians (Indonesian, Philippino and Thai); and (3) "Middle East"-Arab and non-Arabic Middle East. A fourth comparison of the remaining two national groups--Hispanic and Northern European--was also made in order to cover the entire sample. The Kruskel Wallis One-Way Analysis of Variance was applied to the subjects' scores with gender as a treatment 
variable in an effort to isolate any effect this might have on sample variance. Tests were run on both the entire sample and within each identified cultural group.

Because of the relatively small number of subjects in each category, the BSTAT program was modified to utilize a finer and more mathematically accurate formula for determining the Spearman's Rank Correlation Coefficient (McClave, 1982, p. 469), and the adapted program was applied to determining the correlation between the age of the subjects and their scores. This was performed on both the total sample and on a differentiated scale for males and females.

In order to assess the similarity or dissimilarity of the international student sample to the norms established for specific fields of study in American universities, raw data were obtained for the comparison of engineering and computer science majors from available tables (Kolb, 1976, p. 22; Kolb, 1981, p. 320). Faced with an absence of like data for other fields of study, students were compared individually by their identification as assimilators, divergers, accommodators, or convergers on the LSI. Those who were located in an entirely different quadrant than the one determined as normative for their chosen academic field (Kolb, 1976, p. 35) were considered "dissimilar" in learning style. 
CHAPTER IV

RESULTS

The criterion for statistical significance for all analysis was set at alpha $=.10$.

\section{DESCRI PTION}

In an effort to establish some internal validity for the modified inventory, the results of the study were first broken down so that histograms for the entire sample could be viewed in relationship to the factors of $C E, R O, A C, A E$, $A E-R O$ and $A C-C E$. All showed an essentially normal curve in their patterns of distribution.

Descriptive statistics were then done with a breakdown by national grouping (see Table IX), by major (Table X), by sex (Table XI), and by age (Table XII) with respect to these same six variables. These results will provide the raw data for subsequent analysis.

\section{RESEARCH QUESTIONS}

Are the Learning Styles of the International students Tested Different From Those Established by Kolb in Previous Studies for American Students?

This analysis was performed on two levels. First, the 
TABLE IX

DESCRIPTIVE STATISTICS BY NATIONALITY

(Mean/Standard Deviation)

\begin{tabular}{|c|c|c|c|c|c|c|c|}
\hline SAMPLE & $\mathbf{N}$ & $\mathrm{CE}$ & RO & AC & $A E$ & $A C-C E$ & $A E-R O$ \\
\hline Japanese & 23 & $\begin{array}{r}15.35 \\
4.20\end{array}$ & $\begin{array}{r}14.61 \\
4.31\end{array}$ & $\begin{array}{r}15.39 \\
3.04\end{array}$ & $\begin{array}{r}15.13 \\
2.77\end{array}$ & $\begin{array}{l}0.91 \\
6.54\end{array}$ & $\begin{array}{l}0.52 \\
6.35\end{array}$ \\
\hline Chinese & 9 & $\begin{array}{r}13.00 \\
4.00\end{array}$ & $\begin{array}{r}16.00 \\
3.84\end{array}$ & $\begin{array}{r}16.33 \\
2.65\end{array}$ & $\begin{array}{r}15.22 \\
2.05\end{array}$ & $\begin{array}{l}3.33 \\
6.36\end{array}$ & $\begin{array}{r}-0.78 \\
5.61\end{array}$ \\
\hline Korean & 7 & $\begin{array}{r}13.29 \\
2.81\end{array}$ & $\begin{array}{r}15.86 \\
4.53\end{array}$ & $\begin{array}{r}16.71 \\
1.98\end{array}$ & $\begin{array}{r}15.14 \\
3.39\end{array}$ & $\begin{array}{l}3.42 \\
3.55\end{array}$ & $\begin{array}{r}-0.71 \\
7.72\end{array}$ \\
\hline vietnamese & 7 & $\begin{array}{r}14.71 \\
2.75\end{array}$ & $\begin{array}{r}17.00 \\
3.56\end{array}$ & $\begin{array}{r}14.57 \\
3.21\end{array}$ & $\begin{array}{r}16.14 \\
3.90\end{array}$ & $\begin{array}{r}-0.14 \\
5.79\end{array}$ & $\begin{array}{r}-0.86 \\
6.87\end{array}$ \\
\hline Cambodian & 10 & $\begin{array}{r}14.60 \\
3.13\end{array}$ & $\begin{array}{r}17.60 \\
2.50\end{array}$ & $\begin{array}{r}14.80 \\
2.15\end{array}$ & $\begin{array}{r}14.30 \\
3.37\end{array}$ & $\begin{array}{l}0.20 \\
4.44\end{array}$ & $\begin{array}{r}-3.30 \\
5.38\end{array}$ \\
\hline $\begin{array}{l}\text { Other SE } \\
\text { Asian }\end{array}$ & 11 & $\begin{array}{r}14.00 \\
2.41\end{array}$ & $\begin{array}{r}16.82 \\
2.36\end{array}$ & $\begin{array}{r}15.36 \\
2.06\end{array}$ & $\begin{array}{r}14.09 \\
1.87\end{array}$ & $\begin{array}{l}1.36 \\
2.91\end{array}$ & $\begin{array}{r}-2.73 \\
3.55\end{array}$ \\
\hline Arabic & 15 & $\begin{array}{r}13.60 \\
3.02\end{array}$ & $\begin{array}{r}16.73 \\
2.66\end{array}$ & $\begin{array}{r}15.67 \\
2.32\end{array}$ & $\begin{array}{r}15.13 \\
3.00\end{array}$ & $\begin{array}{l}2.07 \\
4.46\end{array}$ & $\begin{array}{r}-1.60 \\
4.67\end{array}$ \\
\hline $\begin{array}{l}\text { Mid-East } \\
\text { Non-Arabic }\end{array}$ & 8 & $\begin{array}{r}17.25 \\
3.96\end{array}$ & $\begin{array}{r}13.38 \\
2.67\end{array}$ & $\begin{array}{r}16.25 \\
3.65\end{array}$ & $\begin{array}{r}15.63 \\
2.56\end{array}$ & $\begin{array}{r}-1.00 \\
5.71\end{array}$ & $\begin{array}{l}2.25 \\
3.58\end{array}$ \\
\hline Hispanic ${ }^{C}$ & 12 & $\begin{array}{r}15.08 \\
5.23\end{array}$ & $\begin{array}{r}16.17 \\
4.90\end{array}$ & $\begin{array}{r}13.75 \\
3.19\end{array}$ & $\begin{array}{r}15.58 \\
2.75\end{array}$ & $\begin{array}{r}-1.33 \\
8.16\end{array}$ & $\begin{array}{r}-0.58 \\
7.08\end{array}$ \\
\hline $\begin{array}{l}\text { Northern } \\
\text { Europeand }\end{array}$ & 3 & $\begin{array}{r}18.33 \\
0.58\end{array}$ & $\begin{array}{r}11.00 \\
1.00\end{array}$ & $\begin{array}{r}14.33 \\
2.52\end{array}$ & $\begin{array}{r}16.67 \\
2.08\end{array}$ & $\begin{array}{r}-4.00 \\
3.00\end{array}$ & $\begin{array}{l}5.67 \\
1.53\end{array}$ \\
\hline $\begin{array}{l}\text { GRAND } \\
\text { SAMPLE }\end{array}$ & 105 & $\begin{array}{r}14.70 \\
3.75\end{array}$ & $\begin{array}{r}15.77 \\
3.76\end{array}$ & $\begin{array}{r}15.33 \\
2.76\end{array}$ & $\begin{array}{r}15.15 \\
2.77\end{array}$ & $\begin{array}{l}0.82 \\
5.68\end{array}$ & $\begin{array}{r}-0.62 \\
5.77\end{array}$ \\
\hline
\end{tabular}

a Indonesia, the Philippines, and Thailand.

b Afghanistan, Iran, and Turkey.

C Brazil, Chile, Colombia, Costa Rica, the Dominican Republic, El Salvador, Equador, and Panama.

dGermany, sweden, and switzerland. 
TABLE $X$

DESCRIPTIVE STATISTICS BY MAJOR

(Mean/Standard Deviation)

\begin{tabular}{|c|c|c|c|c|c|c|c|}
\hline SAMPLE & $\mathbf{N}$ & CE & RO & $A C$ & $\mathrm{AE}$ & $A C-C E$ & AE-RO \\
\hline Accounting & 6 & $\begin{array}{r}13.83 \\
3.31\end{array}$ & $\begin{array}{r}14.83 \\
4.40\end{array}$ & $\begin{array}{r}17.33 \\
1.03\end{array}$ & $\begin{array}{r}15.16 \\
2.86\end{array}$ & $\begin{array}{l}3.50 \\
4.14\end{array}$ & $\begin{array}{l}0.33 \\
7.03\end{array}$ \\
\hline Business & 14 & $\begin{array}{r}15.29 \\
3.58\end{array}$ & $\begin{array}{r}15.07 \\
3.12\end{array}$ & $\begin{array}{r}14.79 \\
3.24\end{array}$ & $\begin{array}{r}15.43 \\
2.68\end{array}$ & $\begin{array}{r}-0.50 \\
6.01\end{array}$ & $\begin{array}{l}0.36 \\
5.46\end{array}$ \\
\hline Computer & 22 & $\begin{array}{r}12.67 \\
2.93\end{array}$ & $\begin{array}{r}16.17 \\
3.66\end{array}$ & $\begin{array}{r}16.42 \\
2.35\end{array}$ & $\begin{array}{r}15.75 \\
2.83\end{array}$ & $\begin{array}{l}3.75 \\
4.41\end{array}$ & $\begin{array}{r}-0.42 \\
5.55\end{array}$ \\
\hline Education & 3 & $\begin{array}{r}16.33 \\
2.08\end{array}$ & $\begin{array}{r}16.00 \\
5.00\end{array}$ & $\begin{array}{r}14.00 \\
1.00\end{array}$ & $\begin{array}{r}16.33 \\
2.89\end{array}$ & $\begin{array}{r}-2.33 \\
2.08\end{array}$ & $\begin{array}{l}0.33 \\
7.64\end{array}$ \\
\hline $\begin{array}{l}\text { English/ } \\
\text { Linguistics }\end{array}$ & 19 & $\begin{array}{r}16.68 \\
4.73\end{array}$ & $\begin{array}{r}14.05 \\
4.48\end{array}$ & $\begin{array}{r}14.68 \\
3.23\end{array}$ & $\begin{array}{r}15.26 \\
2.40\end{array}$ & $\begin{array}{r}-0.95 \\
6.98\end{array}$ & $\begin{array}{l}1.21 \\
5.71\end{array}$ \\
\hline Engineering & 18 & $\begin{array}{r}13.72 \\
3.21\end{array}$ & $\begin{array}{r}16.78 \\
2.96\end{array}$ & $\begin{array}{r}15.33 \\
2.97\end{array}$ & $\begin{array}{r}14.67 \\
3.01\end{array}$ & $\begin{array}{l}1.61 \\
5.50\end{array}$ & $\begin{array}{r}-2.11 \\
5.44\end{array}$ \\
\hline Pine Arts & 7 & $\begin{array}{r}15.57 \\
2.15\end{array}$ & $\begin{array}{r}16.86 \\
3.58\end{array}$ & $\begin{array}{r}15.86 \\
2.04\end{array}$ & $\begin{array}{r}14.29 \\
2.63\end{array}$ & $\begin{array}{l}0.29 \\
3.99\end{array}$ & $\begin{array}{r}-2.57 \\
5.44\end{array}$ \\
\hline Math/Physics & 2 & $\begin{array}{r}19.00 \\
1.41\end{array}$ & $\begin{array}{r}12.50 \\
0.71\end{array}$ & $\begin{array}{r}11.00 \\
0.00\end{array}$ & $\begin{array}{r}15.50 \\
2.12\end{array}$ & $\begin{array}{r}-8.00 \\
1.41\end{array}$ & $\begin{array}{l}3.00 \\
2.83\end{array}$ \\
\hline $\begin{array}{l}\text { Medical/ } \\
\text { Nursing }\end{array}$ & 2 & $\begin{array}{r}17.00 \\
1.41\end{array}$ & $\begin{array}{r}16.50 \\
0.71\end{array}$ & $\begin{array}{r}12.50 \\
0.71\end{array}$ & $\begin{array}{r}18.00 \\
0.00\end{array}$ & $\begin{array}{r}-4.50 \\
2.12\end{array}$ & $\begin{array}{l}1.50 \\
0.71\end{array}$ \\
\hline Science & 5 & $\begin{array}{r}13.80 \\
4.55\end{array}$ & $\begin{array}{r}17.40 \\
3.36\end{array}$ & $\begin{array}{r}15.60 \\
3.36\end{array}$ & $\begin{array}{r}15.00 \\
4.47\end{array}$ & $\begin{array}{l}1.80 \\
7.01\end{array}$ & $\begin{array}{r}-2.40 \\
7.02\end{array}$ \\
\hline $\begin{array}{l}\text { Social } \\
\text { Science }\end{array}$ & 4 & $\begin{array}{r}15.50 \\
5.07\end{array}$ & $\begin{array}{r}15.00 \\
4.32\end{array}$ & $\begin{array}{r}16.25 \\
1.50\end{array}$ & $\begin{array}{r}15.25 \\
2.06\end{array}$ & $\begin{array}{l}0.75 \\
6.29\end{array}$ & $\begin{array}{l}0.25 \\
5.91\end{array}$ \\
\hline Undeclared & 13 & $\begin{array}{r}13.08 \\
3.07\end{array}$ & $\begin{array}{r}17.08 \\
4.11\end{array}$ & $\begin{array}{r}15.69 \\
2.18\end{array}$ & $\begin{array}{r}14.54 \\
3.20\end{array}$ & $\begin{array}{l}2.62 \\
4.43\end{array}$ & $\begin{array}{r}-2.54 \\
6.72\end{array}$ \\
\hline $\begin{array}{l}\text { GRAND } \\
\text { SAMPLE }\end{array}$ & 105 & $\begin{array}{r}14.70 \\
3.75\end{array}$ & $\begin{array}{r}15.77 \\
3.76\end{array}$ & $\begin{array}{r}15.33 \\
2.76\end{array}$ & $\begin{array}{r}15.15 \\
2.77\end{array}$ & $\begin{array}{l}0.82 \\
5.68\end{array}$ & $\begin{array}{r}-0.62 \\
5.77\end{array}$ \\
\hline
\end{tabular}




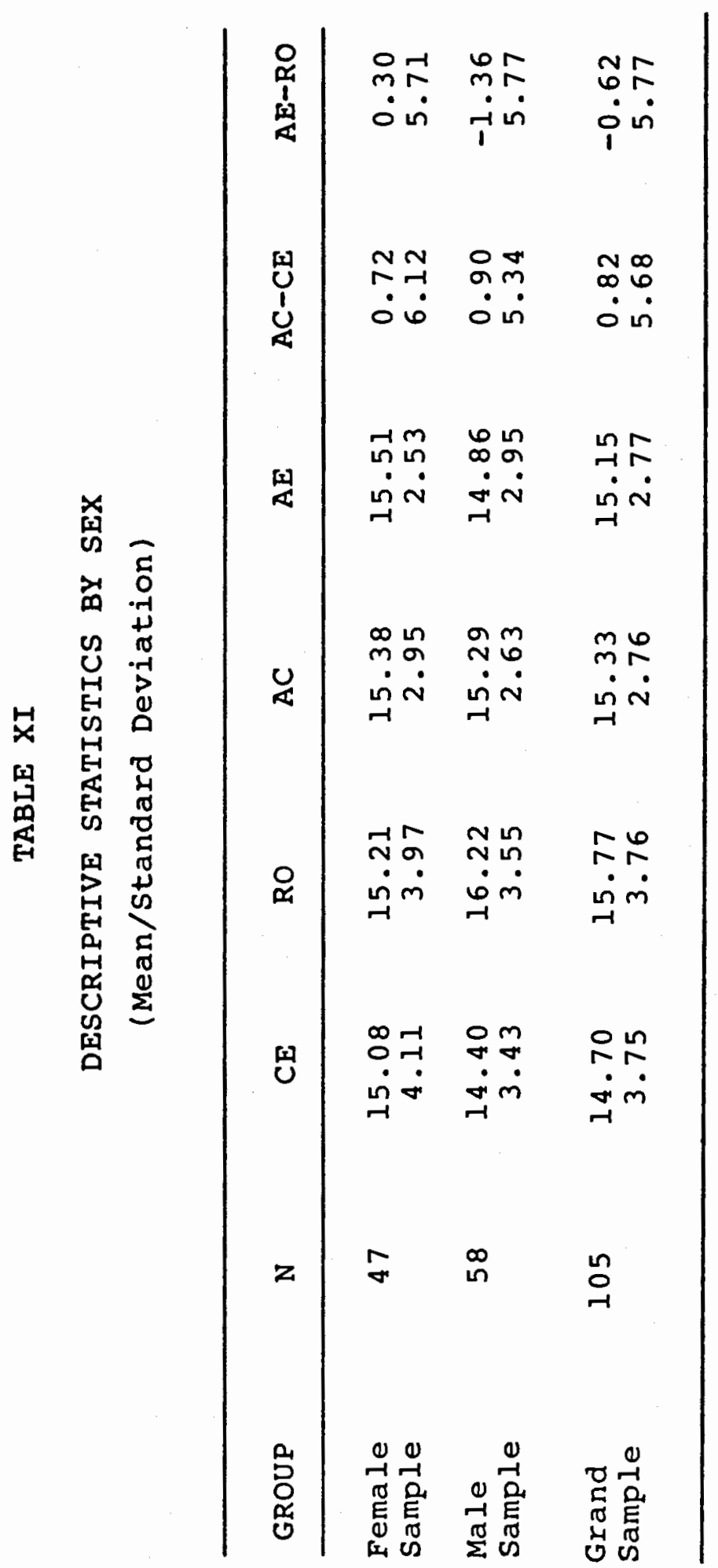


TABIE XII

SAMPLE AGE BY NATIONALITY AND SEX

(In Years)

\begin{tabular}{|c|c|c|c|c|}
\hline GROUP & $\mathbf{N}$ & MEAN & SD & RANGE \\
\hline \multicolumn{5}{|c|}{ By Nationality } \\
\hline Japanese & 23 & 22.9 & 4.1 & $17-31$ \\
\hline Chinese & 9 & 24.4 & 4.8 & $19-32$ \\
\hline Korean & 7 & 31.0 & 10.4 & $20-44$ \\
\hline Vietnamese & 7 & 25.3 & 5.8 & $20-35$ \\
\hline Cambodian & 10 & 31.0 & 10.5 & 21.58 \\
\hline other SE Asian & 11 & 22.7 & 5.6 & $18-37$ \\
\hline Arabic & 15 & 21.7 & 2.1 & $19-27$ \\
\hline Mid-East Non-Arabic & 8 & 22.3 & 5.5 & $19-34$ \\
\hline Hispanic & 12 & 33.1 & 8.3 & $18-44$ \\
\hline Northern European & 3 & 19.0 & 1.0 & $18-20$ \\
\hline \multicolumn{5}{|c|}{ By $\operatorname{sex}$} \\
\hline Males & 58 & 25.7 & 8.2 & $18-58$ \\
\hline Females & 47 & 24.8 & 6.2 & $17-40$ \\
\hline $\begin{array}{l}\text { Grand } \\
\text { Sample }\end{array}$ & 105 & 25.3 & 7.4 & $17-58$ \\
\hline
\end{tabular}


T statistics for the grand sample were compared with those extrapolated for the American sample. Then each national grouping was individually compared with the American sample to look for distinctive trends in variance.

The comparison of the grand sample of international students and the norms extrapolated for American adults is shown in Table XIII. Significant differences were found in five of the six variables tested. There was no significant difference in the CE scores. In the test sample, RO scores were significantly higher $(p<.005)$, AC scores significantly lower $(p<.005)$, and AE-RO scores significantly different $(p<.005)$ from those of the normative American sample. Table XIV shows differences in scores by national group as compared with the American norms. The Japanese group showed no significant difference in $C E$ or $A E$ scores, but significantly higher RO $(p<.05)$ and lower AC $(p<.01)$ scores. Both $\mathrm{AC}-\mathrm{CE}$ and $\mathrm{AE}-\mathrm{RO}$ showed significantly different scores $(p<.10)$.

The Korean sample showed no significant difference in scores for $C E, A C$ or $A E$, but significantly greater $(P<.05)$ RO scores. Of the combined scores only AE-RO showed significant difference $(p<.10)$.

The Vietnamese group showed no significant difference in $A E$ or $C E$ mode scores, but significantly greater RO $(p<.005)$ and lower AC scores. Of the combined scores only 


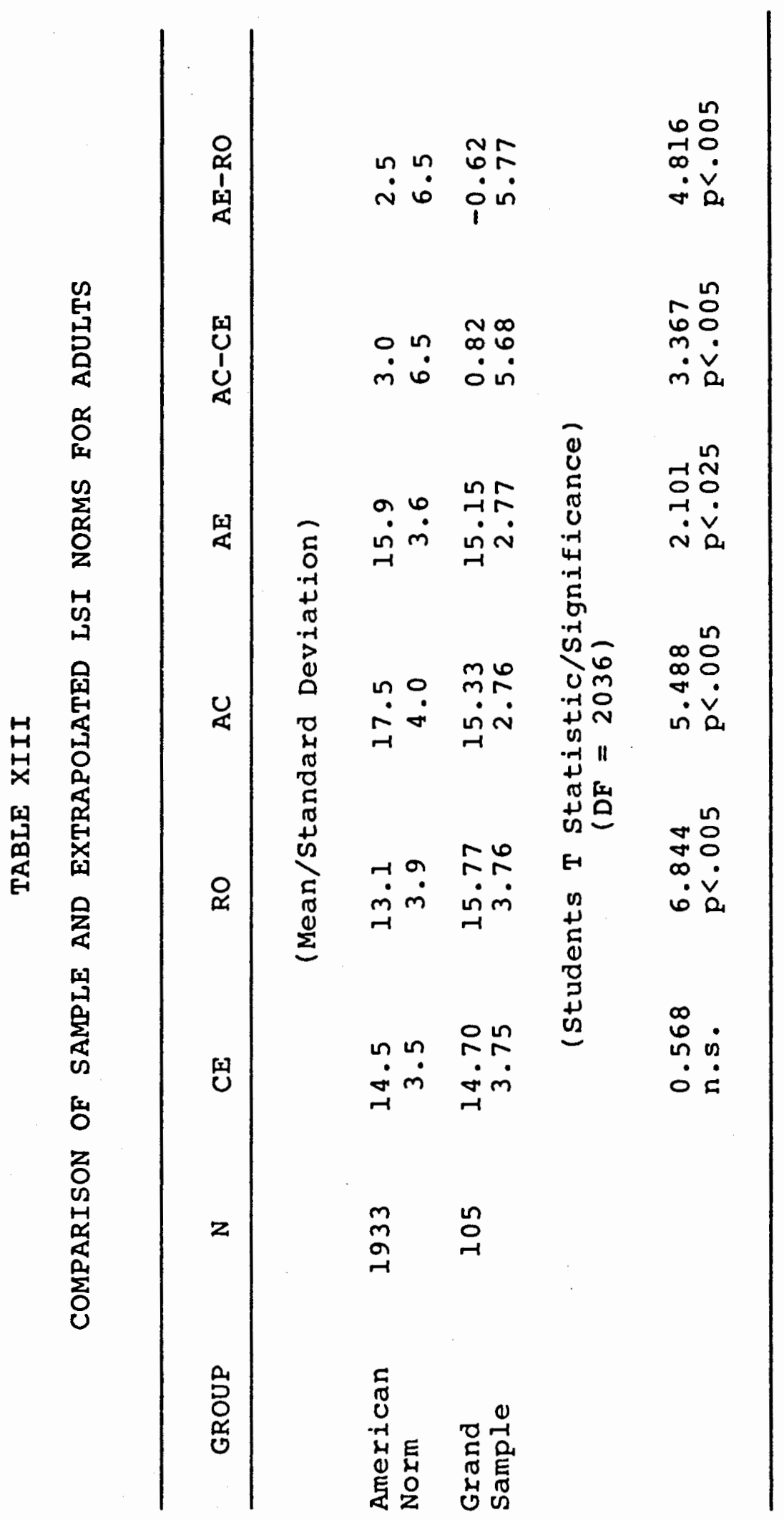


TABLE XIV

COMPARISON TO EXTRAPOLATED ISI NORMS BY NATIONALITY

(Students T Statistic/Significance)

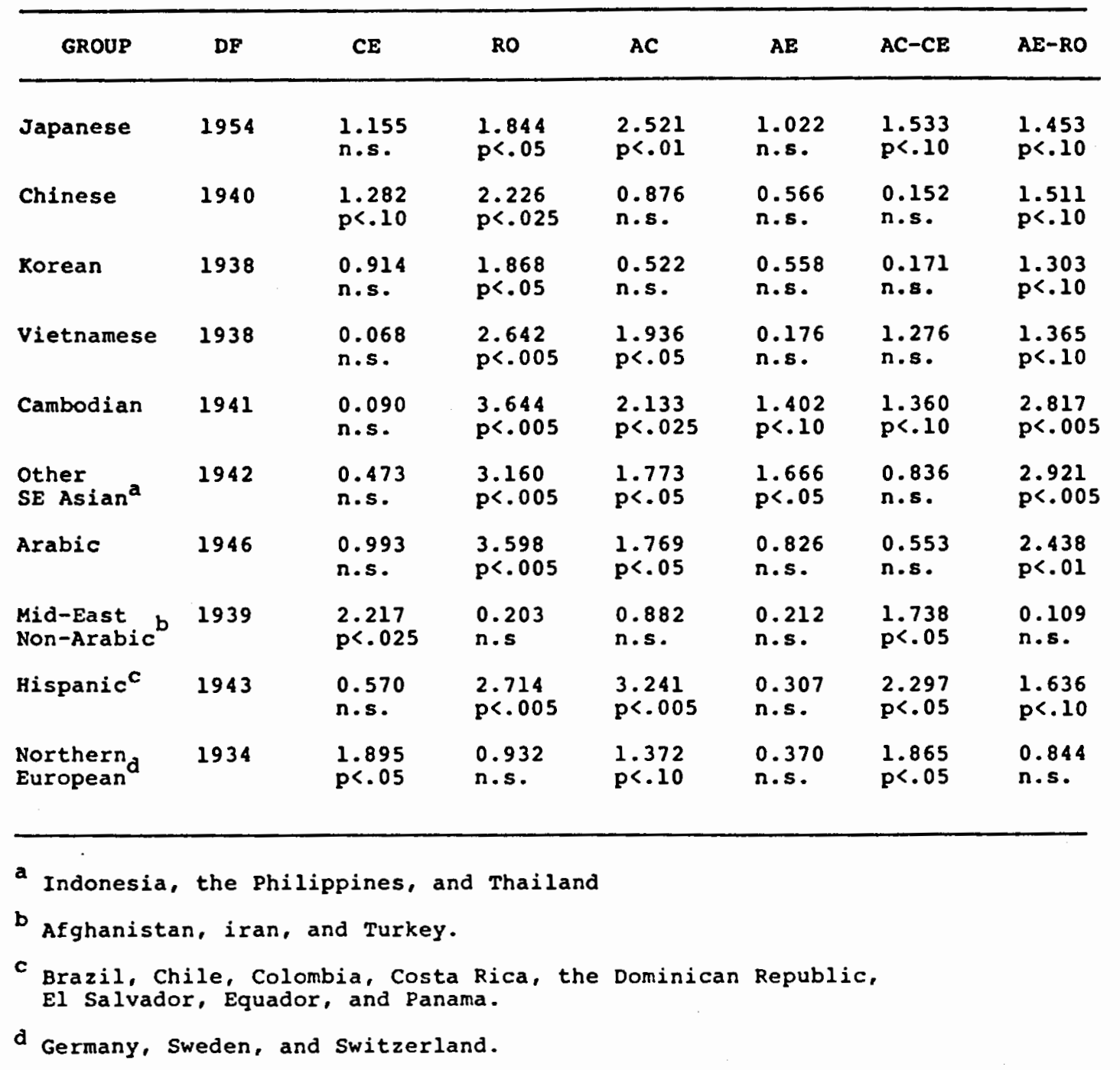


AE-RO showed significant difference $(p<.10)$.

The Cambodian sample showed no significant difference in $C E$ scores. Of the other variables, RO showed significantly higher $(p<.005)$ and $A C(p<.025)$ and $A E(p$ $<.10)$ significantly lower scores. Both $A C-C E(p<.10)$ and AE-RO $(P<.005)$ showed significant difference.

The other Southeast Asian sample failed to show difference only in the CE mode. Significantly higher RO I $p$ $<.005)$, lower $\mathrm{AC}(\mathrm{p}<.025)$ and lower $\mathrm{AE}(\mathrm{p}<.01)$ scores were measured. AE-RO showed significant $(\mathrm{p}<.005)$ difference.

The Arabic sample showed no significant difference in $C E$ or AE scores. Significantly higher RO ( $<<.005)$, lower $A C(p<.025)$ and lower AE $(p<.10)$ scores were measured. AE-RO showed significant difference $(p<.005)$.

The non-Arabic Mid-East sample showed no significant differences in RO, $A C$ or $A E$ scoring. $C E$ showed significantly higher scores $(p<.05)$. AC-CE showed significant difference $(p<.05)$ in the scores.

The Hispanic sample showed no difference in scores for $C E$ or $A E$. RO showed significantly higher $(p<.005)$ and $A C$ significantly lower $(p<.005)$ scores. Both $A C-C E(p<.05)$ and $A E-R O(p<.10)$ modes showed significant difference from the American norms.

The Northern European sample showed no significant 
difference in scores in the RO and $A E$ modes. But scores for

$C$ were significantly higher $(P<.05)$ and for $A C$ significantly lower $(p<.10)$. AC-CE showed significant difference $(p<.05)$.

of the ten national sample groups only three showed any variation in Concrete Experience (CE), and of these only the Chinese group scored lower; both non-Arabic Mid-East and Northern European groups scored higher in this area. All but two groups (non-Arabic Mid-East and Northern European) showed significantly greater Reflective (RO) scores. Only the Chinese, Korean and non-Arabic Mid-East samples showed no significant difference in scoring of the Abstract (AC) mode; all the rest scored lower in this area than their American counterparts. Only two of the ten sample groups (Cambodian and Other Southeast Asians) showed significant variation from the normative American data in Active Experimentation (AE) scoring. Five of the ten groups showed significant difference in the $A C-C E$ scoring, while all but non-Arabic Mid-East and Northern European samples showed significantly different scores in the AE-RO mode.

Do the Learning Styles of the International students Tested Differ Among the Various Groups?

An analysis of variance using the Kurskal wallis $\mathrm{H}$ Statistic was used to look at the variation within four subgroups of the total sample. The results are shown in 
Table XV. Significant difference was noted between the Arabic and non-Arabic Mid-East samples. Variation was present in the CE $(\mathrm{p}<.05)$, the RO $(\mathrm{p}<.025)$ and the $A E-R O$ $(p<.05)$ modes. No significant variations were noted within the other groupings.

Are There Differences Among the International Students Tested That Can be Related to Gender?

Using the Kruskel Wallis One-Way Analysis of Variance only three of the sample groups (Chinese, uther SE Asian and Korean) showed any significance in scores which could be linked to gender differences. Table XVI shows a breakdown of the scoring for those groups. The highest degree of variance is displayed by the Korean sample with $C E, R O$ and AE-RO all showing a significant degree of difference $(p<.05)$.

An additional difference appeared as an interesting dynamic related to age and will be discussed in depth in the following section.

Do the Learning Styles of the International Students Tested Show Any Pattern of Variation According to Age? If Present, Does that Pattern Differ in Any Way From Patterns Identified by Kolb for American Subjects Tested?

Using Spearman's Rank Correlation Coefficient, measurements were made for the grand sample and then broken down into male and female populations (Table XVII). As age increased, significant positive correlations were shown with 


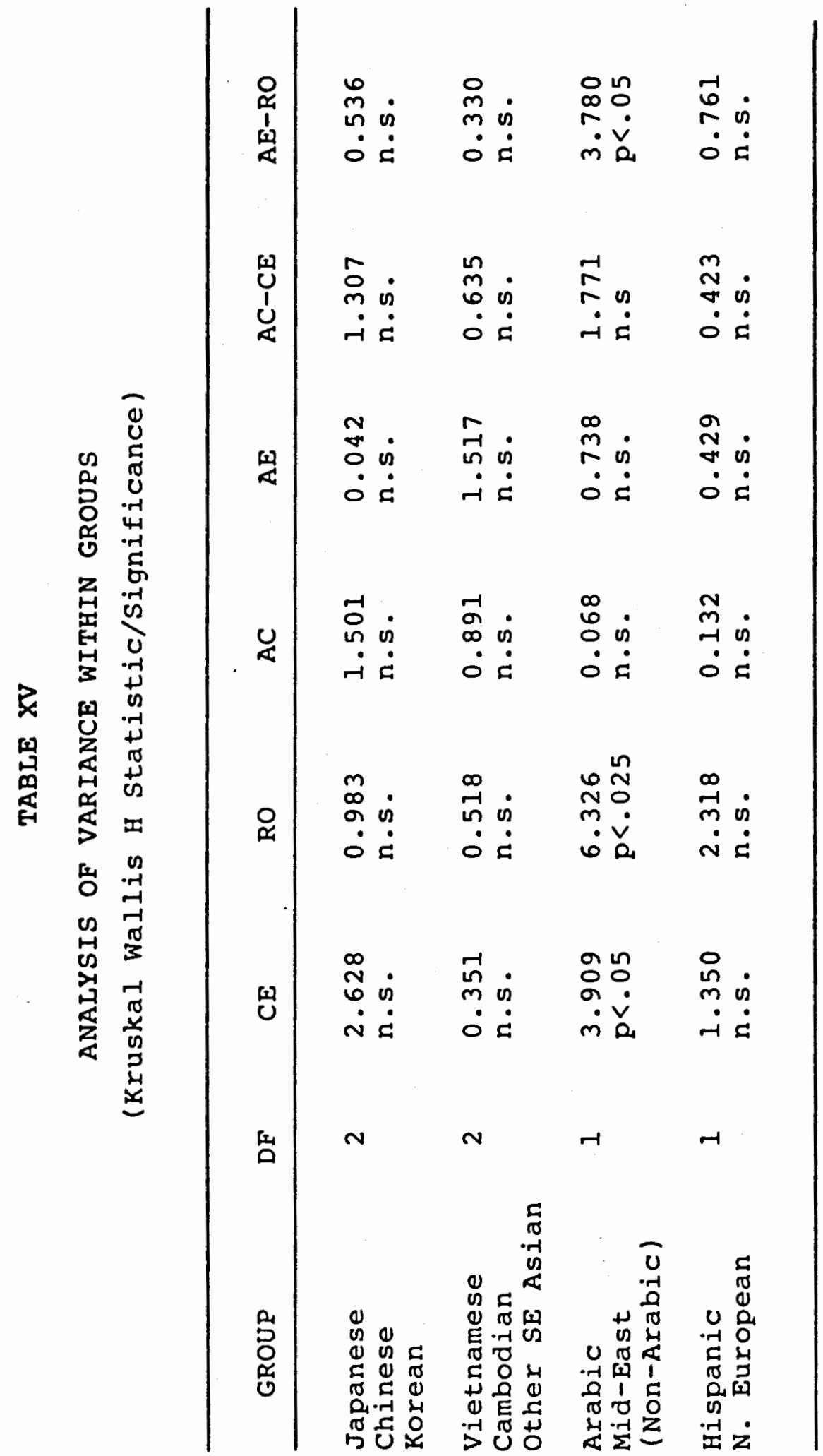




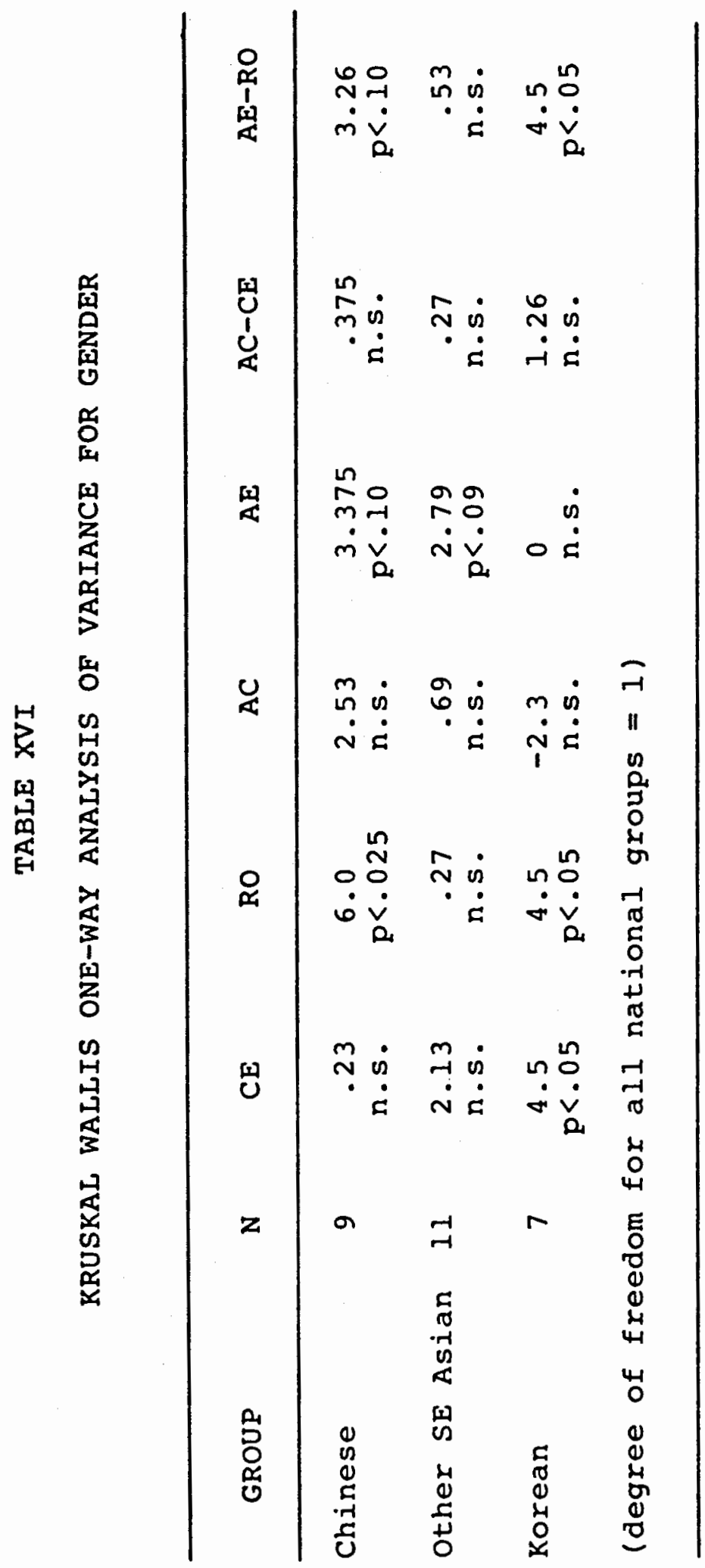




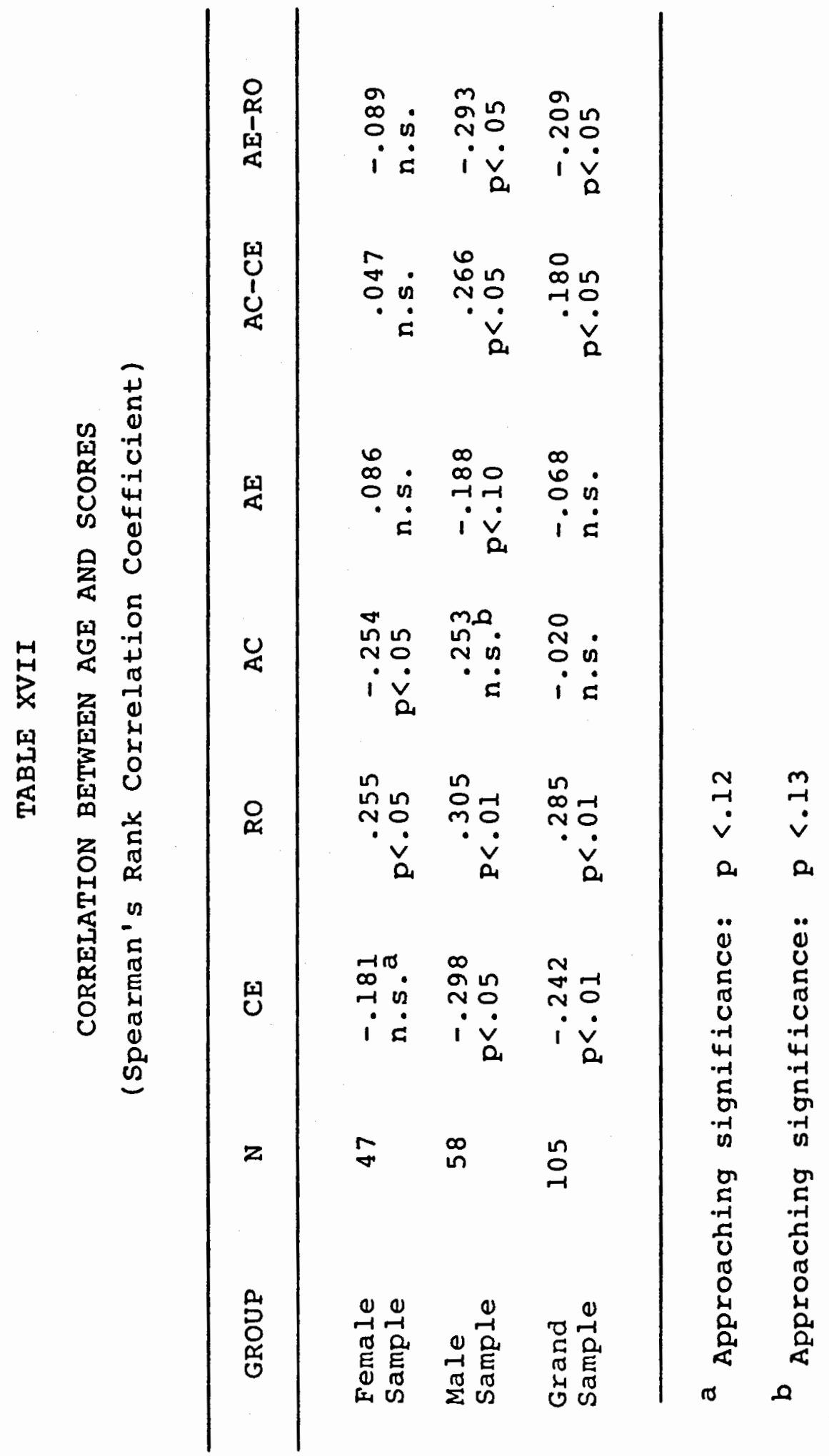


the RO $(\mathrm{p}<.01)$ and $\mathrm{AC}-\mathrm{CE}(\mathrm{p}<.05)$ scores, while significant negative correlation appeared for $C E(p<.01)$ and AC-RO scores. With advancing age, the female sample showed significantly positive correlation for RO scores $(p<.05)$ and negative correlation with $A C$ scores $(p<.05)$. The male sample, however, showed no significant change in the AC sample, but for an increase in age showed significant negative correlation with $C E(p<.05), A E(p<.10)$ and $A E-$ RO $(\mathrm{p}<.05)$ scores and positive correlation with RO $(p<.01)$ and $A E-R O(p<.05)$.

An interesting contrast appears to be indicated in the pattern of movement or change with increasing age between males and females in the sample. Females showed significant change with age in only two of the six variables, while males showed significant change in five of the six variables.

Figure 6 shows the findings by Kolb on age variation in LSI scores. The graph shows a slight tendency toward increasing abstraction as one grows older. The relationship in the AE-RO dimension is curvilinear. From age 16-35, the tendency toward an active orientation increases and then seems to taper off toward a more reflective orientation in the later years (Kolb, 1976, p. 24).

In the International student population the male sample showed a similar increase in the abstract and reflective 


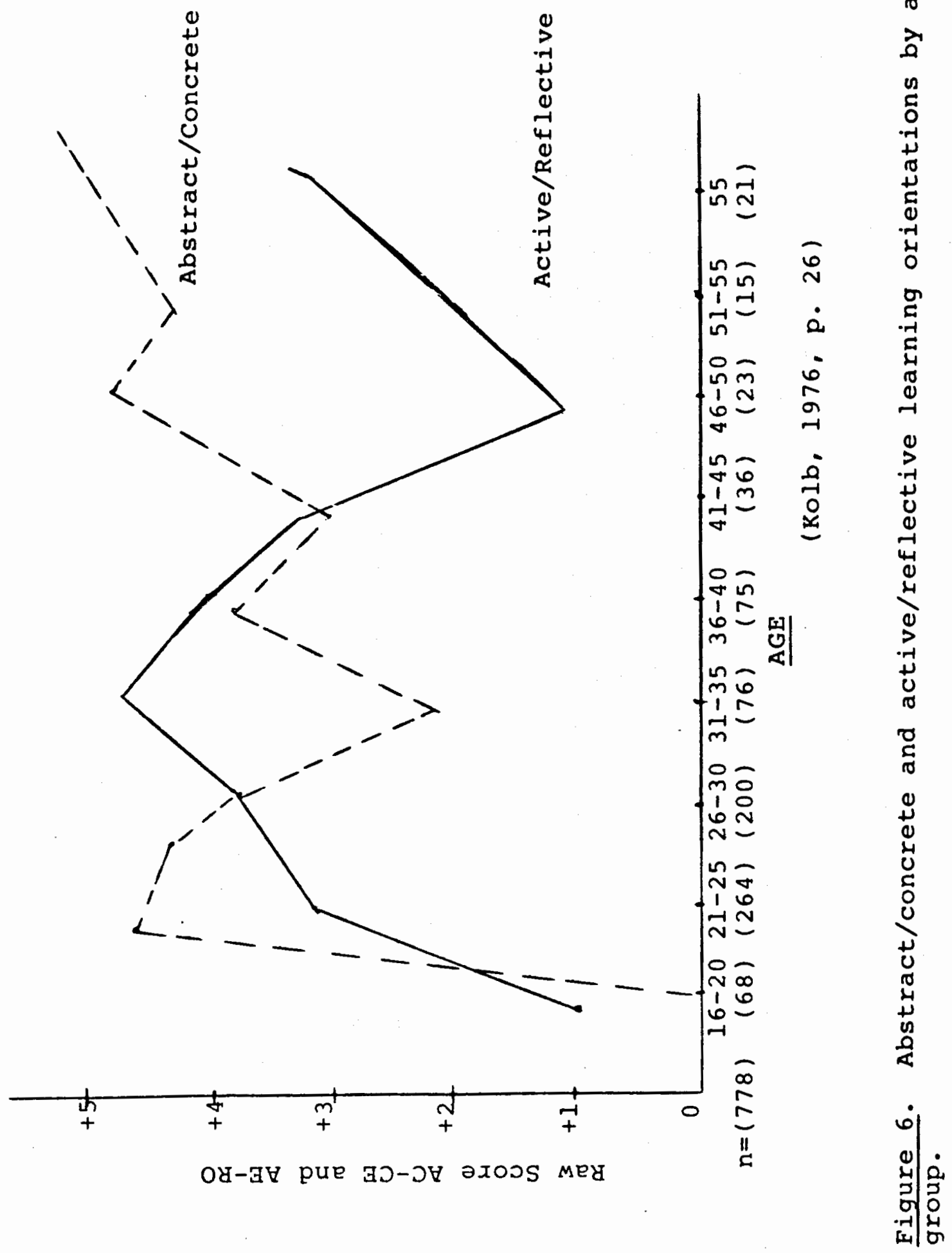


orientations and decrease in concrete and active orientations with increasing age. The female population, however, showed no significant change in the active dimension and showed a decreased abstract orientation which might possibly represent a narrowing of flexibility in the $A C-C E$ dimension. The only similarity seems to be in the increasing reflective pole.

Are the Learning Styles of the International Students Tested Similar or Dissimilar from the Norms Established by Kolb as Normative for Various Fields of Study at American Universities?

Table XVIII shows a comparison of the International student Engineering sample to the scores of undergraduate engineering students from the University of Massachusetts. Significantly larger RO $(p<.005)$ and lower $A C(p<.025)$ and $A E(p<.10)$ scores were noted. AE-RO scores also showed significant $(\mathrm{p}<.01)$ variation. A further comparison to a professional engineering sample (Table XIX) shows significant difference in both $A C-C E$ and $A E-R O$ scores $(p<.005)$.

A comparison of the student computer programing sample to a professional sample (Table $X X$ ) showed significantly greater $R O(\mathrm{p}<.005)$ and lower $C E(\mathrm{p}<.025)$ and $A C$ $(p<.10)$ scores. The AE-RO scores also differed significantly $(p<.05)$.

Using the broad categories of accommodator, diverger, 


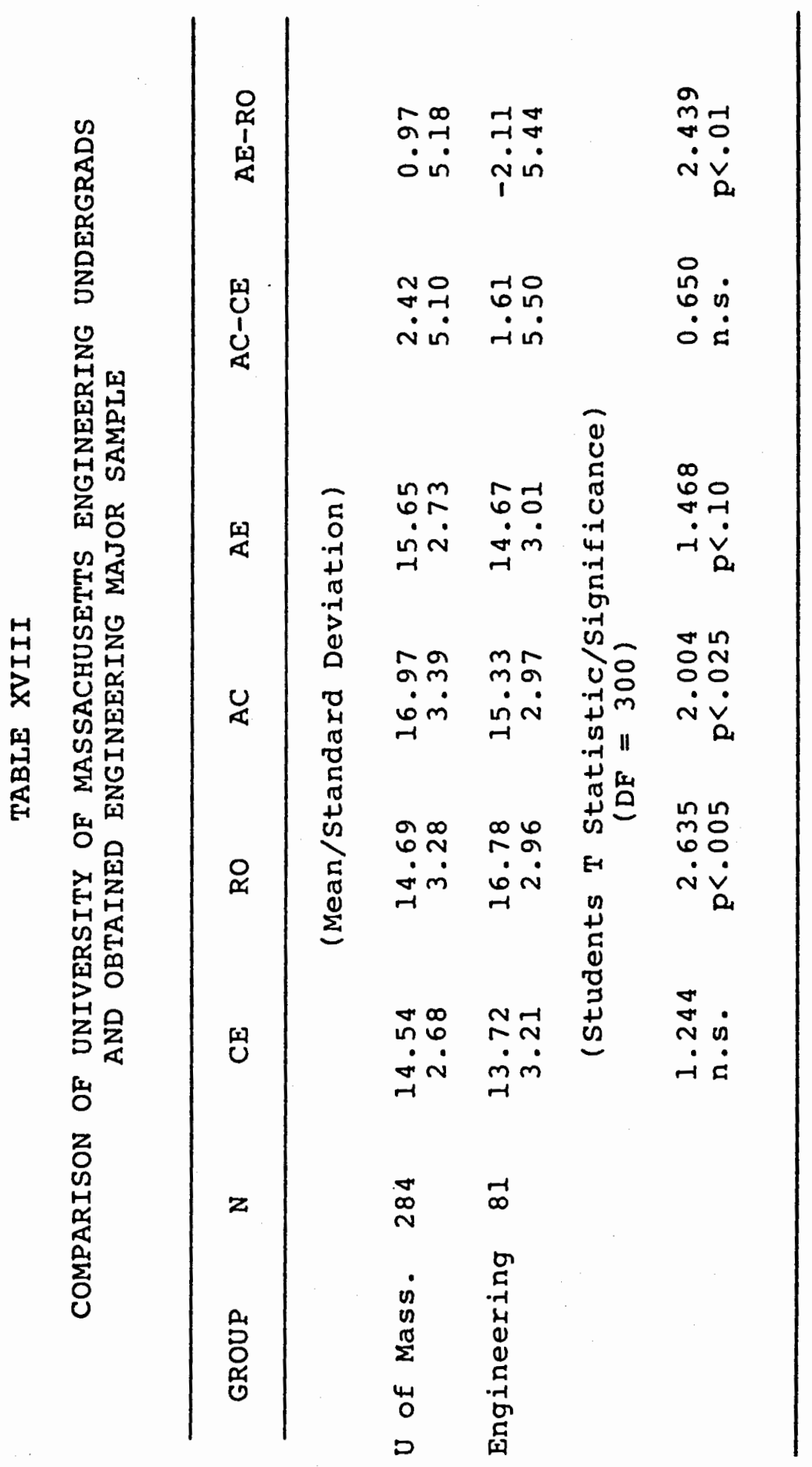


TABLE XIX

COMPARISON OF PROFESSIONAL ENGINEERS

TO ENGINEERING MAJOR SAMPLE

\begin{tabular}{|c|c|c|c|}
\hline GROUP & $\mathrm{N}$ & $A C-C E$ & $A E-R O$ \\
\hline \multicolumn{4}{|c|}{ (Mean/Standard Deviation) } \\
\hline Engineers & 270 & $\begin{array}{l}4.56 \\
5.31\end{array}$ & $\begin{array}{l}3.61 \\
5.19\end{array}$ \\
\hline \multirow[t]{3}{*}{$\begin{array}{l}\text { Engineering } \\
\text { Major Sample }\end{array}$} & 18 & $\begin{array}{l}1.61 \\
5.50\end{array}$ & $\begin{array}{r}-2.11 \\
5.44\end{array}$ \\
\hline & \multicolumn{3}{|c|}{$\begin{array}{c}\text { (Students } T \text { Statistic/Significance) } \\
(D F=286)\end{array}$} \\
\hline & & $\begin{array}{r}2.277 \\
\mathrm{p}<.005\end{array}$ & $\begin{array}{r}4.514 \\
p<.005\end{array}$ \\
\hline
\end{tabular}




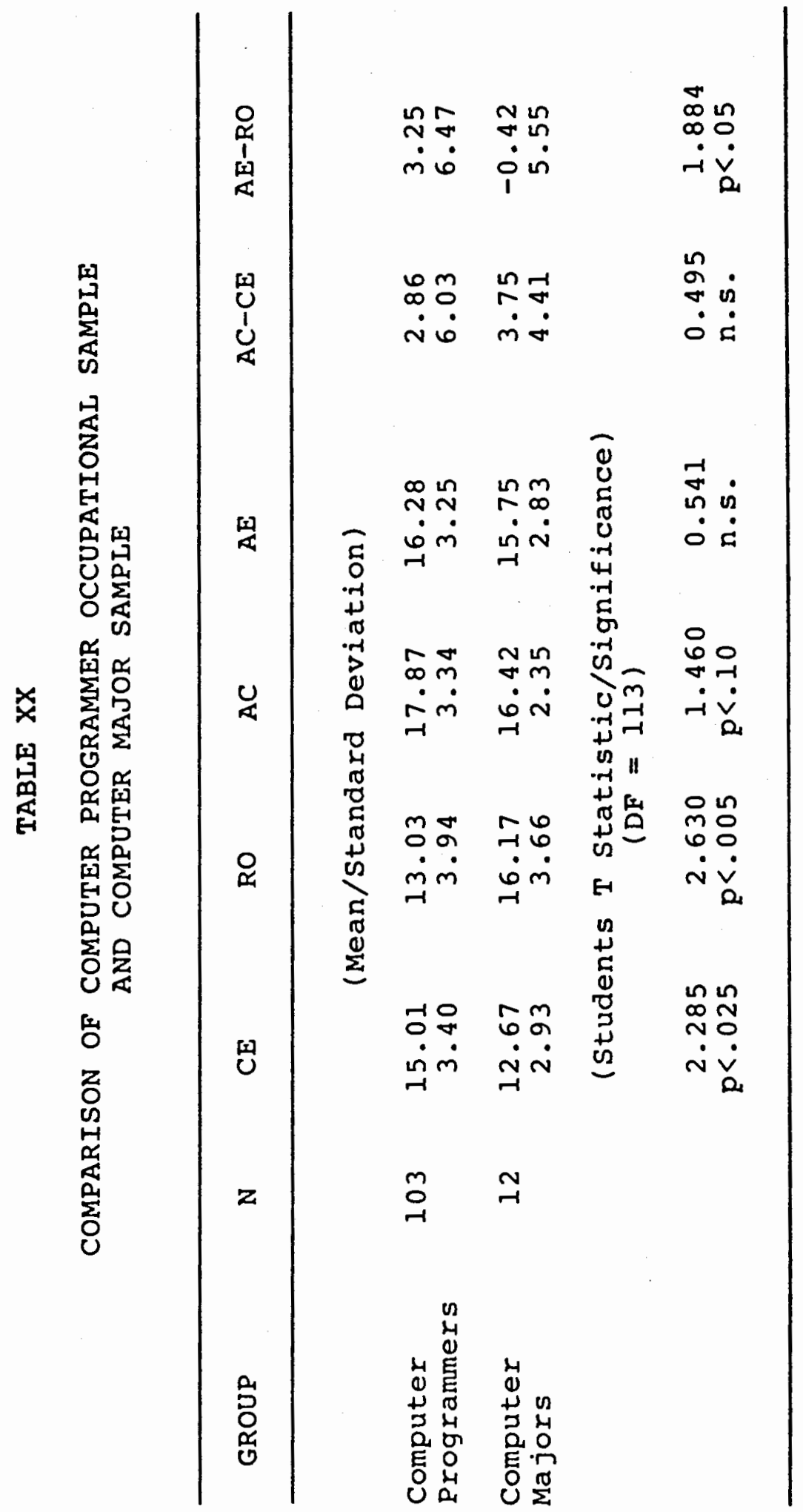


assimilator and converger as descriptors of learning style, students were then looked at individually to see how many had learning stules dissimilar to those viewed as normative for the field they have chosen to study (Table XXI). Of the total sample, 808 were dissimilar in learning style from the one determined as normative for Americans in their desired field. Among the national groups the percentage of dissimilar learning styles ranged from $100 z$ among other SE Asians to 508 among the Koreans and Northern Europeans (Table XXII).

Table XXIII shows a breakdown of the national groups by the same learning style categories. An accommodative learning style was preferred by $25.6 \%$ of the total sample, but varied by national sample from 0 preference for the Cambodians to $100 \%$ preference by the Northern Europeans. divergent style of learning was favored by 42.98 of the total sample and ranged from 0 preference by the Northern Europeans to 658 by the Other SE Asian group. The assimilator mode was preferred by 26.88 of the total sample and ranged from 08 for the Northern Europeans to 42.88 for the Koreans. The convergent style of learning was favored by 4.68 of the total sample with a range of 0 for seven national groups with 22.28 for the Chinese the highest. of the total sample, the greatest preference was displayed for the accommodative mode, the least preference 


\section{PREFERRED EDUCATIONAL AND VOCATIONAL FIELDS BY LEARNING STYLE}

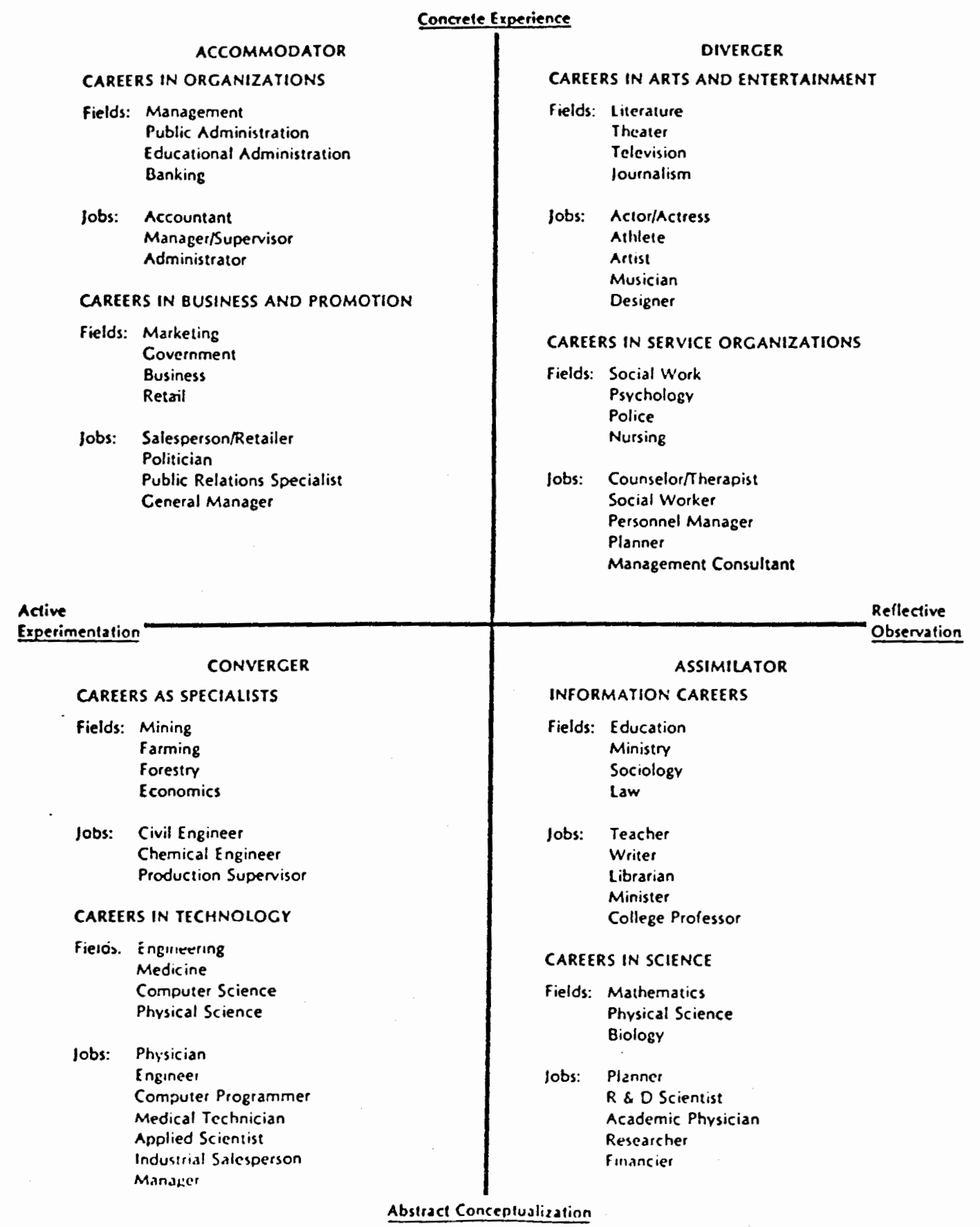


TABLE XXII

DISSIMILARITY OF LEARNING STYLE IN CHOSEN FIELD OF STUDY BETWEEN INTERNATIONAL STUDENTS AND AMERICAN NORMS

\begin{tabular}{|c|c|c|c|}
\hline Group & $\begin{array}{l}\text { Students with } \\
\text { Preference of } \\
\text { Major }\end{array}$ & $\begin{array}{l}\text { P of Students } \\
\text { With Dissimilar } \\
\text { Learning Styles }\end{array}$ & $\begin{array}{c}q \text { of } \\
\text { Dissimilarity }\end{array}$ \\
\hline Japanese & 20 & 18 & 90 \\
\hline Chinese & 8 & 6 & 75 \\
\hline Korean & 6 & 3 & 50 \\
\hline Vietnamese & 6 & 5 & 83 \\
\hline Cambodian & 7 & 6 & 85 \\
\hline $\begin{array}{l}\text { Other SE } \\
\text { Asian }\end{array}$ & 10 & 10 & 100 \\
\hline Arabic & 15 & 13 & 89 \\
\hline $\begin{array}{l}\text { Mid-East } \\
\text { Non-Arabic }\end{array}$ & 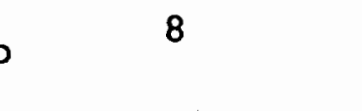 & 6 & 75 \\
\hline Hispanic & 10 & 6 & 60 \\
\hline $\begin{array}{l}\text { Northern } \\
\text { European }\end{array}$ & 2 & 1 & 50 \\
\hline Total & 92 & 74 & 80 \\
\hline
\end{tabular}
a Indonesian, the Philippines and Thailand
b Afghanistan, Iran and Turkey
C Brazil, Chile, Columbia, Costa Rica, the Dominican Republic, El Salvador, Equador and Panama
d Germany, Sweden and switzerland 
TABLE XXIII

PERCENTAGE BREAKDOWN OF NATIONAL GROUPS BY LEARNING STYLE

\begin{tabular}{lrcccc}
\hline \multicolumn{1}{c}{ GRouP } & N & ACCOMMODATOR & DIVERGER & ASSIMIIATOR & CONVERGER \\
\hline Japanese & 23 & 39.0 & 26.0 & 35.0 & 0.0 \\
Chinese & 9 & 11.1 & 33.3 & 33.3 & 22.2 \\
Korean & 7 & 28.6 & 28.6 & 42.8 & 0.0 \\
Vietnamese & 7 & 28.6 & 42.8 & 28.6 & 0.0 \\
Cambodian & 10 & 0.0 & 60.0 & 40.0 & 0.0 \\
$\begin{array}{l}\text { Other SE } \\
\text { Asiana }\end{array}$ & 11 & 7.3 & 65.4 & 27.3 & 0.0 \\
Arabic & 15 & 6.1 & 60.0 & 13.9 & 20.0 \\
$\begin{array}{l}\text { Middle East } \\
\text { Non-Arabic }\end{array}$ & 8 & 37.5 & 50.0 & 0.0 & 12.5 \\
Hispanic & 12 & 42.7 & 33.3 & 25.0 & 0.0 \\
$\begin{array}{l}\text { Northern } \\
\text { European }\end{array}$ & 3 & 100.0 & 0.0 & 0.0 & 0.0 \\
$\begin{array}{l}\text { Grand } \\
\text { Sample }\end{array}$ & 105 & 25.6 & 42.9 & 26.8 & 4.7 \\
\hline
\end{tabular}

a Indonesia, the Philippines and Thailand

b Afghanistan, Iran and Turkey

C Brazil, Chile, Columbia, Costa Rica, the Dominican Republic, El Salvador, Equador and Panama

d Germany, Sweden and Switzerland 
for the convergent mode with seven of the ten groups having no preference for that learning style. The accommodator and assimilator modes showed similar degrees of preference at 25.68 and 26.88 respectively. The narrowest range of preference was displayed by the Northern European sample with a 1008 accommodative preference and the Cambodian sample second with preferences in only two modes. Another six groups showed a range that included only three categories. Only the Chinese and the Arab samples placed students in all four learning modes. 


\section{CHAPTER V}

\section{DISCUSSION}

Regarding the five research questions, the results of the study allow for the following implications:

1. Significant differences in learning style were demonstrated by the national groups tested for all six of the variables measured.

2. Significant difference was demonstrated among the groups tested, most clearly in the Middle East sample between Arab and non-Arabic Mid-East groups.

3. Differences associated with gender were not evident in the overall sample, but were demonstrated in the Chinese, Korean and Other SE Asian samples.

4. A pattern of variation associated with age demonstrated itself in the International student sample. For the males in the sample, it was a similar pattern to that demonstrated by the American groups tested; for the females, it presented itself in a significantly different way. 
5. Available statistical information showed significant difference in the learning styles of the International student engineering and computer science majors when compared with the normative American samples. Overall comparison of the national groups tested show 808 of the total sample dissimilar to the preferred learning style of the Americans in their chosen field of study.

Following is a discussion of these differences as they relate to the theoretical assumptions of this study.

\section{DISCUSSION}

American and International student Differences for the Six Variables

All of the six variables tested $(C E, R O, A C, A E, A C-C E$, and $A E-R O)$ showed significant statistical differences in at least two groups; however, the $R O$ and $A C$ modes showed the highest degree of variation. Eight of the ten groups scored higher in the reflective dimension, and seven out of the ten had lower socres in the abstract dimension than the normative American sample.

The manifestations of these differences are not without potential consequences. As previously defined, the process of learning is characterized by the way a person grasps (through apprehension or comprehension) and transforms 
(through intention or extension) his or her experience. Students who express a strong preference for intention as a mode of transforming and utilizing experience will tend to internalize information, examining it for its implications and connections to other things already known. As a result, these students may be perceived by American instructors as overly quiet, slow to ask questions or speak up in class. When they do respond, their answers are generally thoughtful, may even seem profound in some cases, but can just as easily be viewed as tangential.

When students also exhibit concomitantly lower AE scores as seen in the Cambodian and Other SE Asian samples, they are likely to show a genuine aversion to tasks that are highly extensional in nature, i.e., oral presentations, group discussions, role playing and interviewing projects. Predictable conflict arises in situations such as one recently reported to this researcher in which a student from a highly reflective culture (Indonesia) entered a field with a highly extensional orientation (business) and received a lowered grade in a class because she simply could not bring herself to do a community interviewing assignment with a total stranger.

The presence of lowered AC scores indicates that students may be less practiced at using analysis as a form of grasping their experience, preferring a more synthetic or 
holistic approach in processing information than their American counterparts.

The difficulties that can arise when there is a marked difference in the modes of apprehension and comprehension was illustrated in a university statistics class. A professor had painstakingly developed a series of linear operations necessary for a statistical analysis. An Arab student suddenly raised his hand and asked how the present equation related to the original problem. The professor responded with the admonition that if the student had been paying attention, he would know how they had arrived at their present position. He could see no rational reason why the student would be concerned about how the whole operation fit together; from his perspective, each part was a logical and coherent manifestation of a linear progression that was sufficient unto itself. The professor was angry, the student confused and embarrassed, yet both behaved consistently within the confines of their own prehensive modes.

In seeking explanations for the overwhelming presence of these two learning modalities in such a wide variety of cultural groups, the work of Edward Hall (1981) may provide an interesting insight. According to his definition, all the groups displaying highly reflective tendencies (six of the eight also exhibited comparatively lower AC scores) are 
"high context" in nature; i.e., systems in which

- . most of the [communication] information is either in the physical context or internalized in the person while very little is coded in the explicitly transmitted part of the message. (p. 91)

For such cultures, it is relationships, the when, where, how and who of human interactions, which are of maximum importance.

Given such a description, the ability to internalize information becomes a socially valuable cognitive function and requires a greater awareness of the situational and environmental context (CE) than it does the analysis of individual details $(A C)$. Inappropriate action in any given situation could summarily produce embarrassment or offense, neither of which is very desirable in cultures where "saving face" is highly valued.

The American and Northern European samples are more likely to be considered "low context," i.e., having a style of communication in which "the mass of information is vested in the explicit code" (p. 91). While this could account for the similarity in the Ro scores, it does not explain the higher $C E$ and lower $A C$ scores in the Northern European group. At least three possible factors could account for this: (1) the low $\mathrm{N}$ of the sample invalidates the findings; (2) if these students are experiencing culture shock, it could account for them being more closely in touch with 
their immediate experience; or (3) Northern European cultures are in fact higher context and less individualistic than American culture, perhaps due to a greater sense of historic continuity.

The non-Arabic Mid-East sample provides the most challenging opportunity for examination of differences. Given the previous explanations, they exhibit test scores that could be indicative of elements of both high and low context cultures (high CE scores, with other variables similar to the American sample).

Zonis (1979) in his article on Iranian students provides information that could shed some light on these results. He describes them as"distrustful of hierarchy and authority," independent with regard to all aspects of their lives except in obedience to their fathers, viewing behavior as "essentially self-serving," highly volatile and emotional (pp. 75-9) and "not prone to the development of introspection" (p. 83). these factors, plus their recent history of western influence and cultural norms that encourage impassioned displays of opinion (p. 103) may to some degree explain the unique quality of their scores.

\section{Differences Among National Groups}

Among the combined groups, only the Middle East sample displayed significant differences in the six variables. While this indicates that educators would be 
well disposed to distinguish between their Arabic and nonArabic Middle Eastern students, it does little to discourage the tendency to employ poorly-defined categories for their Asian Students.

Given that various Asian and Southeast Asian groups have no difficulty in identifying a great deal of difference between themselves, failure to measure those differences may be due to a number of reasons: (1) the small number of subjects in each cultural group does not allow for accurate measurement of cultural trends, (2) the instrument may be unable to detect more finely-tuned cultural variations in cognitive style, (3) an ethnocentric component in the assumptions or the language of the instrument may be confounding the data, (4) the Confucian heritage common to all groups has caused a significant similarity in their values and approaches to human relationships and education, or (5) the differences existing between the groups are essentially unimportant in assessing their overall learning style preferences. Further exploration of these issues could be very valuable.

Gender Differences in Learning Style

Findings in this area were inconclusive. No generalizable variation in learning style was apparent in the analysis of the entire sample. However, significant differences were indicated in the Chinese, Korean, and Other 
SE Asian national groups. While the overall findings are consistent with Kolb's (1976) inability to locate any systematic differences between male and female learning style ( $p .24)$, the incidence of culture-specific variation is supportive of the idea that gender differences in cognitive style are socially and culturally determined. Further exploration of these findings is indicated.

The following discussion of age as a variable reveals the most interesting dynamic related to gender. It is in the area of development, growth and change that the possible influence of culture on male/female learning styles became most apparent.

Age as a Variable in Determining Learning Style

The findings indicated an identifiable pattern of variation in learning style associated with increasing age. As previously noted, the male portion of the International student sample showed a developmental trend very similar to the one displayed by Kolb's American subjects. The female sample, however, exhibited a totally different pattern with decreasing preferences in the $C E, R O$ and $A C$ learning dimensions. This represented an unprecedented tendency toward narrowing of learning flexibility.

Kolb has theorized that maturation carries with it an increasing complexity in the development of the learning modes. Yet the female sample appears to be showing no 
increase in behavioral complexity and a diminishing perceptual, affective and cognitive complexity. If, as Kolb (1976) suggests, these developmental processes are the result of dynamic interaction between the learner and the "social, educational, and organizational" (p. 7) forces in her environment, a rather startling hypothesis can be drawn from this data. It is possible that the women in this study are displaying an adaptation pattern necessary in a system where fixed role expectations and limited options for change exist relative to those of the male and American samples.

Learning, as Piaget defined it, can serve to elaborate or expand our known world. The differences demonstrated in these results may be representative of the effect of these two learning tasks on the cognitive processes over time. Further study with much larger populations might provide interesting insight into the patterns of development dictated by our social roles.

Similarity and Dissimilarity of Learning style in Chosen Field of study

Findings in this are indicated that a full 808 of the total sample was dissimilar in learning style from the normative modes established by Kolb for Americans in their chosen field of study. Within the national groups these findings ranged from 50-1008. The implications of these results could be directly related to the potential academic 
success or failure of these students.

Kolb (1981) explored the consequences of students not "fitting in" to the learning style predominant in a given academic field. These students earned poorer grades, expressed greater dissatisfaction with the field and their teachers, and experienced a greater sense of anomie among their classmates (p. 246-7). They complained of depression, confusion and loss of energy (p. 233). In short, they were exhibiting the classic symptoms of culture shock.

Oberg (1972) suggested that culture shock was caused by anxiety resulting from the "loss of familiar signs and symbols of social intercourse" (p. 1). Bennett (1977) in her article "Transition Shock" echoes and refines this definition to include the "loss of a familiar frame of reference or change of values" and adds that "Iife will be unmanageable until the continuity of meaning has been restored through a process of abstraction and redefinition" (p. 45$)$.

The dilemma presented to these students is twofold. In many cases they may be simultaneously suffering from two kinds of transition shock: (1) culture shock brought on by the demands of adapting to a different language, behaviors and values, and (2) "cognition shock" which is demanding an alteration of the very processes they have traditionally employed in learning about their environment. 
Further difficulty in this process is suggested by the findings that many of these students are relatively unpracticed in the use of "abstraction" as a form of cognitive processing. This puts the student in a significant double bind. The methods are at odds with the expectations of the institution. They are expected to cope, but they are to simultaneously abandon the very processes by which they normally think and communicate to do it (Condon, $1986)$.

The realization that these students are experiencing a "double whammy" in the area of psychic adjustment is exacerbated by the impact of the process on achievement of the task they have set for themselves, attaining an academic degree.

Cowan (1976) has noted that only 608 of the Middle Eastern students who come to the United States "actually get the degree for which they have come" (p. 6). Not surprisingly, the highest rate of failure is among students who have been chosen by their governments to pursue a dictated field of study.

It should also be considered that these students see themselves as operating with a narrower range of options for success. They are seeking to learn skills that are seen as necessary to their countries' movement into a highly technological global economy. The familial, the social and 
the political expectations associated with their success are likely to be felt more deeply by these students than by their American counterparts.

The solution, therefore, does not lie in channeling them into "more suitable" fields. Instead, the task facing educators who must teach these students what they need to know is to find ways of increasing their learning flexibility.

However, expanding the available cognitive options of these students does not imply simply helping them to "think like Americans." Success in such an undertaking could, by definition, inhibit their ability to function in their home cultures and successfully adapt their new knowledge to the needs of their own countries.

What is likely needed to balance this equation is the concomitant development of teaching flexibility to allow for a more individualized approach to student needs and the active involvement of the student in the process of education.

\section{SUMMARY}

To a high degree, these results support the original assumptions of this study. Culture appears to exert a measurable and systematic influence on the processes that an individual employs to organize and make sense of her 
environment. It further emphasizes the awareness that our educational institutions serve as strong supporters of those cognitive norms, teaching students not only what they need to know, but more importantly, how they need to know it. Kolb's model has provided a means and a perspective for looking at how those differences might be categorized. As a result, it is possible to look at more than just the symptomology of adaptation; through the application of a system of definitions, we can look at possible causes and possible solutions to those problems. 


\section{CHAPTER VI}

LIMITATIONS, AND IMPLICATIONS FOR FURTHER RESEARCH, AND APPLICATIONS OF THE STUDY

\section{LIMITATIONS OF THE STUDY}

Five limitations of this research can be readily identified and will be briefly presented.

1. The populations for each national and academic group were too small to obtain data reliable enough for truly safe cultural generalization. A much broader cross section of students needs to be looked at for each test group. Given the necessity for a greater number of subjects, a smaller number of test groups would be advisable. Under such circumstances the differences between the "more similar" groups which were not apparent in this study might present themselves.

2. Statistical problems previously discussed make suspect the findings that resulted from comparison to the total American normative sample. Providing a control group of American students from the same universities and departments as the International students tested would provide much more reliable data. 
3. The MLSI itself needs to be checked more carefully for validity and reliability. While a cursory check was done in the form of student and instructor feedback and in the use of histograms to assess normal distribution of results, the major confidence placed in the instrument was found in the original testing by Kolb of the ISI. If it is to be used in future research, this is not enough. Test-retest and split-half reliability studies should performed.

4. While students were "randomly selected" on the basis of simply being in an ESL class, wider sampling from more varied environments would be preferable. It is quite possible that the process of studying a second language could, in itself, be an influence on the learning styles of the students tested.

5. Checking for patterns related to an "instructor effect" would be advisable. Different instructors could conceivably have considerable influence on the learning styles of their students through their choice of teaching methods. Teaching style inventories based on Kolb's model are available and could be used to crosscheck the patterns of learning preference demonstrated in a particular class. A wider sampling would also help control for this phenomenon. 
While extensive, these limitations are not insurmountable. This research has unearthed some interesting trends which could prove useful if followed up with more rigorous testing methods.

\section{IMPLICATIONS FOR FUTURE RESEARCH}

The basic thrust of this research was heuristic. A minimal number of test subjects were approached with a maximum number of possible questions about differences in learning style. Although limited in several ways, a number of interesting avenues for future exploration have been identified.

Kolb's Learning Styles Inventory and his experiential learning theory have already proven to be useful tools in the assessment of American students and in increasing awareness of the potential range of teaching approaches. It is a simple-to-use and easily-understandable perspective, and therefore has a wide spectrum of application.

Even Kolb has cautioned that the use of the LSI is only a first step in the evaluation of a student, but through the use of broad categorization, it opens the door to individualization of the learning process by allowing recognition or and respect for the differences it uncovers. As a result, application of this model to more in-depth studies of the questions raised in this research and 
rigorous attempts to validate the findings of this study could prove intellectually stimulating and useful to both the International students who come here to study and the teachers who are charged with their education.

Further application could also be made in the study of other nontraditional learning populations, i.e., returning adult students and ethnic and socially disadvantaged minorities who find success in the university system more difficult to achieve.

\section{APPLICATION}

Patricia cross (1986) identified two groups of "nontraditional" students who are now dominating the rolls of higher education: low performing students who are part of the "access revolution," and returning adults for whom time and money are major determiners of their educational choices (p. 9). It is the needs of these students that Cross credits for the cry emerging in the field of higher education for "good" and "relevant" teaching, teaching which goes beyond the rudimentary skills of "recall and comprehension" to include development of the "higher-level skills of analysis, synthesis and evaluation" (p. 10), thus nurturing the "growth of the whole person... intellect . . practical competence . . [and] affective dispositions" (p. 11). 
The arguments applied to the need for "individualization" of teaching approaches for these students (Edgerton, 1985, p. 5) can be easily expanded to include International students. The method selected is not a new one, but the idea of applying it to the International student population is. And it is a population which requires unique investigation, research and fresh approaches and new ideas in order that the goals of "good teaching" be achieved.

Application of these goals to the findings of this study must be cautiously pursued. It is not realistic to advise these students out of their majors, nor is it advisable to indoctrinate them in the finer points of American thinking. Experience with our own ethnic minorities warns against such methods. As Lessor (1979) pointed out:

[Minority] students most often do not return to their communities after completing their education; seeking higher education almost demands the renunciation, or at least the abandonment of the cultural group. (p. 139)

Helping international students to achieve their educational goals and still return home as productive members of their own cultures requires attention to some important considerations. 
Recognition of Difference

The initial step in improving the experience of International students in the American university system involves redefining the realities in which educators have so long operated. Cole and Bruner (1971) listed this as their first priority in improving the performance of cultural minorities:

- . recognition of educational difficulties in terms of a difference rather than a special kind of intellectual disease should change the students in the eyes of the teacher. (p. 245)

Respect for those Differences

Once0 recognized, educators need to cease evaluating differences in negative terms. Redefinition of alternative approaches to knowing can be framed as potentially valuable to the task at hand.

\section{Application of those Differences}

Cole (1976) found that the distinctive cognitive structures of ethnic minorities in this culture remained stable over time; students tested displayed the same cognitive preferences in high school and college as they did in grammar school. Given the deeply rooted nature of these constructs, it is reasonable that instructors 
- . stop laboring under the impression that he must create new intellectual structures and start concentrating on how he can get the child to transfer skills he already possesses to the task at hand. (Cole \& Bruner, 1971, p. 245)

For while it is reasonable to expect students to expand their learning options, it is not advisable to expect them to abandon the ones they already employ. If this is to be accomplished, it is necessary that instructors also expand their teaching options.

Increased Teaching Flexibility

Cole (1976), Cross (1986), Edgerton (1985), Filmore (1982), Kolb (1976, 1981, 1984), Lessor (1979), and Sheckley (1986) are only a few who have advocated and outlined the importance of an individualized approach to teaching and learning. Such an approach requires that the instructor have knowledge of a wide range of possible approaches to teaching the same material. Kolb would further argue that the more methods employed in the educational process, the more deeply the learning will occur.

Increased scope of teaching methods should result in double-edged learning for the student: the content is absorbed more easily, and the learning processes available to the student should increase as well.

Increased Student Learning Flexibility

If the goal is ultimately to expand the options open to 
teacher and learner while still maintaining the integrity of both, attention must be paid to the careful construction of what Useem and Useem (1963) have called "Third Culture Solutions," ones which are constructed in a world which is

- . created, shared and learned by men of different societies who are in the process of relating their societies, or sections thereof, to each other. (p. 178)

The successful completion of such a task requires that both parties be conscious participants in the process.

\section{Awareness of the Process}

Rhinesmith and Hoopes (1978) have observed that

- - persons can function successfully abroad only when they are: (1) aware of themselves as culturally conditioned individuals [and] (2) alert to the differences in perception which exist between themselves and others... (p.43)

It is, therefore, advisable to ensure the best possible results that the student be enlisted as an informed participant in the process of her own education. It seems likely that a knowledge of the nature of their own transformation can help ease that transformation and the process of future re-entry into their own culture. 


\section{BIBLIOGRAPHY}

Bannai, H. (1980). Socio-cultural influences on the development of Asian ESL students. In On TESOL: Building Bridges: Research and Practice in Teaching English as a Second Language, pp. 147-157.

Barnlund, D. M. (1973). Communication: The context of change. In C. D. Mortenson (Ed.), Basic readings in communication theory. New York: Harper and Row.

Barnlund, D. M. (1984). Communication in a global village. In L. A. Samovar \& R. E. Porter (Eds.), Intercultural communication: A reader, 4 th edition. Belmont, CA: Wadsworth Publishing Company.

Barnlund, D. L. (1975). Public and private self in Japan and the United States: Communication styles of two Cultures. Tokyo, Japan: The Simul Press, Inc.

Bennett, M. J. (Dec., 1977). Transition shock: Putting culture shock in perspective. In International and Intercultural Communication Annual, Vol. IV, pp. 44-51. Folks Church, VA: Speech Communication Association.

Bennett, M. J. (1979). Overcoming the golden rule:

Sympathy and empathy. In D. Nimmo (Ed.), Communication Yearbook 3, pp. 407-442. Washington, D.C.:

International Communication Association.

Bennett, M. J. (1984). Towards ethnorelativism: A developmental model of intercultural sensitivity. Paper presented at the annual conference of the council of International Educational Exchange. Minneapolis, MN.

Berger, P. L. \& Luckman, T. (1967). The social construction of reality. New York: Doubleday \& Co.

Berry, J. W. (1974). Radical cultural relativism and the concept of intelligence. In J.W. Berry \& P. R. Dasen (Eds.), Culture and cognition: Readings in cross cultural psychology. London: Methuen \& CO., Inc. 
Broverman, D., Klaiber, E., Kobayashi, Y., \& Vogel, W. $(1968)$. Roles of activation and inhibition in sex differences in cognitive abilities. In Psychological Review, 75, pp. 23-50.

Bruner, J. (1981). Studies in cognitive growth. New York: Wiley press.

Bruner, J. (1979). The conditions of creativity. In D. Golman \& R. J. Davidson (Eds.), Consciousness: Brain, states of awareness, and mysticism. New York: Harper \& ROW.

Bruner, J. (1966). On knowing and theories for the left hand. New York: Atheneum.

Cole, M. (1971). The cultural context of learning. New York: Basic Books.

Cole, M. (1976). Cultural differences in the world of learning. In S. Messick (Ed.), Individuality in Learning,. San Francisco: Jossey Bass.

Cole, M. \& Bruner, J. S. (1971). Cultural differences and inferences about psychological processes. In J. $W$. Berry \& P. R. Dasen (Eds.), Culture and cognition: Readings in cross-cultural psychology. London: Methuen \& Col, Ltd.

Cole, M. \& Scribner, S. (1974). Culture and thought: A psychological introduction. New York: John Wiley \& Sons, InC.

Condon, E. C. (1985). Cross-cultural interferences affecting teacher-pupil communication in American schools. In International and Intercultural Communication Annual, pp. 108-117.

Condon, J. C. (June, 1986). The ethnocentric classroom. In J. C. Civikly (Ed.), Communicating in college classrooms: New Directions in teaching and learning, no. 26. San Francisco: Jossey-Bass.

Condon, J. C. \& Yousef, F. (1981). An introduction to intercultural communication. Indianapolis: BobbsMerril Co., Inc.

Cowan, J. (1979). Factors in-country and in the United states. In G. L. Althen (Ed.), Students from the Arab world and Iran. Washington, D. C.: NAFSA. 
Cross, K. P. (Sept., 1986). A proposal to improve teaching--or--what "taking teaching seriously" should mean. In AAHE Bulletin, pp. 8-15.

Dewey, J. (1938). Experience and education. New York: Dover Publications.

Diekman, E. (1971). Bimodal consciousness. In Archives of General Psychiatry, 25, pp. 481-89.

Edgerton, R. (Sept., 1985). It all begins in the classroom: An interview with $K$. Patricia cross. In AAHE Bulletin, pp. 3-7.

Edwards, B. (1979). Drawing on the right side of the brain. Los Angeles: J. P. Tarcher.

Filmore, L. W. (1982). The language learner as an individual: Implications of research on individual differences for the ESL teacher. In On TESOL: Pacific Perspectives on Language Learning and Teaching, pp. 157-171.

Gladwin, T. (1974). Culture and logical process. In J.W. Berry \& P. R. Dasen, Culture and cognition: Readings in cross-cultural psychology. London: Methuen \& Co., Ltd.

Galin, D. (1979). The two modes of consciousness and the two halves of the brain. In D. Golman \& R. J. Davidson (Eds.), Consciousness: Brain, states of awareness, and mysticism. New York: Harper \& Row.

Gay, G. (1978). Viewing the pluralistic classroom as a cultural microcosm. Educational Research Quarterly, 2, pp. 45-59.

Hal1, E. T. (1976). Beyond culture. New York: Anchor/Doubleday.

Hatch, E. Faraday, H. (1982). Research design and statistics for applied linguistics. Rowley, MA: Newbury House.

Hoopes, D. S. (1981). Intercultural communication concepts and the psychology of intercultural experience. In D. Pisch (Ed.), Multicultural education: a cross-cultural training approach. Chicago: International Press, Inc. 
Ishi, S. (1985). Thought patterns as modes of rhetoric: The United States and Japan. In L. Samovar \& R. Porter (Eds.), Intercultural communication: A reader. Belmont, CA: wadsworth publishing Co.

Jung, C. (1977). Psychological types. In Collected works of Carl G. Jung, Vol. 6. Princeton: Princeton University Press.

Kamin, L. J. (April, 1974) . Heredity, intelligence, politics, and psychology. Paper presented at the meeting of the Eastern Psychological Association, Philadelphia, PA.

Kaplan, R. B. (Sept., 1966). Cultural thought patterns in intercultural education. In Language Learning, Vol. $X V I$, No. $1 \& 2$.

Kelly, G. A. (1963). A theory of personality. New York: W. Norton \& Co., Inc.

Kluckholn, F. \& Strodbeck, F. (1961). Variations in value orientations. New York: Peterson Press.

Kolb, D. A. (1984). Experiential learning. Englewood Cliffs, NJ: Prentice Hall.

Kolb, D. A. (1976). Learning style inventory: Technical manual. Boston: MCBer \& Co.

Kolb, D. A. (1981). Learning styles and disciplinary differences. In A. Chickering (Ed.). The modern American college, pp. 232-255. San Francisco: JosseyBass.

Kolb, D. A. (1985). ISI: Learning styles inventory. Boston: MCBer \& Co.

Kolb, D. A. \& Wolf, D., et al. (1981). Professional education and career development: A cross sectional study of adaptive competencies in experiential learning. ERIC NIE/G/Grant P. P. 77/0053 030519. ERIC P. ED $209493 \mathrm{CE}$.

Kurfiss, J. (1980). Cognitive, psychological, and moral development in college: Four major theories. Paper prepared for the Curriculum Design Workshops on Quality Undergraduate Education, Ogden, UT: Council for the Advancement of Small Colleges. 
Lessor, J. (1976). Cultural differences in learning and thinking. In S. Messick (Ed.), Individuality in learning. San Francisco: Jossey Bass.

Lippet, R. (1949). Training in community relations. New York: Harper \& Row.

Luria, A. R. (1979). The brain's three functional units. In Golman \& Davidson (Eds.), Consciousness: Brain, states of awareness, and mysticism. New York: Harper and Row.

MCClave, J. T. \& Dietrich, F. H. (1982). Statistics. Santa Clara, CA: Dellen.

McNichols, C. W. (1984). IBM PC statictics-BASIC programs and applications. Reston, VA: Reston Press.

McLuhan, M. (1964). Understanding media: The extensions of man. New York: MCGraw Hill.

Mead, G. H. (1936). Mind, self, and society. (C. W. Morris, Ed.). Chicago: Chicago Press.

Myers-Briggs, I. (1962). The Myers-Briggs type indicator manual. Princeton, NJ: Educational Testing Service.

Oberg, K. (1972). Culture shock and the problems of adjustment to new cultural environments. In D. S. Hoopes (Ed.), Readings in intercultural communication. Pittsburg: Regional Council for International Education.

Oliver, R. I. (1965). Foreword. In M. Nathanson \& H. Johnstone (Eds.), Philosophy, rhetoric and argumentation. University Park, PA: University Press.

Pearson, R. P. (June, 1977). Cross-cultural value conflict: Uniting the conception of multicultural education. In International Journal of Intercultural Relations, Vol. I. No. 2, Pp. 88-98.

Piaget, J. (1970). Genetic epistemology. New York: Columbia University Press.

Plovnick, M. (1974). Individual learning styles and the process of career choice in medical students. Doctoral dissertation, M.I.T. 
Rappaport, J. (1977) . Community psychology: Values, research, and action. New York: Reinhart \& Winston.

Rhinesmith, S. A. \& Hoopes, D. A. (1972). The learning process in an international setting. In $D$. $S$. Hoopes (Ed.), Readings in intercultural communication, Vol. 3. Pittsburg: Regional Council for International Education, University of Pittsburg.

Rorschach, H. (1951). Psychodynamics, 5th edition, P. Lemkau \& B. Kronenberg (Trans.). Berne, Switzerland: Verlag Hans Huber.

Sereno, K. K. \& Bodaken, E. M. (1975). Trans-per: Understanding human communication. Boston: Houghton Mifflin Co.

Sereno, K. K. \& Mortensen, C. D. (1970). Foundations of communication theory. New York: Harper and Row.

Sheckley, B. G. (1985). The Adult Learner: Increasing application for individual differences. In CAEL News, Vol. 8 , No. 4 .

Sperry, R. W. , Gazzaniga, M. S., \& Bogen, J. E. (1969). Interhemispheric relationships: The neocortical commisures; syndromes of hemispheric disconnections. In P. J. Vinken \& G. W. Bruyn (Eds.), Handbook of clinical neurology. Amsterdam: North Holland Publishing.

Stewart, E. C. (1976). American cultural patterns: A cross-cultural perspective. Pittsburg: Intercultural Communication Network.

Triandis, H. C. (1983). Essentials of studying cultures. In R. Brislin \& D. Landis (Eds.), Handbook of intercultural communication, Vol. 1. New York: Pergammon Press.

Tubbs, S. L. \& Moss, S. (1983). Human Communication, Fourth Edition. New York: Random House.

Tyler, S. A. (1969). Introduction to cognitive anthropology. In S. A. Tyler (Ed.), Cognitive anthropology. New York: Reinhart \& Winston. 
Useem, J., Useem, R., \& Donoghue, J. (Fall, 1963). Man in the middle of the third culture: The roles of American and nonwestern people in cross-cultural administration. In Human Organization, vol. 22, No. 3, pp. 169-179.

Ward, L. D. (Nov., 1983). Warm fuzzies vs. hard facts: Four styles of adult learning. In Training, pp. 31-33.

Whorf, B. L. (1956). Language, thought, and reality: Selected writings of Benjamin Lee Whorf. (J. B. Carrol, Ed.). Cambridge, MS: The M.I.T. Press.

Witkin, H. A. (1967). A cognitive style approach to crosscultural research. In International Journal of Psychology, Vol. 2, No. 4, pp. 233-246.

Witkin, H. A. (1976). Cognitive styles in academic performance and teacher-student relations. In $S$. Messick (Ed.), Individuality in learning. San Francisco: Jossey Bass.

Zonis, M. (1978). Social, cultural and religious factors affecting Iranian students. In G. L. Althen (Ed.), Students from the Arab world and Iran. Washington, D.C.: NAFSA. 


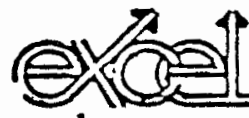

EXCEL INC.

Surte 101.600 Enlerprise Drivo, Oak Brook. IL 60521

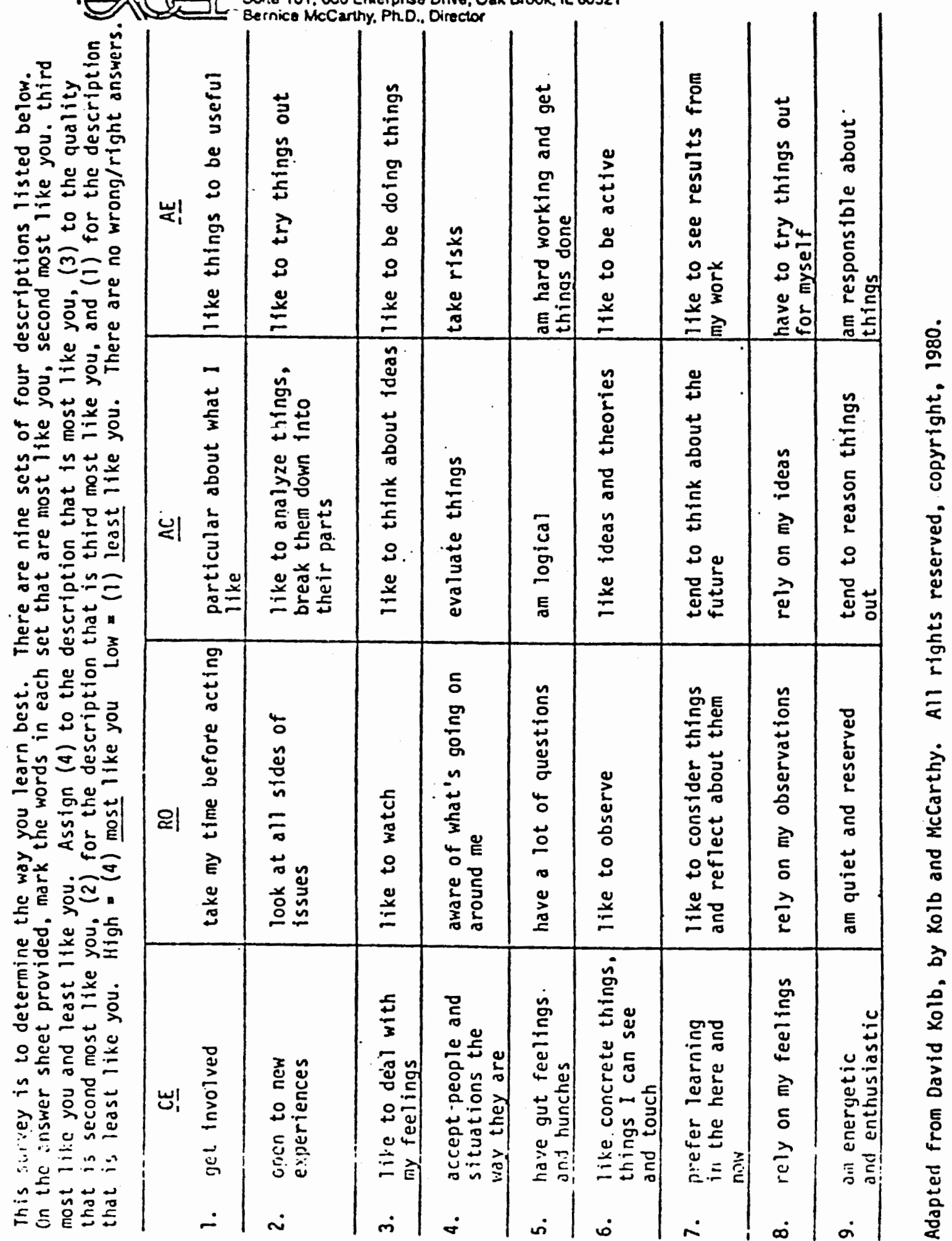




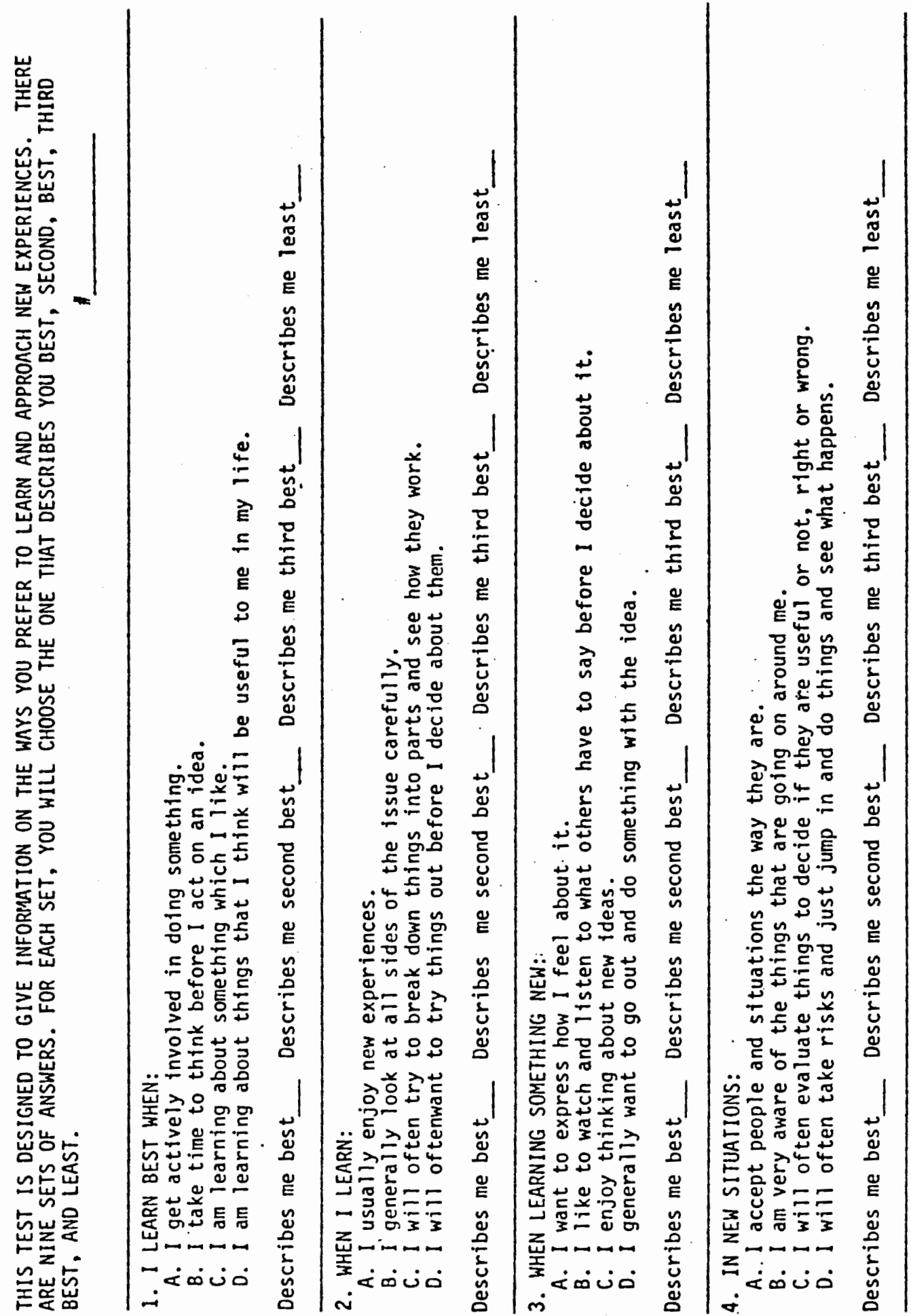




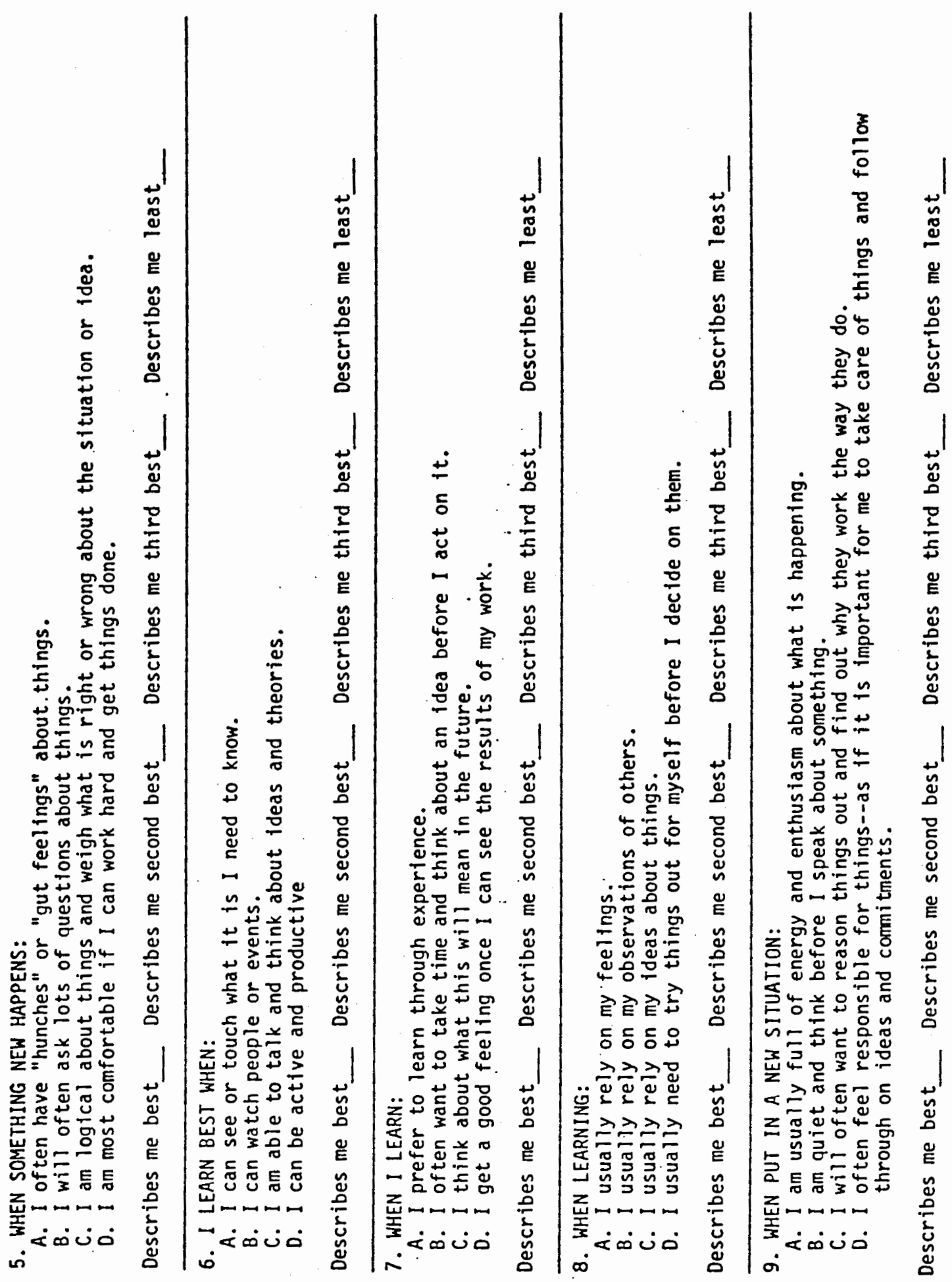


$\#$

MAJOR FIELD OF STUDY

AGE

MAE FEHALE (circle one)

COUITRY OE ORIGIA

MATIYE IANEUACE

GבRER LARGGUAGS YOU SPEAK FLUENTLY

DENGTH OF TIIE YOI HAVE LIVED II THE UNITED STATES

HO: LONC YAVE YOU STUDIED ENGLISH IN THE U.S.?

HAYV YOU IIVED IN ANY OTHER COUNTRIËS BESIDES THE U.S. AND YOUR HOHE COU:TRY? IF, "YES," YHEERE?

YHERE THE QUESTIC:OS OAY THE TEST EASY FOR YOU TO AHSUER?

T. " "10,"

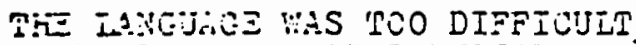

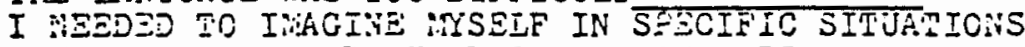

UYEN I IEAAN, I DO IN DIFFEREMTY DEOENDING OH THE SITUATICA

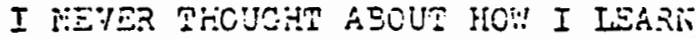

I MEVER TEOUTUT ADUTI LEARNIAG IN THESE V'AYS

CIILR RE.ISC:!S 


\section{INFOZIED CONSEY:T}

I. - UNDEASMAND TRIT THE PURPOSE OE

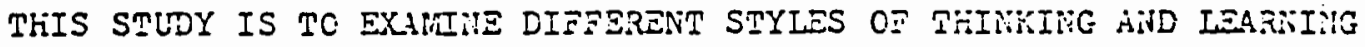
AND KO:: THOSE STYLES HIGHT BE RELATED TO CUITURAL PATTERNS. AS A RESUIT, I REAIIZE TLAT THERE ARE NO RIGHT OR ":RONC ANS THE QUESTIOHS ON THE TEST. FINALLY, I UIDERSTAYS THAT WY IDENTITY VIIL NOT IN ANY WAY SE DISCLOSED IN ANY Y'RITING OR PUBIISHZD MATERIAL THAT HIGHT BE PRODUCED AS A RESULT OF THIS STUDY. $239-4323$. 
ANSWER SHEET

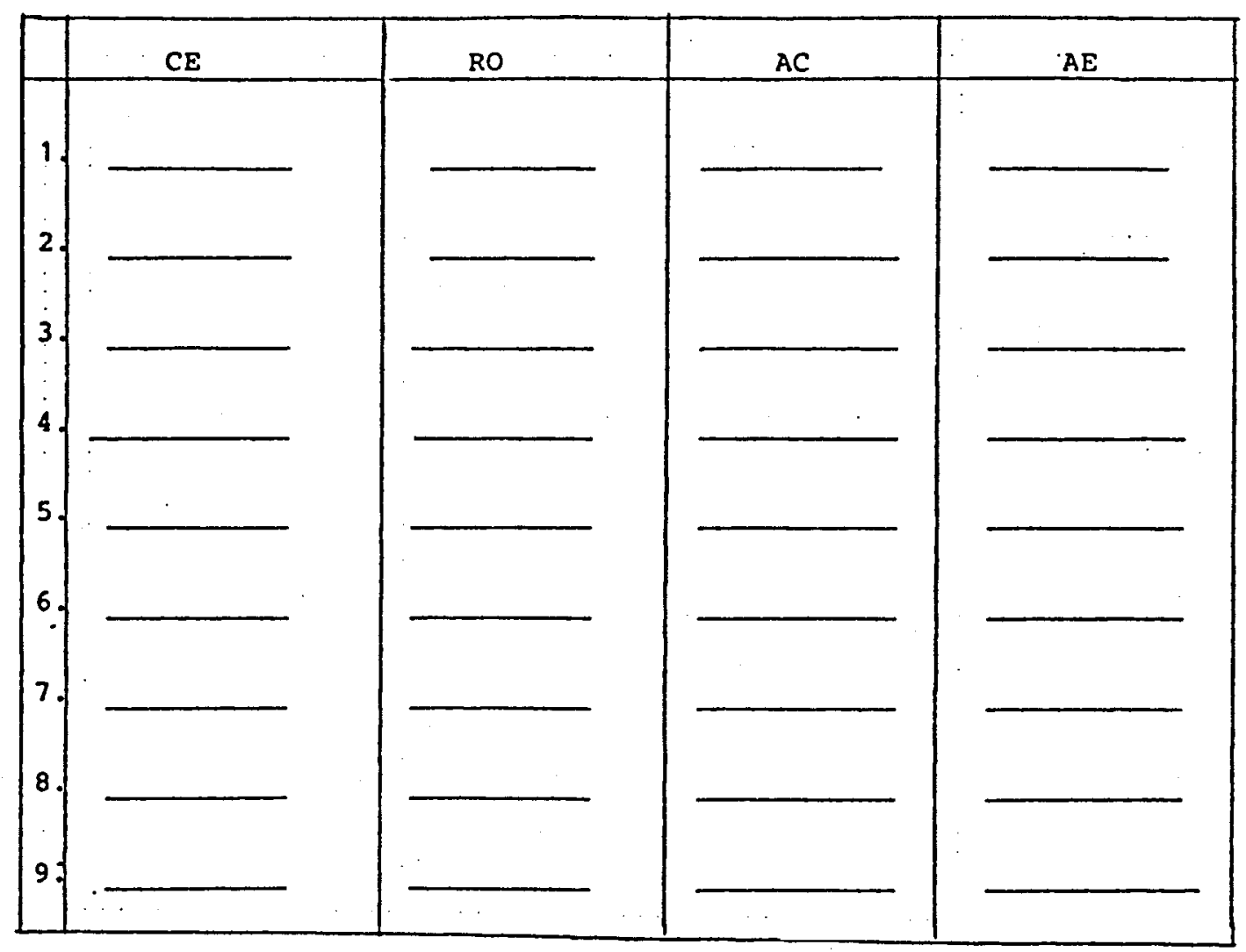




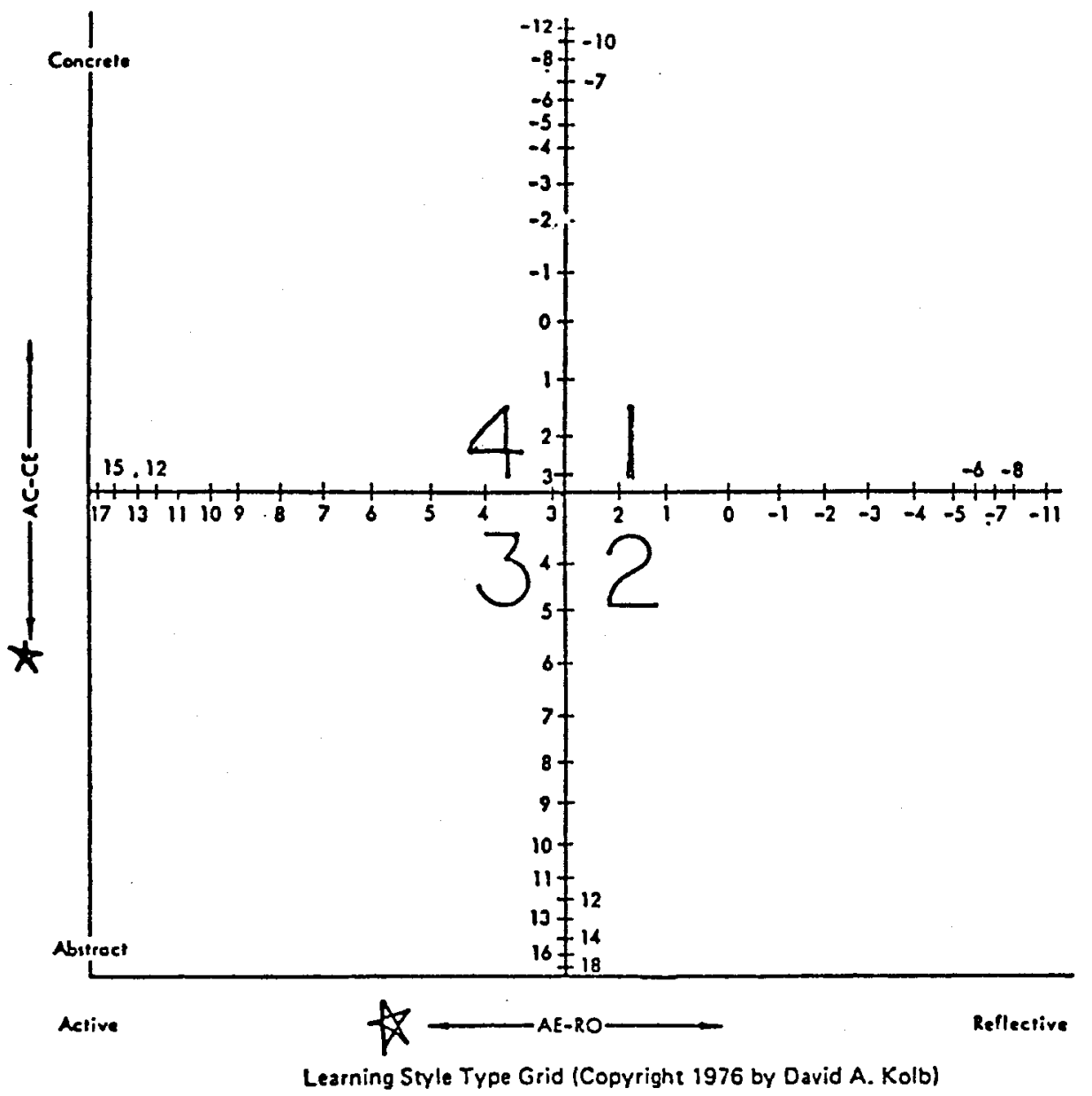

My learning style is

CE

RO

AC

AE

\begin{tabular}{|l|l|}
\hline 1 & \\
\hline 2 & \\
\hline 3 & \\
\hline 4 & \\
\hline 8 & \\
\hline 9 & \\
\hline
\end{tabular}

\begin{tabular}{|l|l|}
\hline 1 & \\
\hline 2 & \\
\hline 3 & \\
\hline 6 & \\
\hline 8 & \\
\hline 9 & \\
\hline
\end{tabular}

\begin{tabular}{|l|l|}
\hline 2 & \\
\hline 3 & \\
\hline 4 & \\
\hline 6 & \\
\hline 8 & \\
\hline 9 & \\
\hline
\end{tabular}

\begin{tabular}{|l|l|}
\hline 2 & \\
\hline 3 & \\
\hline 6 & \\
\hline 7 & \\
\hline 8 & \\
\hline 9 & \\
\hline
\end{tabular}

Refer to DataSH for answers

$C E=$

$\mathrm{RO}=$

$A C=$

$A E=$

\& $A C$ minus $C E=$

AE minus ro = enter this inf. on the grid above 
Fig. 3.4 Excursion-styles explanation

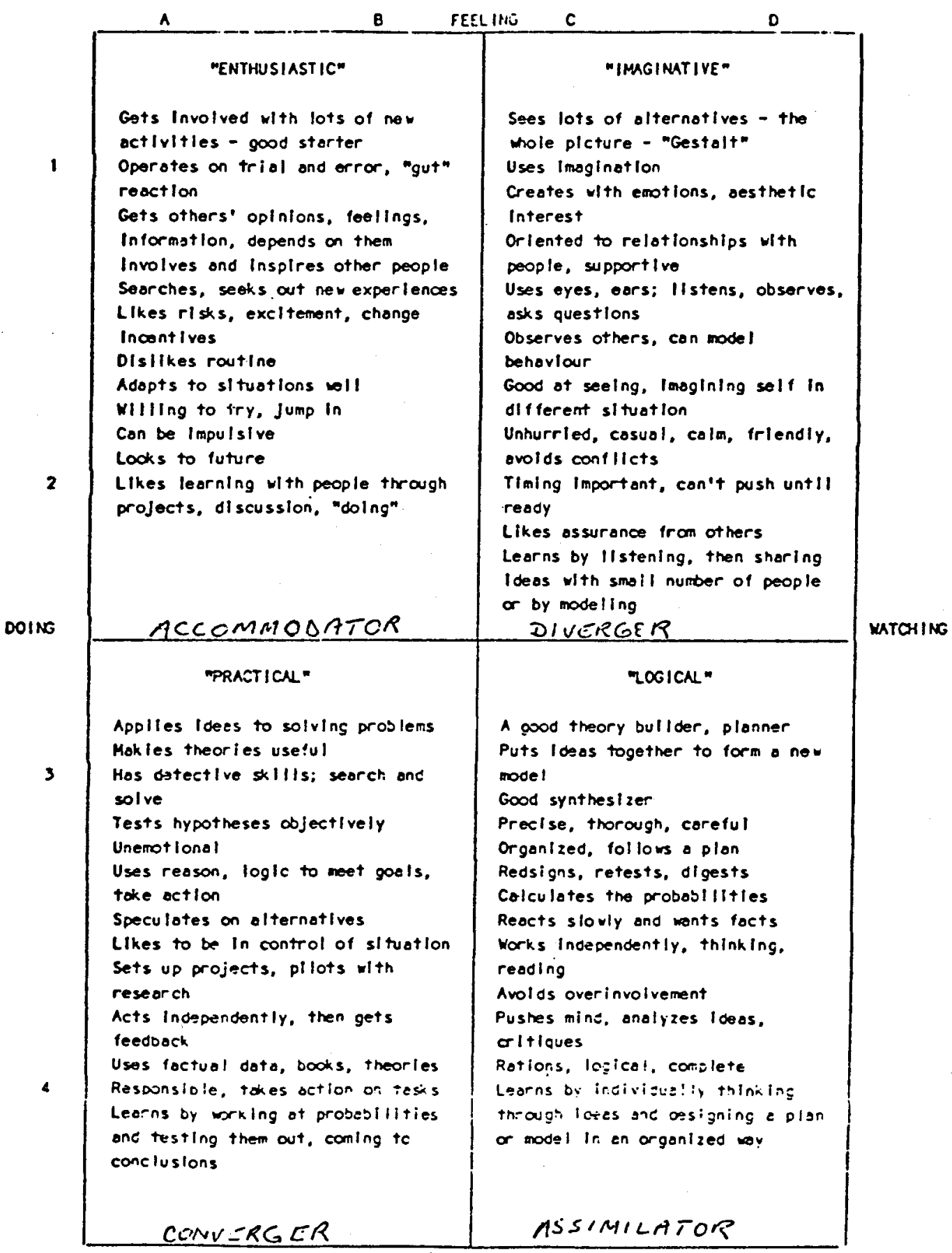




\section{Learning-Style Inventory}

1. When I learn:

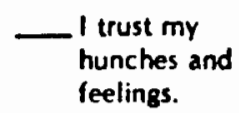
feelings.

3. When I am learning:

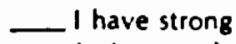
feelings and reactions.

with my

feelings.

2. I learn best when:

4. I learn by:

5. When I learn:

6. When I am learning:

$$
\text { _feeling. }
$$

1 am open to new experiences.

_watching
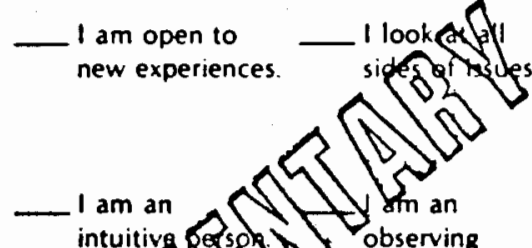
intuitivg

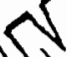

7. I learn best from:

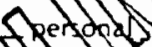

0 )

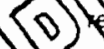

__ observation.

person.

_ rational theories.

things, analyze

them down into

their parts.

1 tend to reason things out.

(0)

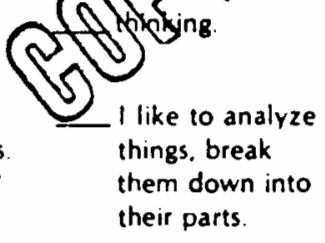

I am a logical person.

I am an active person.

\section{doing}

1 like to try

things out

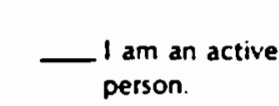
La chance 10 try out and
practice.

8. When I leaprol personally involved in things.

1 take my time before acting.

I l like ideas and theories.

1 like to see results from my work.

9. I learn best when

I rely on my feelings.

I rely on my

I rely on my ideas.

1 can try things out for myself

10. When I am learning

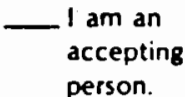 I am a reserved person.

I am a rational person

am a responsible person. person. I get involved. 1 like to observe I evaluate things. 1 like to be active

12 I learn best when:
1 am receptive and openminded.
I am careful. I analyze ideas. I am practical 
APPENDIX 


\section{The Cycle of Learning}

The four columns that you have just totaled relate to the four stages in the Cycle of Learning from Experience. In this cycle are four learning modes: Concrete Experience (CE), Reflective Observation (ROL Abstract Conceptualization (AC), and Active Experimentation (AE). Enter your total scores from each column:

Column 1 (CE)

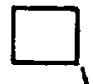

Column 2 (RO):

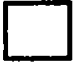

Column $3(\mathrm{AC})$ :

Column 4 (AE):

In the diagram below, dut a dot on each of the lines to correspond with your CE, RO, AC, and AE scores. Then connect the dots with a line so that you at a "kitelike" shape. The shape and placement of this kite will show you which learning modes you prefer most and which you prefer least.

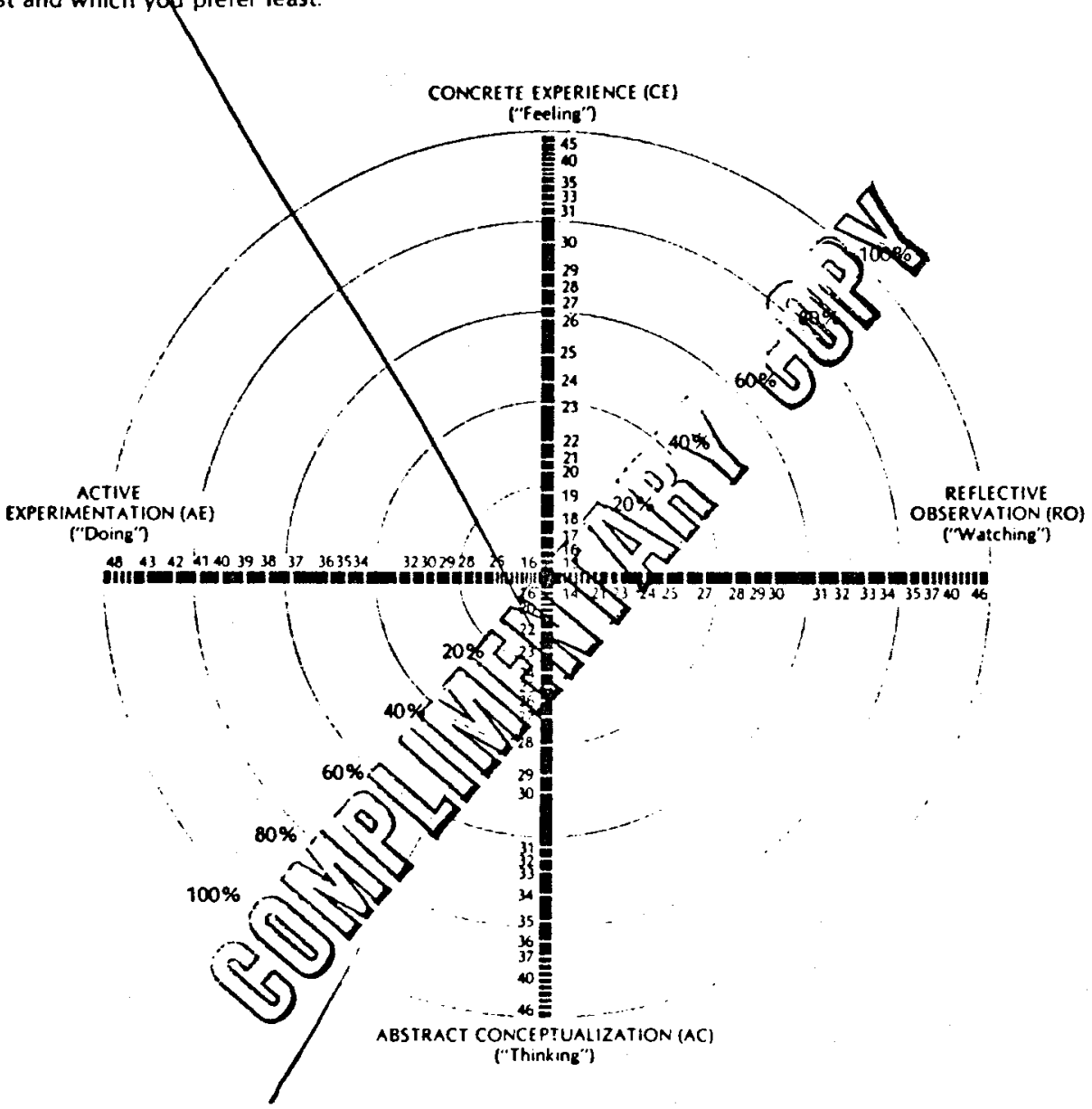

The Learning-Style Inventory is a simple test that helps you understand your strengths and weaknesses as a learner. It measures how much you rely on four different learning modes that are part of a four-stage cycle of learning. Different learners start at different places in this cycle. Effective learning uses each stage. You can see by the shape of your profile (above) which of the four learning modes you tend to prefer in a learning situation.'

On the next page are explanations of the different learning modes.

\footnotetext{
'One way to understand the meaning of vour LSI scores better is to comnare them with the scores of others. The proflle above gives norms on the four basic scales ICE. RO. AC. AE) for 1446 adults ranging from 18 to to vears of age Ihe sample group contained slightly more women than men, with an average of two vears bevond high schoof in formal education $A$ wide rance of occupations and educational backgrounds is represented The raw scores for each of the four basic scales are listed on the crossed lines of the target The concentric circles on the target represent purcentile soores tor the normative group in comparison to the nomative groun. the shape of your protile indicates which of the four basic modes you tend to emphasize and which you emphasize less
} 